Florida International University

FIU Digital Commons

FIU Electronic Theses and Dissertations

University Graduate School

6-11-2018

\title{
A Field Study Examining the Effect of High Intoxication Levels and Identification Format on Witnesses' Memory for Faces and Events
}

Christopher Altman

caltm005@fiu.edu

DOI: $10.25148 /$ etd.FIDC006822

Follow this and additional works at: https://digitalcommons.fiu.edu/etd

Part of the Experimental Analysis of Behavior Commons, and the Other Psychology Commons

\section{Recommended Citation}

Altman, Christopher, "A Field Study Examining the Effect of High Intoxication Levels and Identification Format on Witnesses' Memory for Faces and Events" (2018). FIU Electronic Theses and Dissertations. 3811.

https://digitalcommons.fiu.edu/etd/3811 


\section{FLORIDA INTERNATIONAL UNIVERSITY}

Miami, Florida

\section{A FIELD STUDY EXAMINING THE EFFECT OF HIGH INTOXICATION LEVELS AND IDENTIFICATION FORMAT ON WITNESSES' MEMORY FOR FACES AND EVENTS}

A dissertation proposal submitted in partial fulfillment of the requirements for the degree of DOCTOR OF PHILOSOPHY

in

PSYCHOLOGY

by

Christopher Altman

2018 
To: Dean Michael R. Heithaus

College of Arts, Sciences and Education

This dissertation, written by Christopher Altman, entitled A Field Study Examining the Effect of High Intoxication Levels and Identification Format on Witnesses' Memory for Faces and Events, having been approved in respect to style and intellectual content, is referred to you for judgment.

We have read this dissertation and recommend it be approved.

$\begin{array}{r}\text { Jacqueline Evans } \\ \hline \text { Stephen Charman } \\ \hline \text { Rob Guerette } \\ \hline \text { Nadja Schreiber Compo, Major Professor }\end{array}$

Date of Defense: June 11, 2018

The dissertation of Christopher Altman is approved.

Dean Michael R. Heithaus
College of Arts, Sciences and Education

Florida International University, 2018 
(C) Copyright 2018 by Christopher Altman

All rights reserved. 


\section{DEDICATION}

This dissertation is dedicated to all the faculty members, research assistants,

family members, and friends who helped me throughout my life and graduate school

career. Without your support and guidance I would not be in this position today. Thank

you all so much, from the bottom of my heart! 


\section{ACKNOWLEDGMENTS}

The list of people I need to acknowledge for where I am today is longer than this dissertation. Instead of listing everyone's name or selecting a specific few to write about I am just going to say thank you to everyone who has ever offered me advice, helped me find my way, or offered a hand when I was in need. Each of you knows who you are and what you have done for me. You should also know that I have not forgotten your generosity and at some point in the future, if I haven't already, I will find a way to properly pay you back or thank you for your kindness. My journey through graduate school has been rough and every bit of help I received is not only remembered but also cherished. Without this assistance, every little bit of it, I would not be the proud, confident, hard-working, and determined doctor I am today. From the bottom of my heart, THANK YOU EVERYONE! I would also like to acknowledge the Dissertation Year Fellowship offered by Florida International University. Without this fellowship I would have not been able to conduct this dissertation project. 


\begin{abstract}
OF THE DISSERTATION
A FIELD STUDY EXAMINING THE EFFECT OF HIGH INTOXICATION LEVELS AND IDENTIFICATION FORMAT ON WITNESSES' MEMORY FOR FACES AND EVENTS
\end{abstract}

by

Christopher Altman

Florida International University, 2018

Miami, Florida

Professor Nadja Schreiber Compo, Major Professor

Members of the legal system (e.g., experts, jurors, investigators) are often skeptical of the information provided by intoxicated witnesses given the negative stigma surrounding alcohol and memory. However, studies examining the relationship between alcohol and witness memory often find that alcohol has no effect on peoples' recall or their ability to identify a previously seen face. While insightful, the validity of these findings has been questioned given the low-to-moderate blood alcohol concentration (BAC) levels tested in these predominantly laboratory-based studies, which may not be high enough to consistently expose the cognitive deficits alcohol is expected to create. The present study examined how elevated BAC levels affect witnesses' recall. In addition, it examined how identification format (i.e., showup versus lineup) impacts witnesses' identification decisions at elevated BAC levels. Bar patrons $(N=132)$ were asked to participate in a study examining the effects of alcohol on cognitive and motor functioning. Consenting 
patrons' BAC levels were recorded and they were given instructions for their first motor task. Midway through this task a confederate intruder entered the room and caused a disturbance. Participants were then asked to recall the intrusion via a mock interview and identify the intruder from a lineup or showup in which she was pictured (target-present) or was not pictured (target-absent). This procedure yielded participants with BAC levels as high as $.24 \%$. Linear regressions showed that elevated BAC levels reduced both the quantity and quality of information provided by participants. Logistic regressions showed that alcohol had no effect on identification decisions, regardless of identification format or target presence. These data highlight the importance of testing witnesses' memory across a broad BAC spectrum and suggest that the legal system may benefit from expert information regarding the null effects of alcohol on witnesses' memory for faces. 


\section{TABLE OF CONTENTS}

CHAPTER

PAGE

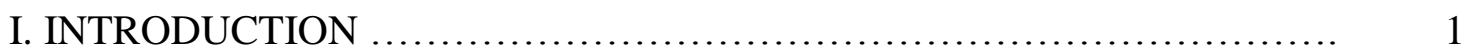

Prevalence of Intoxicated Witnesses ..................................... 1

Perceptions of Intoxicated Witnesses .................................. 2

Alcohol and Memory for Basic Stimuli ................................... 3

II. LITERATURE REVIEW ............................................ 5

Basic Memory Processes ............................................ 5

Alcohol and Memory Processes .......................................... 8

Alcohol myopia theory ............................................ 9

Alcohol-induced blackouts ............................................ 11

Alcohol and Eyewitness Memory ...................................... 14

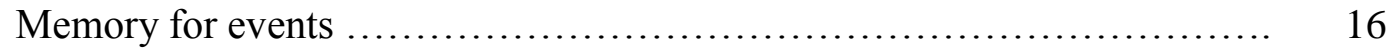

Item centrality ................................................... 17

Low BAC levels ............................................... 19

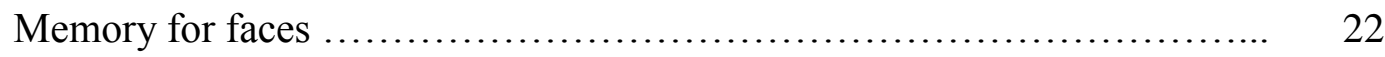

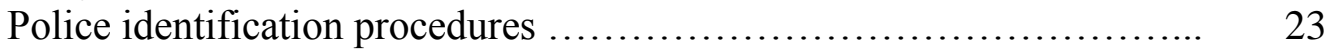

Showups vs. lineups ......................................... 25

Alcohol and identification decisions .............................. 27

III. THE PRESENT STUDY .............................................. 31

Hypotheses ........................................................... 33

Memory for events ................................................. 33

Memory for faces ........................................................... 34

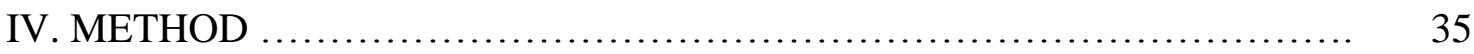

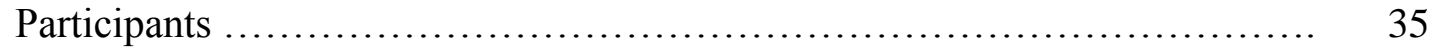

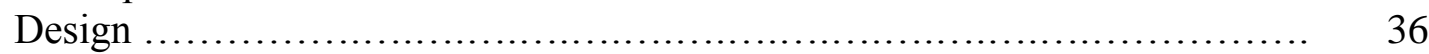

Materials ..................................................................... 36

Intoxication measurements ............................................. 36

Staged eyewitness interaction .......................................... 37

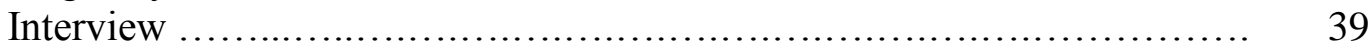

Identification materials .................................................. 40

Fillers ......................................................... 40

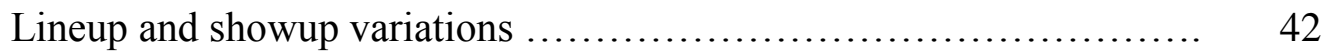

Identification instructions ........................................ 42

Drinking history questionnaire .................................... 43

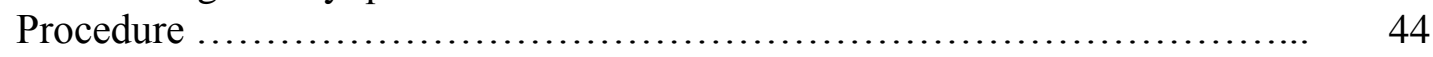

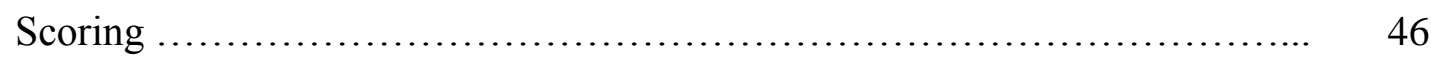

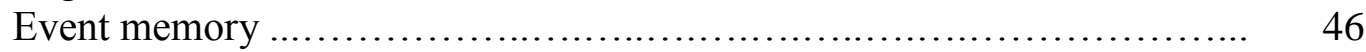

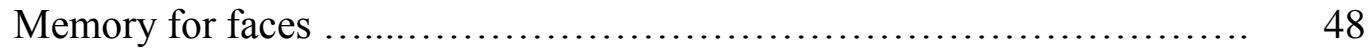


Choosing behavior ............................................ 48

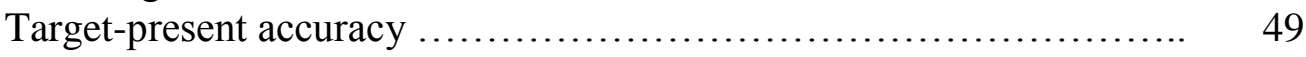

Target-absent accuracy ....................................... 49

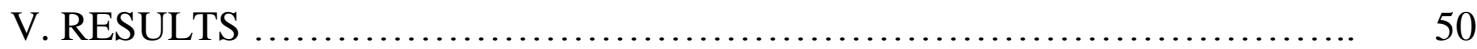

Intoxication Measurements and Procedure Believability ................... 50

Intoxication measurements ...................................... 50

Procedure believability .......................................... 51

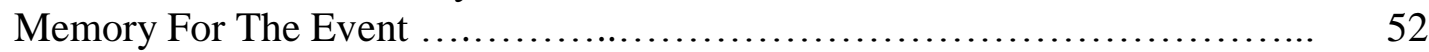

Quantity ........................................................ 52

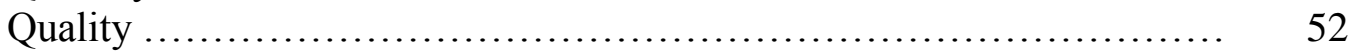

Accuracy ................................................. 52

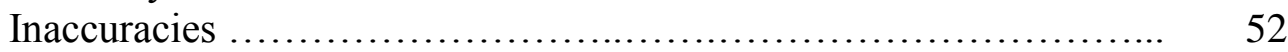

I don't know responses ..................................... 53

Additional measures ............................................. 53

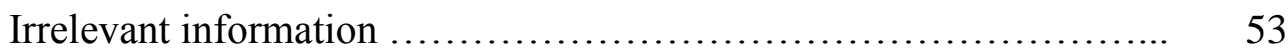

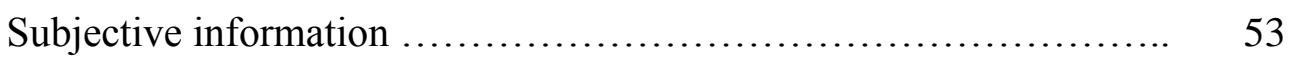

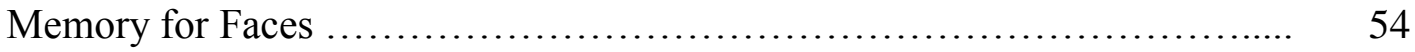

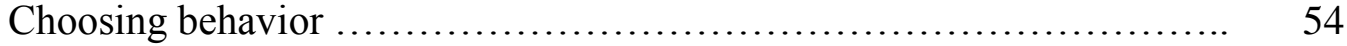

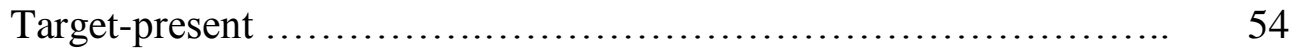

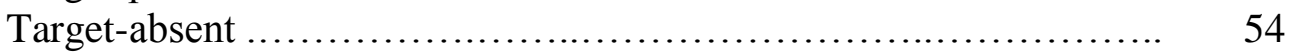

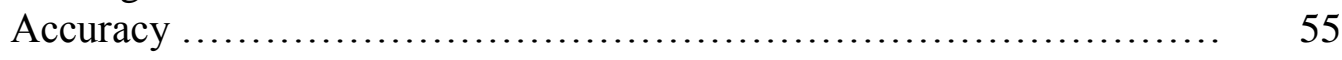

Correct perpetrator identifications ............................ 56

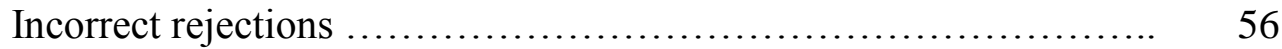

Correct rejections ........................................... 56

False identifications ........................................ 57

Testimony relevant judgements ............................... 57

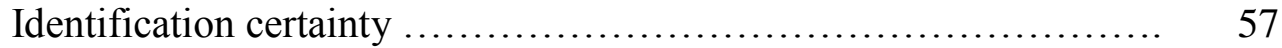

Distance to the perpetrator .................................... 57

View of the perpetrator ....................................... 58

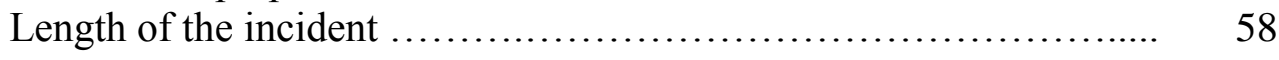

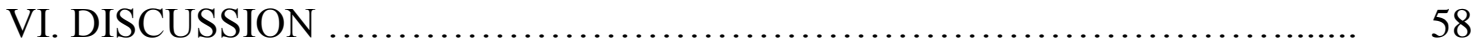

Event Memory .................................................... 59

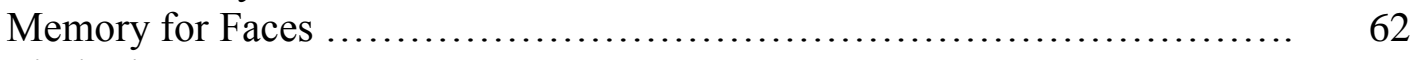

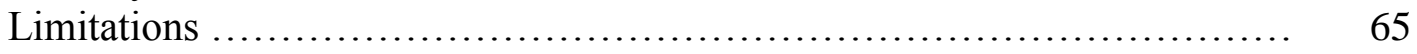

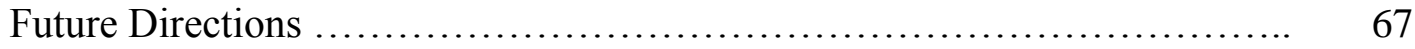

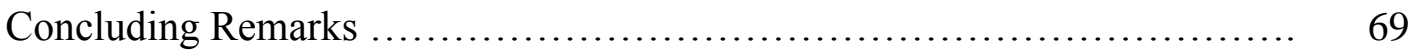

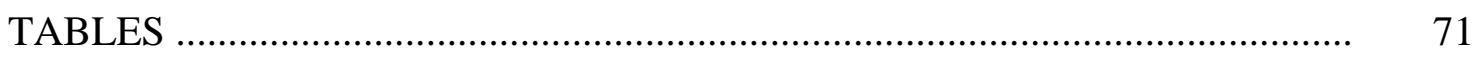

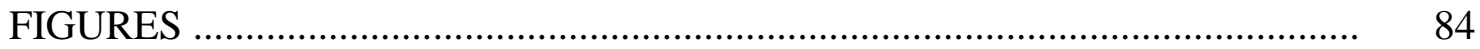


REFERENCES

92

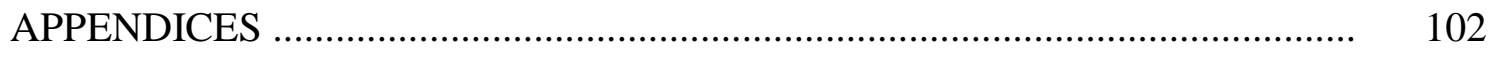

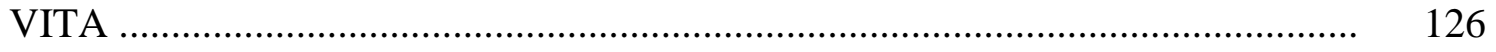




\section{LIST OF TABLES}

TABLE

PAGE

1. Overview of the general findings and procedures used in the studies examining the effects of alcohol on witnesses' memory for events

2. Overview of the general findings and procedures used in the studies examining the effects of alcohol on witnesses' identifications

3. Filler identifications across the various lineup and showup conditions

4. Correlations between participants' objective and subjective drinking measures, DHQ responses, and believability ratings .......................

5. Identification decisions across lineup and showup conditions 


\section{LIST OF FIGURES}

FIGURE

PAGE

1. Number of participants at the various BAC levels recorded

2. Relationship between BAC level and the total number of units reported.

This figure includes subjective and irrelevant information reported

3. Relationship between BAC level and the total number of units reported.

This figure excludes subjective and irrelevant information reported

4. Relationship between BAC level and the proportion of accurate units reported

5. Relationship between BAC level and the proportion of inaccurate units reported

6. Relationship between BAC level and the proportion of 'I don't know' units reported

7. Relationship between BAC level and the proportion of irrelevant units reported

8. Relationship between BAC level and the proportion of subjective units reported 


\section{CHAPTER I}

\section{INTRODUCTION}

\section{Prevalence of Intoxicated Witnesses}

Recent data show that law enforcement officers frequently interact with intoxicated witnesses and victims (Evans, Schreiber Compo, \& Russano, 2009; Palmer, Flowe, Takarangi \& Humphries, 2013). For example, in a 2009 survey of U.S law enforcement officers $73 \%$ reported that interacting with intoxicated witnesses and victims was either common or very common, and $90 \%$ reported having interviewed an intoxicated witness within the past month (Evans et al., 2009). Officers further estimated that intoxicated individuals had an average blood alcohol concentration (BAC) level of $.11 \%$, comprised an estimated $44 \%$ of all witnesses and victims interviewed, and were under the influence of alcohol during the crime, during questioning, or on both occasions. In an archival study, Palmer, Flowe, Takarangi, and Humphries (2013) analyzed 1307 cases referred to the U.S. prosecutor's office and found that $13 \%$ involved at least one intoxicated witness. Although witnesses' BAC levels were not reported in this study $94 \%$ were questioned about the incident on the same day as the event or the following day.

While intoxicated witnesses and victims appear in a variety of criminal situations it is worth noting their prevalence in sexual assaults, given the extent to which it has been documented (Abbey, 2002; Department of Justice [DOJ], 1998; Evans et al., 2009; National Council on Alcoholism and Drug Defense [NCADD], 2016). Although estimates fluctuate between studies (45-75\%) approximately 50\% of sexual assault victims report being under the influence of alcohol during the time of the offense (Abbey, 
2002; Abbey, Wegner, Woerner, Pegram, \& Pierce, 2014; Mohler-Kuo, Dowdall, Koss, \& Wechsler, 2004; NCADD, 2016). In one large national sample of college women $72 \%$ reported being under the influence of alcohol when they were assaulted (Mohler-Kuo et al., 2004). Most bystanders (i.e., witnesses) of sexual assaults are also intoxicated since the crime is typically initiated in settings where large quantities of alcohol are consumed (Abbey, 2002; Abbey et al., 2014; Rape, Abuse, and Incest National Network [RAINN], 2016; Testa, Hoffman, \& Livingston, 2010; Testa \& Livingston, 2009). There are several reasons why a majority ( 68\%) of sexual assault cases go unreported; however, of interest here is that witnesses and victims often remain silent because of the negative stigma surrounding intoxication and memory (Littleton, Grills-Taquechel, \& Axsom, 2009; RAINN, 2016; Testa \& Livingston, 2009). In particular, witnesses and victims remain silent out of fear that their memory and/or credibility will be challenged due to their intoxication (National Institute of Health [NIH], 2016).

\section{Perceptions of Intoxicated Witnesses}

Intoxicated witnesses and victims' fear regarding their credibility is buttressed by findings that others in the legal system (e.g., investigators, jurors, experts) believe alcohol distorts witness memory and diminishes credibility (Evans et al., 2009; Evans \& Schreiber-Compo, 2010; Kassin, Tubb, Hosch, \& Memon, 2001). For example, Evans and Schreiber Compo (2010) asked mock jurors to read hypothetical crime reports given by witnesses and victims believed to be sober, moderately intoxicated, or highly intoxicated during the incident. Regardless of crime type, both moderately and highly intoxicated witnesses and victims were rated as more cognitively impaired, less credible, 
and less able to make an accurate identification than those who were sober. The opinion of intoxicated individuals' memory impairment is also held by legal experts. For example, Kassin, Tubb, Hosch, and Memon (2001) surveyed 64 psychological experts on an array of topics pertaining to eyewitness memory. Of these experts, $90 \%$ agreed that the current literature was reliable enough to endorse the statement "alcohol intoxication impairs an eyewitness's later ability to recall persons and events" (p. 4). Most of the experts $(61 \%)$ also stated they would testify about the phenomenon and almost every expert $(95 \%)$ agreed that the negative relationship between alcohol and memory could be considered common sense.

\section{Alcohol and Memory for Basic Stimuli}

When the studies above (i.e., Evans \& Schreiber Compo, 2010; Kassin et al., 2001) were published a solid body of empirical work had demonstrated that alcohol can negatively affect memory processes across a variety of basic cognitive tasks and methodological designs (e.g., Birnbaum \& Parker, 1977; Josephs \& Steele, 1990; Maylor \& Rabbit, 1987, 1993; Tracy \& Bates, 1999). In addition, many studies showed a direct link between alcohol and impaired memory by experimentally manipulating participants' intoxication levels and testing their memory for arbitrary stimuli (Goodwin, Powell, Bremer, Hoine, \& Stern, 1969; Mintzer, 2007). That is, memory was tested using digit span tasks (e.g., Dougherty, Marsh, Moeller, Chokshi, \& Rosen, 2000; Nordby, Watten, Raanaas, \& Magnussen, 1999), word lists (e.g., Fillmore, Vogel-Sprott, \& Gavrilescu, 1999; Maylor \& Rabbit, 1987; Tracy \& Bates, 1999), word pairs (e.g., Curran \& Hildebrandt, 1999; Lombardi, Sirocco, Andreason, \& George, 1997; Weissenborn \& 
Duka, 2000), and pictures (e.g., Goodwin et al., 1969; Parker, Birnbaum, \& Noble, 1976). At the time, however, only two studies had experimentally tested how alcohol affects memory for episodic events likened to eyewitness scenarios (Yuille \& Tollestrup, 1990; Dysart, Lindsay, MacDonald, \& Wicke, 2002; see Appendix A).

Since the Kassin et al. (2001) and the Evans and Schreiber Compo (2010) studies the body of work regarding alcohol's effect on basic cognitive functioning has continued to grow. Whereas most of these experimental studies continue to highlight the negative relationship between alcohol and memory (Mintzer, 2007; Molnár, Boha, Czigler, \& Gaál, 2010; Söderlund, Parker, Schwartz, \& Tulving, 2005) a handful are also revealing a variety of situations in which alcohol does not affect memory (see e.g., Brown, Brignell, Dhiman, Curran, \& Kamboj, 2010; Garfinkel, Dienes, \& Duka, 2006; Jarosz, Colflesh, \& Wiley, 2012; Molnár et al., 2010). Under certain conditions alcohol has even been shown to facilitate memory, such as during a change-blindness task or when consumed after tobe remembered information (Colflesh \& Wiley, 2013; Molnár et al., 2010; Moulton et al., 2005). The more recent studies yielding mixed results suggest the experts' and jurors' opinions may have been premature. More importantly, the findings in the studies examining the alcohol-memory relationship within criminal contexts cast doubt on the degree to which the general findings using arbitrary stimuli translate to the cognitive processes of real-world intoxicated witnesses.

Given the extent to which intoxicated individuals appear in criminal situations and the limited studies directly examining how memory is affected under these conditions additional research is warranted. Data from studies examining this infrequently tested 
population will help researchers understand how alcohol affects memory and inform policy on how to best collect evidence from intoxicated individuals. The benefit to the legal system is considered of greater importance than the contribution to the research community given that most law enforcement agencies have no specific guidelines for collecting evidence from intoxicated witnesses (Evans et al., 2009; Palmer et al., 2013). As such, many officers use the same procedures for all witnesses, not considering the potential limitations of those who are intoxicated.

Next, the paper will review the primary stages of the memory process and provide the theoretical frameworks for how alcohol may disrupt each stage. Attention will then shift to the existing literature on alcohol and witness memory, highlighting the limitations of these studies. Finally, an empirical study that addresses some of these limitations and adds to the dearth of research available regarding intoxicated witnesses' memory will be described, analyzed, interpreted, and discussed.

\section{CHAPTER II}

\section{LITERATURE REVIEW}

\section{Basic Memory Processes}

The formation and retrieval of memory is a complex process that requires knowledge of both cognition and neurology (Kassin, 2004; Smith \& Kosslyn, 2007). At a basic level, memory formation entails three stages (encoding, storage, retrieval) that function independently and in conjunction with one another (Atkinson \& Shiffrin, 1968; Kassin, 2004; Smith \& Kosslyn, 2007). At the first step, encoding, information in the environment is perceived through the five senses and temporarily stored in working 
memory (WM). Encoding relies heavily on attention because the human senses are constantly exposed to environmental stimuli, far too many for WM to hold (Kassin, 2004). To compensate for the limited capacity of WM the brain directs attention toward important (central) information in the environment (Bauer, 2013; Kassin, 2004; Soutschek, Strobach, \& Schubert, 2013). This important information is then temporarily stored in WM.

The second stage of the memory process, storage, involves transferring information from WM to long-term memory (i.e., LTM; Atkinson \& Shiffrin, 1968; Kassin, 2004; Smith \& Kosslyn, 2007). Since WM is limited in capacity it must constantly be cleared for new information to be encoded, requiring the information temporarily stored in WM to be discarded (forgotten) or transferred to LTM. An important aspect in the transfer of information to LTM is the level at which the temporarily stored information is processed (Bauer, 2013; Kassin, 2004; Smith \& Kosslyn, 2007). Information processing (i.e., level of specificity, elaboration) is variable from person to person, situation to situation, and stimuli to stimuli but is often categorized in one of two ways, shallow or deep (Craik \& Lockhart, 1972; Kassin, 2004; Smith \& Kosslyn, 2007; Soutschek et al., 2013). Shallow processing requires only basic information and a minimum amount of thought be devoted toward the information in WM. Deep processing requires an individual to think more critically about the information temporarily stored in WM. As such, deep processing requires more time, effort, and attention than information that is processed at a shallow level (Kassin, 2004; Smith \& Kosslyn, 2007). For example, an individual passively watching a commercial will likely not remember the information later, due to the shallow level at which he/she 
processed the information. However, an individual who intently watches the commercial, considers how the information is valuable, or thinks more critically about the information while it is presented will likely recall more information at a later time because of the deeper level at which the information was processed.

Information processing occurs in conjunction with consolidation, the period in which encoded information is related to and distinguished from information stored in LTM. The consolidation process can be active (e.g., studying for an exam) or passive (e.g., while sleeping); however, of more relevance to this paper is active consolidation. Active consolidation relies heavily on the hippocampus (Smith \& Kosslyn, 2007; White, 2003), a region of the brain that uses pyramidal cells to communicate information between WM and LTM (White, 2003). Newly encoded information is then related to and distinguished from information in long-term storage. The stronger the communication process between these two memory-storage systems (i.e., higher pyramidal cell activity) the easier it is for newly encoded information to be stored in LTM (Smith \& Kosslyn, 2007; White, 2003).

The third stage of the memory process, retrieval, involves recovering previously stored information in LTM (Kassin, 2004; Smith \& Kosslyn, 2007). Retrieval is initiated during encoding, when information perceived in the environment triggers information stored in LTM (Atkinson \& Shiffrin, 1968; Kassin, 2004; Smith \& Kosslyn, 2007). For example, through contextual retrieval information housed in LTM is automatically triggered and recalled due to its overlap with the information being encoded (Smith \& Kosslyn, 2007), such as when an unexpected fire whistle triggers a post-traumatic stress 
victim's memory about the war. Another way to access information in LTM is through cued retrieval. Cued retrieval occurs when a cue in the environment (e.g., a question) triggers the search for a specific memory, fact, or experience. While holding this cue in WM, information related to the cue in LTM is activated and pulled back into WM, allowing people to access their LTM to answer specific questions they are asked.

The terms and stages of the memory process vary slightly across models (Atkinson \& Shiffrin, 1968; Bauer, 2013; Kassin, 2004; Smith \& Kosslyn, 2007). However, each model suggests that memory formation and retrieval begins when attention is devoted toward relevant information in the environment. Environmental information is then processed and transferred through the hippocampus where it is stored in LTM. Information in LTM can then be retrieved when a context or cue provides a trigger. While these are the basic components of the memory process there are a plethora of factors (e.g., rehearsal, brain abnormalities, duration of the event) that impact whether a given piece of information will be formed into a retrievable memory. At the epicenter of this paper is how alcohol affects basic memory processes under the specific encoding and retrieval conditions an eyewitness might encounter. The following sections will review the theories regarding how alcohol potentially affects the memory process followed by a review of how alcohol affects witness memory in particular.

\section{Alcohol and Memory Processes}

Research using arbitrary stimuli (e.g., word lists, word pairs, digit spans) shows that alcohol negatively affects all three stages of the memory process across a variety of basic cognitive tasks (Maylor \& Rabbit, 1987, 1993; Mintzer, 2007; Molnár et al., 2010; 
Söderlund et al., 2005). However, alcohol induced memory deficits are most often attributed to problems during encoding and consolidation (Altman, Schreiber Compo, Hagsand, \& Evans, in press; Mintzer, 2007; White, 2003). To the authors' knowledge, two hypotheses explain why this occurs. One hypothesis stems from the literature on alcohol-induced blackouts and suggests that drinkers' ability to consolidate information housed in WM is slowed down or completely stopped (Lee, Roh, \& Kim, 2009; Perry et al., 2006; White, 2003). The second explanation is referred to as Alcohol Myopia Theory (AMT), which postulates that intoxicated individuals are unable to perceive certain aspects of the environment and subsequently fail to process information at a deeper level (Josephs \& Steele, 1990; Steele \& Josephs, 1990). These theories are discussed separately below but that is not to suggest they are contradictory; in fact, because each explains how alcohol potentially affects different stages of the memory process, it is likely the two work in tandem to affect those who are intoxicated.

Alcohol myopia theory. The AMT was proposed by Claude Steele and Robert Josephs in 1990 to explain how alcohol affects peoples' behavior and decision-making abilities (Josephs \& Steele, 1990; Steele \& Josephs, 1990). According to the theory, alcohol depletes an individual's mental resources. Under limited mental resources, drinkers are forced to concentrate on salient aspects of a situation at the expense of those considered by the drinker as less salient. While disregarding these less important aspects, drinkers are expected to make less inhibited decisions and rely more on impulse rather than deliberative thought because they cannot consider or properly weigh alternative options (see Abbey, Saenz, Buck, Parkhill, \& Hayman 2006; George, Rogers, \& Duka, 2005). These alcohol-induced decision impairments are more pronounced when the 
action requires planning or is associated with a delayed consequence because the drinker is unable to consider alternative outcomes for his/her decisions. In other words, alcohol reduces the drinker's ability to utilize information outside of what is readily available to render the most well-informed decision. For example, intoxicated individuals wishing to drive across town will not consider or properly weigh the risk of getting into an accident, getting pulled over, or other thoughts that might inhibit their initial desire. As such, a drinker may act on this urge to drive despite the potential consequences of his/her current level of intoxication. This decrease in inhibition has been shown across a variety of situations (e.g., sexual promiscuity, engagement in violent activity, gambling) and led people under the influence of alcohol to make more irrational and impulsive decisions than those who are less intoxicated (Abbey, Saenz, \& Buck, 2005; Fillmore \& VogelSprout, 2000; George et al., 2005; Morewedge, Krishnamurti, \& Ariely, 2014; Zawacki, 2011).

In addition to the decision-making impairments created by alcohol, recent research has focused on how the perceptual/attentional deficits postulated under the AMT might impair an individual's ability to later recall information (e.g., Dysart et al., 2002; Harvey, Kneller, \& Campbell, 2013a, 2013b). That is, while functioning under limited cognitive resources, drinkers can only attend to details they feel are important (central) to the situation at the expense of details they consider irrelevant (peripheral). For example, when looking for a place to continue drinking, intoxicated individuals might notice their favorite beer on sale across the street; however, drinkers might not notice the "Do Not Walk" sign flashing across the intersection or the cars driving by because those details are not central to their desired task. As such, the narrow vision leads drinkers to 
encode, and later recall, less information than non-drinkers in similar situations.

Relatedly, given their weakened memory of the event, intoxicated individuals are expected to recall more inaccurate information, especially when prompted by an outside source or provided misinformation about the event, compared to sober individuals (Loftus, 2005; van Oorsouw, Merkelbach, \& Smeets, 2015).

Within the eyewitness literature the perceptual/attentional component of the AMT has been tested a handful of times (Harvey et al., 2013a, 2013b); however, to my knowledge the behavior and decision-making component of the AMT has never been applied to or tested within an eyewitness context. To delineate which component of the AMT is being referred to throughout this paper, I have used the term original to denote the behavioral and decision-making component of the AMT and the term attentional to denote the perceptual/attentional component of the AMT.

Alcohol-induced blackouts. Unlike alcohol myopia theory, the literature on alcohol-induced blackouts suggests that drinkers' memory impairments stem from complications during the consolidation process (Lee et al., 2009; Perry et al., 2006; Wetherill \& Fromme, 2016; White, 2003). That is, alcohol is believed to slow down pyramidal cell activity and hinder drinkers' ability to transfer information between WM and LTM (see White, 2003 for review). Drinkers may therefore participate in various events while intoxicated but later have no recollection of the experience, a phenomenon often referred to as a blackout (see Wetherill \& Fromme, 2016; White, 2003 for reviews).

Alcohol-induced blackouts occur in two forms, en bloc and fragmentary (Lee et al., 2009; White, 2003). En bloc blackouts occur when pyramidal cell activity is 
completely stopped and there is no communication between WM and LTM (White, 2003). Once this happens, the drinker is unable to encode subsequent information about the events he/she experiences (i.e., complete memory loss), even if the experience was emotionally arousing or the drinker is later provided cues about the event (e.g., told by a friend, saw a video). Fragmentary blackouts (i.e., grayouts) are more common and occur when pyramidal cell activity is reduced but partially intact (Lee et al., 2009; Perry et al., 2006; White, 2003). A person experiencing this type of memory loss will have trouble recalling information about some parts of the drinking episode while still remembering others.

Identifying the specific BAC level at which a blackout of either variety will occur is difficult because they appear across a broad range of BAC levels and are dependent on a variety of factors such as physical characteristics of the participant (height, weight, etc.) and the rate of consumption (Perry et al., 2006; Wetherill \& Fromme, 2016; White, 2003). Researchers are also not ethically allowed to administer high doses of alcohol to participants, further complicating any possible examination of how memory functions at BAC levels likely to elicit a blackout of either kind. Not being able to examine witnesses under elevated intoxication levels has led most researchers examining alcohol-induced blackouts to rely on post-hoc reports given by individuals who reached elevated BAC levels days, weeks, or months before their memory was tested (see Wetherill \& Fromme, 2016 for review). For example, Perry et al. (2006) interviewed participants who were incarcerated and charged for an alcohol-related offense over the last six months. To determine whether these individuals experienced a blackout, the completeness and accuracy of their recall was compared to the recall of other at the crime scene. When 
available, participants' memory was also compared to video footage of the night in question. Using these resources, Perry and his colleagues (2006) pieced together each participant's night for signs of memory impairments and alcohol-induced blackouts. These impairments were positively and significantly correlated with participants' BAC levels; however, signs of alcohol-induced blackouts (although unlikely) were not found until BAC levels of .10\% were reached. Given the variability in events and ways in which information was verified these findings, and others regarding alcohol-induced blackouts, are not without flaw; however, they shed light on how elevated BAC levels affect the likelihood of experiencing an en bloc or fragmentary blackout. For instance, conservative estimates suggest the lowest BAC level at which an en bloc blackout can occur is .14\% (see Rybalt, 1970 as cited in White, 2003). Signs of fragmentary blackouts (although unlikely) have been found at BAC levels as low as .10\% (Perry et al., 2006). While the exact onset levels are debated, there is agreement that the probability of experiencing a blackout of either variety is positively correlated with a person's BAC level (Perry et al., 2006; White, 2003).

The literature regarding alcohol-induced blackouts and the AMT provide insight into how alcohol can potentially affect peoples' memory and decision-making processes. However, these theories have seldom been tested within eyewitness contexts. That is, the original AMT has been used to explain behavior and decision-making processes in various contexts (Fillmore \& Vogel-Sprout, 2000; George et al., 2005; Kassel, Wardle, Heinz, \& Greenstein, 2010; Zawacki, 2011) but never a scenario likened to an eyewitness situation. The attentional AMT has been tested within eyewitness contexts (Harvey et al., 2013a, 2013b) but only a handful of times, and only three studies have used an 
eyewitness context to examine how individuals at risk of experiencing an alcoholinduced blackout (i.e., high BAC levels) recall a controlled stimulus (Altman, Schreiber Compo, McQuiston, Hagsand, \& Cervera, 2018; Crossland, Kneller, \& Wilcock, 2016; Dysart et al., 2002). Thus, to better understand the potential impairments of intoxicated witnesses, inform theory, and guide policy, more studies examining the relationship between alcohol and witness memory are paramount. Ideally, these studies will expose participants to controlled, detail-rich, and interactive environments similar to those witnesses might encounter (Altman et al., 2018; Flowe, Takarangi, Humphries, \& Wright, 2015) and will include participants who reach elevated BAC levels that include the potential for an en bloc or fragmentary blackout.

\section{Alcohol and Eyewitness Memory}

To the author's knowledge, 18 studies have directly examined how alcohol affects memory within an eyewitness context (see Appendix A). Those 18 studies exclude 3 studies examining the effects of alcohol on offender memory, the rationale for which is included in Appendix A. Participants in these eyewitness studies typically enter the lab and are randomly assigned to a sober or alcohol group. Depending on their assigned group, participants drink one or more glasses of juice that contain no alcohol or a predetermined dose of alcohol, typically vodka. These doses are typically determined by characteristics of the participant (e.g., height, weight) to ensure each person reaches approximately the same BAC level. Safety and ethical restrictions typically require this BAC level to be set at or below .08\% (e.g., Hagsand, Roos af Hjelmsäter, Granhag, Fahlke, \& Söderpalm Gordh, 2017; Schreiber Compo et al., 2011; 2012). Some studies 
also incorporate a third condition (placebo) in which the participants consume a beverage that contains a very small dose of alcohol, such as one or two drops or a vodka soaked lime, meant to trick participants into thinking they consumed alcohol when in fact they did not, allowing researchers to examine how the expectation of alcohol affects witness memory (e.g., Schreiber Compo et al., 2011, 2012).

After consuming their assigned beverage (sometimes during), participants view a live-staged interaction ( Schreiber Compo et al., 2011, 2012; Yuille \& Tollestrup, 1990), a video of a mock crime (Hildebrand Karlén, Roos-af-Hjelmsäter, Fahlke, Granhag, \& Söderpalm Gordh, 2017; Schreiber Compo et al., 2017) or a slide show that depicts a staged-interaction or a mock-crime (Harvey et al., 2013a, 2013b). Participants are then asked to recall information about the witnessed event and/or asked to identify an individual from the event. These recall formats and face identification procedures vary considerably across studies. For example, whereas some researchers choose written retrieval tasks (Crossland et al., 2016; La Rooy, Nicol, \& Terry, 2013; Schreiber Compo et al., 2011), others use live mock interviews in which participants answer free, cued, multiple choice and/or yes/no questions provided by an interviewer (Hagsand et al., 2013a, 2017; Yuille \& Tollestrup, 1990). Identification procedures consist of showups (Dysart et al., 2002), simultaneous lineups (Hagsand et al., 2013b; Harvey et al., 2013b; Kneller \& Harvey, 2015) or face recognition paradigms (Colloff \& Flowe, 2016; Harvey, 2014; Hilliar, Kemp, \& Denson, 2010). The data from these interviews and identifications are then compared to determine how alcohol affects witness memory. 
Memory in the alcohol-eyewitness literature is typically assessed in two ways, memory for events and/or memory for faces (see Tables $1 \& 2$ ). Most studies focus on intoxicated witnesses' ability to remember events (e.g., actions, conversations, objects). Fewer studies have concentrated on intoxicated witnesses' ability to recognize faces (i.e., make an identification of the perpetrator). Only four published studies have simultaneously tested both types of witness memory within the same experiment. Findings regarding these two types of memory have been considerably different; therefore, to disentangle how alcohol affects each they will be discussed separately below.

Memory for events. The event memory literature has shown modest support for the attentional AMT, which postulates that alcohol affects peoples' ability to attend to (i.e., see) details that are peripheral to the situation. For example, in a direct test of the theory Harvey et al. (2013a) tracked participants' eye movements while viewing slides that depicted a criminal event. As expected, intoxicated participants spent more time fixating on central aspects of the scene while sober participants attended more to peripheral aspects. In a follow-up study Harvey et al. (2013b) used the same procedure but a different criminal event and found that alcohol had no effect on participants' eye fixations.

Indirect tests of the theory have also yielded inconsistent findings. In these studies, the attentional AMT is assessed by participants' recall of central relative to peripheral information. In support of the theory, Schreiber Compo et al. (2011) found that intoxicated participants recalled fewer peripheral details than participants in the sober and 
placebo condition. No differences were found in the number of central items recalled by intoxicated individuals. Other indirect tests of the theory have failed to replicate these findings and not shown support for the attentional AMT (Crossland et al., 2016; Flowe et al., 2015). Lack of support for the attentional AMT can be attributed to a variety of methodological differences across studies, such as the timing of the recall and question formats administered (Schreiber Compo et al., 2017). Other notable concerns which are more relevant to this paper include the difficulty in determining item centrality and the low to moderate BAC levels at which participants have been tested.

Item centrality. One limitation when examining the attentional AMT in an eyewitness context is the classification of central and peripheral items, which is not determined on a participant-by-participant basis but rather predetermined and applied to the entire study population. For example, in Schreiber Compo et al.'s (2011) mock-bar event the researchers determined that the bartender's actions were central to the situation whereas wall fixtures behind the bartender were peripheral. A similar classification was used by Harvey et al. (2013b) in that information relevant to the perpetrator was considered central and all other information provided in the slides was considered peripheral. In Harvey et al.'s (2013a) initial test of the theory centrality was determined by the objects location on the slide with those located closer to the midpoint deemed central. Each object was also given a centrality rating by a group of pilot participants. These pilot ratings were used in conjunction with the objects' position on the slide to determine its overall centrality. Lastly, Crossland et al. (2016) had pilot participants rate each item's centrality on a 1-5 scale. Each item was then classified as central or peripheral on the basis of these pilot ratings. 
Varied approaches in determining item centrality help explain differential support for the attentional AMT in the alcohol-eyewitness memory literature, especially when considering individual variability in item centrality ratings provided by pilot participants across studies (Crossland et al., 2016). Furthermore, item centrality may change throughout the duration of an event (Crossland et al., 2016; Harvey et al., 2013b). According to Harvey et al. (2013b) participants' initial focus may be on items considered central by most, but as the event progresses attention may shift, arbitrarily, toward objects that were initially considered peripheral. Perceptions of centrality may thus be confounded with the amount of time witnesses had to encode information and the amount of detail within each scene.

Despite inconsistencies in determining item centrality, the attentional AMT still suggests that intoxicated individuals spend more time fixating on central items than those who are sober or less intoxicated. Prolonged encoding of central items would consequently reduce the time intoxicated individuals have to attend to peripheral items, restricting encoding time for peripheral items and reducing the quantity (fewer items attended to) and quality (weaker/incomplete memory) of intoxicated individuals' recall. Tests of the attentional AMT should therefore show that intoxicated individuals report fewer details and less accurate information than those who are less intoxicated. In support of this assumption, most studies find that collapsed across all items (i.e., central and peripheral) alcohol negatively affects witnesses' recall quantity (Altman et al., in press; Crossland et al., 2016; Hagsand et al., 2013a, 2017; Hildebrand Karlén et al., 2015, 2017); however, the effect of alcohol on recall quality has been rather evasive (see Altman et al., in press). That is, most studies find that alcohol has no effect on the quality 
of information reported by participants (Hagsand et al., 2017; Hildebrand Karlén et al., 2015, 2017). When significant differences in memory quality do emerge they are often inconsistent (Flowe et al., 2015; Schreiber Compo et al., 2012; Yuille \& Tollestrup, 1990).

Null findings regarding the effect of alcohol on information quality, and sometimes quantity, can be explained by a variety of methodological differences across studies (see Altman et al., in press; Schreiber Compo et al., 2017 for reviews). Another well noted potential cause of these null/inconsistent findings is the low-to-moderate BAC levels at which most participants are tested.

Low BAC levels. Nearly every study in the alcohol-eyewitness memory literature has been conducted inside a laboratory setting where ethical and safety restrictions prohibit administering high doses of alcohol to participants (see Tables $1 \& 2$ ). As such, participants inside the lab typically reach a mean BAC of $.08 \%$ or less. Although a small percentage of laboratory participants exceed this BAC limit (i.e., reaching peak levels between $10 \%$ and $12 \%$ ) these cases are often too few to analyze as a separate group (Hagsand et al., 2017; Hildebrand Karlén et al., 2015; Schreiber Compo et al., 2012).

The $.08 \%$ BAC cutoff is relevant and frequently used because it denotes the legal driving limit in the U.S and has been shown to consistently impair motor functions (Harrison \& Fillmore, 2005; Laude \& Fillmore, 2015; Marczinski, Harrison, \& Fillmore, 2008). However, Evans et al. (2009) found that real-world witnesses often exceed this cutoff and reach average BAC levels of approximately $.11 \%$. The $.08 \%$ cutoff also fails to test memory under conditions in which participants are likely to experience an en bloc 
or fragmentary blackout. Therefore, participants in these studies may not be intoxicated enough to narrow their vision and consistently expose the cognitive impairments alcohol is expected to create, findings suggest this is especially likely in regard to memory quality (Altman et al., in press; Flowe et al., 2015; Schreiber Compo et al., 2017).

To circumvent BAC restrictions associated with laboratory studies and test witness memory across the broader BAC spectrum, researchers are encouraged to conduct field studies in which participants are voluntarily consuming larger quantities of alcohol (Altman et al., in press). To date, only two published studies (Altman et al., 2018; Crossland et al., 2016) have examined how elevated BAC levels affect witnesses' event memory, yielding BAC levels as high as .29\% (Altman et al., 2018) and .23\% (Crossland et al., 2016). In Crossland et al. (2016) participants were invited to the student union on campus and instructed to engage in their normal drinking behavior. At pre-determined times these participants were told to leave the student union and go to the psychology lab on campus. Inside the lab participants' BAC levels were recorded, they watched a 3minute video depicting a mock crime, and were then dismissed from the testing location. One week later participants returned to the lab and wrote out everything they could remember about the event. Participants also completed a 40-question recognition test of items displayed in the video. In Altman et al. (2018) participants were randomly recruited from a bar setting. Consenting participants were taken to a backroom at the bar where they had their BAC levels recorded, watched a 2-minute video depicting a mock-crime, and were then immediately interviewed about what they witnessed. In line with the notion that the low-to-moderate $\mathrm{BAC}$ levels tested inside the lab were masking the effects 
of alcohol on witness memory, both studies found that higher levels of alcohol negatively impacted the quantity and quality of witnesses' reports.

Building upon these two field studies, the current study recruited participants from a bar setting in which they were voluntarily consuming large amounts of alcohol. After witnessing the event, participants' memory was tested, allowing for the examination of how high levels of alcohol affect the quantity and quality of information reported. However, to circumvent the problems with determining item centrality, the information reported in these interviews will not be scored as central or peripheral. The effects of alcohol on memory were simply assessed by the quantity and quality of participants' reports.

The present study will extend upon Crossland et al. (2016) and Altman et al. (2018) by exposing participants to a live-staged interaction that more closely mimics an eyewitness situation rather than a video-taped mock crime. Given the realistic nature of the event, participants will also undergo questioning that more closely mimics an eyewitness interview. The current project will therefore add ecological validity to the limited research on alcohol and witness memory. Most importantly, it will be the third study in the event memory literature to test witnesses at elevated BAC levels at which they could experience an en bloc or fragmentary blackout. Testing this understudied population of actual drinkers in different (realistic) contexts will also provide a direct test of the conditions under which alcohol affects witness memory. Thus, the current study will inform theories regarding the effects of alcohol on memory and increase the extent to 
which its findings can be translated for legal practitioners (Carlson, 2013; Lane \& Meissner, 2008).

Memory for faces. Researchers examining the effects of alcohol on witnesses' facial memory typically utilize a standard police identification procedure or the face recognition paradigm (Altman et al., in press). In the face recognition paradigm, participants view faces displayed on a screen one at a time. Following a delay these faces are shown to the participant a second time (old faces) along with faces not previously viewed (new faces). The participant's task during the second viewing is to state whether each face displayed is old or new. Findings from these studies are mixed because one study suggested that intoxicated participants recognized fewer old faces than those in the placebo and control conditions (Hilliar et al., 2010), while other studies suggest that alcohol has no effect on the ability of participants to remember old and new faces (Colloff \& Flowe, 2016; Harvey, 2014).

Face recognition studies help elucidate the effects of alcohol on facial memory. However, it is important to note they do not closely mimic eyewitness identifications. For example, although some witnesses experience crimes with multiple perpetrators, it is unlikely that witnesses have a direct view of each suspect's face for the same length of time. Perpetrator's actions also impair witnesses ability to attend to facial features (Simons \& Rensink, 2005), an aspect of the encoding process not accounted for by the facial recognition paradigm. Furthermore, identification decisions using the paradigm are not independent of each other given the multiple decisions made and similarities between faces in the stimulus set. For example, Colloff and Flowe (2016) found that participants 
focused on distinguishing features of old faces but were hesitant to state faces were old. The conservative decision-making criterion displayed in this study suggests that participants were unable to distinguish whether the feature was unique to an old face given the multitude of overlapping features between faces in the stimulus set. Participants in face recognition studies also make multiple decisions about old and new faces during a session; eyewitnesses are typically only asked to view one set of faces and make one decision. Given the encoding and decision-making differences, findings obtained using the face recognition paradigm are considered less transferable to the memory processes of eyewitnesses (Altman et al., in press).

Police identification procedures. Studies using standard police procedures to examine how alcohol affects identification decisions generally expose witnesses to an event in which only one individual (i.e., the perpetrator) must later be identified. The identification procedure used most often is the simultaneous lineup, which is frequently used in U.S. police departments (National Institute of Justice [NIJ], 2013). Under the simultaneous lineup identification format, witnesses view a live or photo presentation of the suspect alongside known innocent individuals (i.e., fillers). These fillers are selected on the basis of similarity to the perpetrator's description (match-description) or their similarity to the police suspect (match-suspect). Witnesses are then asked to determine if one of the photos displayed is the perpetrator from the crime they witnessed. When the perpetrator's photo is among those displayed, the lineup is considered target-present. When the perpetrator's photo is not present among those displayed, the lineup is considered target-absent. In research studies, experimenters often designate one filler in the target-absent lineup to act as the "innocent suspect" (Steblay, Dysart, Fulero, \& 
Lindsay, 2003; Wells \& Turtle, 1986). The innocent suspect can be designated in advance (i.e., a priori) or after the data has been collected (i.e., post hoc) and is most often the individual that best resembles the perpetrator (Clark, Marshall, \& Rosenthal, 2009; Pryke, Lindsay, Dysart, \& Dupuis, 2004; Steblay et al., 2003). The innocent suspect is used to examine the likelihood of a false identification when the perpetrator's photo is not present. Utilizing target-present and target-absent lineups allows researchers to examine the diagnosticity of experimental lineup manipulations, which is represented by the probability of identifying the perpetrator in a target-present lineup divided by the probability of identifying the innocent suspect in a target-absent lineup (Wells \& Luus, 1990). Techniques with higher diagnosticity increase correct identifications in targetpresent lineups without inflating false identifications in target-absent lineups; or, decrease false identifications in target-absent lineups without affecting correct identifications in target-present lineups. In the best case scenario a technique or format will increase accurate identifications and decrease false identifications.

Outside of the simultaneous lineup, the only police identification procedure used to examine the effects of alcohol on identification decisions is the showup (Dysart et al., 2002). Here, witnesses view one photo in which the perpetrator is pictured (targetpresent) or is not pictured (target-absent). Witnesses are then asked to state whether the individual pictured is the perpetrator from the event. In many instances the showup procedure is used when a suspect is apprehended within hours of the crime (Agricola, 2009; Cicchini \& Easton, 2010). The suspect is then taken back to the scene of the crime where he/she is presented to the perpetrator. When the suspect is presented to the witness at the scene of the crime it is referred to as a live showup as opposed to a photo showup. 
Showups vs. lineups. Outside of the alcohol literature, the showup procedure has been criticized by researchers because it reduces and/or eliminates safeguards meant to ensure witnesses are not unjustly persuaded to choose the suspect (Dysart \& Lindsay, 2007; Sjöberg, 2016; Steblay et al., 2003; Wells, 2001). Mainly, the showup has been criticized for its omission of fillers which are meant to 'hide' the suspect and provide a better test of the witness's memory (Wells, 2001). The absence of fillers has little-to-no effect on witnesses' decisions in target-present situations (Steblay et al. 2003). These fillers are important however in target-absent situations because any photo presented without fillers that vaguely resembles the perpetrator is more likely to be falsely identified than a photo presented among fillers (Steblay et al., 2003; Wells, 2001).

The superiority of the lineup in a target-absent situation can be gleaned from Clark's WITNESS model (Clark, 2003), a mathematical model that accurately predicts witness choosing behavior (Fife, Perry, \& Gronlund, 2014; Molinaro, Arndorfer, \& Charman, 2013). According to Clark's model, witnesses search a lineup for the photo that best matches their memory of the perpetrator. If no individual stands out, then the search is terminated and the witness should reject the lineup. If a 'best match suspect' does appear, then the witness simultaneously considers the degree to which this individual matches the perpetrator relative to the other photos presented. If the difference between the best match suspect and the other photos is significant enough to overcome the witness's decision-making threshold, then the best match suspect will be identified as the perpetrator. If this difference does not surpass the witness's decision-making threshold, then the search will be discontinued and the lineup should be rejected. Thus, the 
WITNESS model suggests that the fillers in a target-absent lineup help suppress a witness's urge to identify an innocent lineup member that resembles the perpetrator.

The showup procedure does not provide alternative options for the witness to consider (Sjöberg, 2016; Steblay et al., 2003). Therefore, witnesses who view a targetabsent showup that resembles the perpetrator to a reasonable degree are more likely to make a false identification than witnesses who view that same innocent suspect in a lineup. The increase in false identifications is reflected in a comprehensive meta-analysis by Steblay et al. (2003), which found that witnesses who viewed a target-absent showup were twice as likely to make a false identification (23\%) than those who viewed a targetabsent lineup (10\%). No differences were found in accurate identifications from targetpresent showups (46\%) and target-present lineups (45\%).

The potential problems of the showup have been well-documented and presented to the legal system (see Sjöberg, 2016; Steblay et al., 2003; Wells, 2001 for reviews). Despite these warnings, showup identifications are still admissible as evidence in court (Agricola, 2009; Cicchini \& Easton, 2010). Furthermore, a majority of law enforcement agencies across the U.S support the use of showups (NIJ, 2013; Sjöberg, 2016; Smith et al., 2014). This support stems from the fact that showups are easier to create than lineups and provide officers with a quick way to apprehend and/or eliminate a suspect from an investigation, especially when the suspect is apprehended within hours of the crime (Agricola, 2009; Cicchini \& Easton, 2010). These practical benefits have led to showups being the second most utilized identification procedure across the country (NIJ, 2013). 
Alcohol and identification decisions. The perpetrator of a crime is arguably central to a criminal event (Altman et al., 2018; Flowe et al., 2017). According to the attentional AMT, intoxicated individuals should therefore be just as likely to focus on the perpetrator as less intoxicated individuals and later make identification decisions that are just as accurate (Flowe et al., 2017; Hagsand et al., 2013b). An exception to this would be when the intoxicated individual experiences an en bloc or fragmentary blackout. In this instance, the witness's ability to consolidate central information would be compromised and reduce the probability of making an accurate identification decision.

The original AMT suggests that alcohol should only affect witnesses' identification abilities when the decisions are made while still intoxicated (Josephs \& Steele, 1990; Steele \& Josephs, 1990). That is, functioning under limited cognitive resources, intoxicated individuals will be less likely to consider alternative options and utilize a more liberal decision criterion when scanning the photos for the perpetrator. The liberal decision making criterion created by alcohol will cause drinkers to identify a photo that stands out more often than those who are less intoxicated (Colloff \& Flowe, 2016). In a target-present situation this liberal decision-making criterion should have little-to-no effect on a witness's ability to identify the perpetrator because the perpetrator's photo should stand out regardless of whether it is presented alone or imbedded among fillers. No data suggest that the fillers in a target-present lineup reduce the number of accurate identifications (Altman et al., 2018; Steblay et al., 2003). Intoxicated witnesses' decisions in a target-absent situation are likely to depend on the identification format employed. That is, the alternative options (i.e., fillers) readily available in a lineup should help offset the liberal decision-making criterion created by 
alcohol (Colloff \& Flowe, 2016), rendering it more difficult to locate a best match suspect and result in more correct rejections and 'not sure' responses (Clark, 2003; Fife et al., 2014). Incorrect selections from a target-absent lineup will also be dispersed among the fillers and suspect, reducing the probability of a false identification (i.e., filler siphoning). The showup does not readily provide alternative options for intoxicated witnesses to consider. The liberal decision-making criterion created by alcohol should therefore increase the likelihood of a false identification from a showup, especially if the innocent suspect is a reasonable match to the perpetrator (Dysart et al., 2002).

In the eyewitness literature alcohol has consistently had no effect on identification rates in target-absent or target-present lineups (Altman et al., in press). That is, intoxicated individuals are just as likely to correctly identify the perpetrator in a targetpresent lineup and falsely identify an individual from a target-absent lineup as someone who is less intoxicated or sober. These consistent null findings are in line with the attentional AMT and the literature on alcohol-induced blackouts given that each of these studies was performed inside a laboratory on participants at low-moderate BAC levels (Altman et al. in press). These low-moderate BAC levels are not likely to induce fragmentary and en bloc blackouts, allowing intoxicated participants to properly encode and retrieve central information (i.e., the perpetrator) and identify or reject the lineup at rates equivalent to those who are less intoxicated. Additionally, witnesses in these studies are often tested 24-hours or one-week after the event, while sober (see Table 2). Participants' decision-making abilities are therefore no longer impaired by alcohol (Colloff \& Flowe, 2016; Josephs \& Steele, 1990; Steele \& Josephs, 1990). Altman et al. (2018) is the one exception to the methodology above. That is, participants in this study 
were recruited from a bar setting at BAC levels as high as .29\%. In addition, participants' identification ability was tested immediately after the event (i.e., 5-7 minutes) while they were still intoxicated. Despite these methodological differences, alcohol still had no effect on participants' lineup decisions, target-absent or target-present.

Only one study in the alcohol-eyewitness memory literature has tested identification ability using a showup (Dysart et al., 2002). In the field study, bar patrons were approached by a female assistant and asked to participate in a brief survey. Patrons who agreed were then taken to a back room to interact with another assistant. After a 12minute delay participants were taken outside the bar where the original assistant (targetpresent) or a female that highly resembled the original assistant (target-absent) was standing. Participants were then asked to state whether the female in front of them was, or was not, the female who initially approached them about the study. The field study yielded participants with BAC levels as high as $.21 \%$. At these elevated BAC levels, the ability of participants to identify the perpetrator in the target-present condition was intact; however, alcohol increased the likelihood of a false identification from the target-absent showup, rendering Dysart et al. (2002) the only study in the eyewitness literature to find an effect of alcohol on witnesses' identification decisions.

The significant finding in Dysart et al. (2002) could be attributed to the elevated BAC levels tested, suggesting that impairments in facial memory are not exposed until witnesses are at higher risk of experiencing a fragmentary or en bloc blackout. However, the null findings in Altman et al. (2018) suggest that alcohol alone is not the driving force behind the significant finding, and that the significant finding can be attributed to the combination of elevated BAC levels and the suggestiveness of the showup procedure. 
That is, the suggestiveness of the showup in a target-absent situation combined with the lowered decision-making criterion of intoxicated individuals led to the increase in false identifications in the Dysart et al. study. In lineup studies incorrect selections are siphoned away by fillers, reducing the false identification rate (Wells, 2001) and offsetting the liberal decision-making criteria created by alcohol (Altman et al., in press; Colloff \& Flowe, 2016).

While theory suggests that the lineup would improve identification decisions from intoxicated witnesses, particularly in target-absent situations, the assumption cannot be verified given the dearth of studies examining the relationship between alcohol and eyewitness identifications. Vast differences (e.g., BAC levels, intoxication state, timing of recall) between the lineup and showup studies in the literature also make it difficult to surmise how identification format affects intoxicated witnesses' decisions. Finally, no study has directly compared intoxicated witnesses performance across the two identification formats. Considering the frequency at which law enforcement uses lineups and showups, additional research is needed to understand how alcohol affects decisions from each. In addition to examining these identification formats independently under more similar conditions, researchers should develop studies in which the two are directly compared so the potential benefits, and dangers, can be observed.

To address this important remaining research question, the present study recruited participants from a bar setting in which they were voluntarily consuming quantities of alcohol that were greater than $.08 \%$. After witnessing a live-staged interaction these participants were randomly assigned to view a lineup or showup in which the target was pictured or was not pictured. The present project therefore extends the limited research 
available regarding intoxicated witnesses' identification ability. In addition to testing witnesses at elevated BAC levels it is the second study to examine intoxicated witnesses' identification decisions using a showup. Most importantly, it is the only study to directly examine how identification format (lineup vs. showup) affects intoxicated witnesses identification decisions.

\section{CHAPTER III}

\section{THE PRESENT STUDY}

Taken together, past research suggests that investigators frequently encounter intoxicated witnesses (Evans et al., 2009; Palmer et al., 2013). A large body of research also suggests that alcohol negatively affects basic memory processes (Mintzer, 2007; Molnár et al., 2010; Söderlund et al., 2005), enough so that experts and jurors believe alcohol consistently produces memory impairments in witnesses (Evans \& Schreiber Compo, 2010; Kassin et al., 2001). However, recent work examining the alcohol-memory relationship within eyewitness scenarios casts doubt on whether alcohol consistently impairs witness memory, and the extent to which the research findings using 'basic' stimuli translate to alcohol's effect on witness memory.

Regarding witnesses' memory for events, the eyewitness literature provides modest support for experts' and jurors' assumptions as well as the attentional AMT. That is, several studies suggest that alcohol reduces peoples' ability to pay attention to objects in the environment, decreasing the quantity and quality of their recall (see Altman et al., in press; Schreiber Compo et al., 2017 for reviews). Other studies however have not found an effect of alcohol on witnesses' event recall. These inconsistent findings can be 
partially accounted for by determinations of item centrality. Furthermore, the low-tomoderate BAC levels typically tested inside the predominately lab-based literature could also be masking the negative effects alcohol is expected to create.

When it comes to memory for faces, the literature clearly shows that when presented with a lineup, alcohol has no effect on eyewitnesses' identification accuracy. When presented with a showup however, one study suggests that intoxicated individuals are more likely to make a false identification. No study to date, however, has systematically investigated whether the identification format administered played a role in these differential results.

The present study directly examined the importance of (high) intoxication levels and identification format in alcohol's effect on witnesses' memory for faces and events, simultaneously addressing two gaps in the literature. Specifically, participants in this study were recruited from a bar setting, allowing for the examination of participants across a broad range of BAC levels. The sample included individuals with BAC levels that could result in symptoms associated with en bloc and fragmentary blackouts. Participants were told the study was an assessment of their cognitive and motor functions. However, midway through the first task an intruder entered and caused a disturbance with the research assistant. After witnessing this live-staged interaction between the confederate and research assistant, participants were asked to document the disturbance via an interview. Following the interview participants were asked to identify the confederate from a lineup or showup in which the target was either present or absent. 
The current experiment exposed participants to a live-staged interaction that closely mimics an eyewitness encounter compared to previous studies described in the literature. Additionally, the study gathered data regarding intoxicated individuals' memory for faces and events at elevated BAC levels. Lastly, it allowed for a direct comparison of the two identification formats used in the alcohol-eyewitness identification literature. The current study therefore helped inform theory by elucidating important and ecologically-valid conditions under which alcohol might potentially affect witness memory. The study also benefits legal practitioners in assessing the evidentiary value of intoxicated witnesses statements and identifications.

\section{Hypotheses}

Memory for events. In line with the attentional AMT and previous studies in the field, alcohol is expected to have a main effect on memory quantity and quality. Specifically, as BAC levels increase witnesses are expected to provide less information (quantity) and a lower proportion of accurate information (quality). The negative effect should be more prominent for information quantity than quality. That is, deficits in memory quantity will increase steadily across the BAC spectrum as alcohol limits the attention participants can devote toward the number of objects in a given environment. Deficits in recall quality will be driven by impairments at the upper end of the BAC spectrum as participants are more likely to experience symptoms associated with alcoholinduced blackouts, possibly yielding reconstructive memory processes (see Altman et al., in press). Witnesses at the low-to-moderate range of the BAC spectrum are expected to vary little in terms of recall quality given that they are not likely to experience signs of 
alcohol-induced blackouts, As such, witnesses at the low-to-moderate range of the BAC spectrum are expected to have a more complete memory of the event and provide a similar proportion of accurate information.

Memory for faces. Given the dearth of studies examining the effects of alcohol on eyewitnesses' facial identification abilities these hypotheses are exploratory. However, on the basis of past findings and AMT theory, alcohol is not expected to affect the choosing or accuracy of those in the target-present conditions (Flowe et al., 2017; Hagsand et al., 2013b; Steblay et al., 2003). Identification format is also not expected to affect the choosing or accuracy rates of those in the target-present conditions (Steblay et al., 2003). Thus, alcohol and identification format are not expected to affect decisions made from target-present lineups or showups.

An interaction between alcohol and lineup format is predicted for witnesses in the target-absent conditions. According to the original AMT, intoxicated individuals will utilize a more liberal decision-making criterion than those who are less intoxicated as they cannot properly consider alternatives. The liberal decision-making criterion will increase the probability of choosing a photo that is a relative match to the perpetrator. However, witnesses who view a lineup will utilize a more conservative decision-making criterion given the similarities across the various faces. These similarities will lead more witnesses to reject the lineup or render a not sure response given that a 'best match suspect' will be harder to identify. Incorrect selections in the lineup should also be dispersed among the fillers (i.e., filler siphoning), reducing the false identification rate and rendering no difference between intoxicated and sober individuals. The benefit of 
fillers will not be available to witnesses in the showup condition. The liberal decisionmaking criterion created by alcohol will therefore have a greater impact on decisions made in the showup condition and result in more false identifications compared to the lineup condition.

\section{CHAPTER IV}

METHOD

\section{Participants}

Participants in this study were recruited from a bar in a suburban area of the Northeastern United States. Recruitment was done in two stages via personal communication, 1) potential participants were invited to the bar on testing nights, and 2) on testing nights patrons of the bar were randomly asked to participate. At each stage potential participants were asked to take part in a study that examined the effects of alcohol on cognitive and motor functions. These individuals were also made aware there were no incentives for participating and that the study would take 20-25 minutes to complete. Approval from the university ethics committee (IRB) was obtained before any data were collected. A total of 133 people agreed to participate in the study. However, one participant removed herself from the study before any interview, identification, or demographic data could be collected. Our overall sample consisted of 132 people (53\% male; $47 \%$ female $)$. Participants were between the ages of 19 and $66(M=38.83 ; S D=$ 15.08), and most identified themselves as White/Caucasian $(N=129 ; 97.7 \%)$. The only other reported ethnicities were African American $(N=2 ; 1.5 \%)$ and Hispanic/Latino $(N=$ $1 ; .8 \%)$. Participants' BAC levels ranged from $.00-.24 \%(M=.08 ; S D=.06)$. 


\section{Design}

The present study followed a 2 (identification format: lineup vs. showup) x 2 (target presence: target-present vs. target-absent) experimental design. Intoxication levels above $.08 \%$ cannot be experimentally manipulated, ethically. Therefore, intoxication level acted as a continuous quasi-experimental independent variable.

Dependent measures for event memory included the total number of informational units reported by participants (memory quantity) and the proportion of accurate, inaccurate, "I don't know," subjective, and irrelevant informational units reported (memory quality). Dependent measures for facial memory included choosing and accuracy rates across the various identification conditions. These dependent variables are described in more detail in the "Scoring" section below. Participants' certainty in their identification decision as well as other testimony relevant judgments (e.g., length of event, quality of view, etc.) were also measured (Steblay, Wells, \& Douglass, 2014; Wells \& Bradfield, 1998; 1999).

\section{Materials}

Intoxication measurements. Participants' BAC levels were measured two times during the experiment using one of two BACtrack S80 Pro Breathalyzers: Professional Edition (KHN Solutions, 2016). These handheld breathalyzers are similar to those used in prior field research (Dysart et al., 2002; Morewedge et al., 2014) and laboratory research (Hagsand et al., 2013a; 2013b; 2017). To further ensure accurate measurement, the two breathalyzers used in this study were pilot tested against a calibrated benchtop model Intoxilyzer 5000 housed at Florida International University. The benchtop device is 
considered one of the most accurate tools available for measuring BAC levels (Department of Transportation [DOT], 2012). Across 39 trials the handheld breathalyzers produced the same reading as the benchtop Intoxilyzer 30 times (77\%). The other nine readings differed by less than $.02 \%$. Before the experiment commenced the breathalyzers were also shipped to the manufacturing company where they passed a three-point recalibration test (KHN Solutions, 2016). On the basis of these results it was determined that the two breathalyzers used in this study were valid instruments to assess participants' BAC levels.

Participants in the present study were also asked to provide subjective ratings of their intoxication. Subjective intoxication ratings have been used in other studies to gauge participants' cognitive and psychological perceptions of their own intoxication (Crossland et al., 2016; Flowe et al., 2015). These ratings were given on a 0 (not drunk at all) to 100 (extremely drunk) scale every time an objective BAC reading was recorded on the handheld device. The objective and subjective intoxication readings were then recorded on each participant's BAC chart (see Appendix B). Participants were blind to their objective BAC readings throughout the experiment.

Staged eyewitness interaction. The live-staged interaction involved an adapted version of the backyard game 'Cornhole' (American Cornhole Association [ACA], 2016). Cornhole is a recreational game similar to horseshoes. However, instead of horseshoes and metal spikes players throw corn-filled bean bags at rectangular wooden platforms with holes in the upper-middle part of the surfaces. These platforms are 20-30 feet away from each thrower. The goal of the game is to earn points by landing the bags 
on the board ( 1 point) or inside the hole ( 3 points). Teams alternate throwing the bean bags between the platforms trying to obtain 21 points using a cancellation scoring system.

The Cornhole platforms and bags were used in the present study but the rules provided to participants were modified so that those with previous knowledge of the game were not under a reduced cognitive load. For this modified version of the game participants were given five cornhole bags ( 4 pink, 1 blue) and told the objective was to accumulate as many points as possible across four rounds of tosses. One round consisted of throwing all 5 bean bags. Participants were also told how each throw was scored (see Appendix C).

Midway through the Cornhole game, each participant was interrupted by a confederate intruder (Alex) who entered the room and asked if she could join the game. The research assistant (RA) in charge of the Cornhole game then informed Alex she was in a restricted area and would have to leave immediately. Disregarding the RA's comments, Alex sat down at the nearest table and began touching one of the breathalyzers. In a more agitated tone, the RA informed Alex that she must leave immediately or the owner of the bar would be notified. Upset, Alex stood up, yelled back at the RA, knocked over a chair, and left the room (see Appendix D). This intrusion lasted approximately 1 minute. During that time Alex remained across the room from the participant $(\approx 14 \mathrm{ft})$ who was able to view her face from multiple angles. After the intrusion, the RA apologized to the participant and asked him/her to finish the remaining tosses of the Cornhole game before moving on to the next part of the study. 
The Cornhole adaptation was chosen for its entertainment qualities, that is, an activity that would be able to keep participants' attention (even if intoxicated) and could serve as a context to witness the staged interactive event. The game also provided an opportunity for a detail-rich and complex interaction between the participant and confederate that was emotionally engaging yet not raise suspicion. That is, the interaction contained a verbal altercation, inappropriate touching of laboratory equipment, and an aggressive outburst (i.e., chair throw) that could be expected giving the setting. Furthermore, Cornhole games often appear in settings where alcohol is consumed (e.g., bars, tailgates, parties); thus, it mimics an activity intoxicated witnesses might engage in before, or while, an incident occurs.

Interview. Information about the live-staged interaction was collected via a mock-witness interview. Interviews were conducted by trained research assistants, but never the research assistant who was in charge of the cornhole game. Each interview began with two open-ended questions: (1) In as much detail as possible, please tell me everything you can remember about what happened starting from the time you entered the room where you played Cornhole, and (2) Is there anything else you can remember about what happened? These open-ended questions were followed by 11 cued questions (see Appendix E) directed at specific aspects of the intrusion (e.g., What was the intruder wearing? What, if anything, did the intruder say?). These questions were asked in a neutral tone so that the interviewer's emotions or rapport did not affect participants' recall. These interviews took place in another room offered by the bar that was void of guests and noises from the main bar area. Interviews were also audio-recorded and later transcribed for scoring purposes. 
Identification materials. Following the recall portion of the interview participants were randomly assigned to view a showup or lineup. This portion of the procedure was carried out by the same research assistant who conducted the interview. Participants in the showup condition viewed one photo in which the confederate was pictured (target-present) or was not pictured (target-absent). Participants in the lineup condition viewed a 6-person simultaneous lineup in which the confederate's photo was pictured (target-present) or was not pictured (target-absent).

Fillers. Pilot testing of the target-absent photos was done in several stages. In the first stage three assistants blind to the confederate's appearance were shown the targetpresent photo for this experiment (see Appendix F). These assistants independently described the confederate's appearance as she was depicted in the photo. Any feature mentioned by at least two assistants was used in the initial composite description of the confederate (see Appendix G).

In the second stage, four different assistants blind to the confederate's appearance were given the initial composite description of the confederate created in stage one. These assistants were asked to find people (e.g., friends, family members, co-workers, and strangers) who matched this composite description (i.e., match-description approach). Three other assistants also blind to the confederate's appearance were given the target-present photo and asked to find people who matched her general appearance (i.e., match-suspect approach). Using these approaches the seven research assistants produced nine potential filler photos for the experiment. These photos were of young 
females in their early-mid 20s who fit the confederate's description and/or appearance in the target-present photo (see Appendix H).

In the third stage, six randomly selected students in the author's Legal Psychology class who were blind to the confederate's appearance independently watched a video of the confederate performing the activities in the staged eyewitness interaction. Immediately after watching the video each assistant provided a description of the confederate's appearance in the video. Any feature mentioned by at least 3 assistants was used to make a final composite description of the confederate (see Appendix I).

In the fourth and final stage undergraduates $(N=56)$ at Florida International University were given the confederate's final composite description and asked to view each of the nine potential filler photos. These photos were randomly presented one at a time to each student using the Qualtrics survey system. The students' task was to rate how well each photo matched the final composite description of the confederate using a 0 (not at all) to 10 (perfect match) scale. The confederate's photo was also included in the Qualtrics survey to measure how well students felt she matched her own description. The six highest rated photos from this survey (excluding the confederate) were then used as fillers for this study (see Appendix J).

Fillers were identified in this manner because it mimics how real-world investigators might generate suspects to show a witness. That is, investigators would likely start by collecting descriptions of the perpetrator from witnesses at the scene. Those descriptions would be used to search for people who might be the perpetrator. 
Individuals rated by the investigators as moderately or highly similar to the description are then liable to be shown to the witness in a showup or lineup format.

Lineup and showup variations. On the basis of the data collected in the Qualtrics survey, the six highest rated filler photos were used in conjunction with the confederate's photo to create the lineups and showups for this study. Each filler photo served as an independent target-absent showup photo, creating six versions of the target-absent showup (see Appendix K). These six versions were randomly selected and presented to participants in the target-absent showup condition, helping to ensure the identification rate in this condition was not simply a function of the unreasonably high or low similarity between the confederate and any one filler photo. The confederate's photo was shown to all those in the target-present showup condition (see Appendix F).

The target-absent lineup consisted of the six highest-rated filler photos (Appendix L). Six versions of the target-present lineup were created. In each version the confederate's photo replaced a different filler photo from the target-absent lineup (Appendix M). These six versions of the lineup were randomly selected and displayed to participants in the target-present lineup condition, helping to ensure that accuracy rates in the target-present lineup condition were not a function of any one combination of five fillers that accompanied the confederate's photo.

Identification instructions. Before viewing their respective lineup or showup, participants were given unbiased instructions in line with best evidence gathering guidelines (Technical Working Group, 1999). Specifically, participants were told, "the bar gave us photos of people who have been here before and caused disturbances. We 
need you to look through the photos and see if any match the girl who interrupted your game. Keep in mind the individual may or may not be here." Participants in the showup condition were then presented a photo and asked "is this the girl who interrupted your Cornhole game?" Participants in the lineup condition were asked "are any of these the girl who interrupted your Cornhole game?” Participants who responded 'yes' (made an identification) or 'no' (rejected the photos) were then asked to "rate on a scale from 0 (not at all certain) to 100 (extremely certain), how certain are you in your decision." (see Appendix N). Participants who responded 'not sure' were not asked to provide a measure of certainty. The decision to not ask these participants about certainty was made after the first few participants who stated they were unsure had difficulty interpreting the question. For example, one participant asked "because I am not sure does that make me 0 percent certain, or because I know I'm not sure does that make me 100 percent certain?" To avoid varying interpretations of the uncertainty question and potentially arbitrary ratings it was determined that participants who stated they were not sure would refrain from providing measures of certainty.

Drinking history questionnaire. After completing the recall (interview) and recognition (identification) portions of the interview participants were asked to quantify how long and how much they had been drinking on the night of the experiment (see Appendix O). Participants were also asked to quantify their typical drinking behaviors (e.g., how many times a month do you drink, how many drinks do you consume on a typical drinking occasion). Finally, participants rated how believable each part of the experiment was (intrusion, interview, photos) on a 0 (not at all believable) to 10 (completely believable) scale, provided demographic information, and disclosed whether 
they were currently under the influence of any prescription/non-prescription drugs.

Participants' readiness to disclose this information in prior work (Altman et al., 2018)

suggested it would also be obtainable here.

\section{Procedure}

Approval from the Florida International University IRB was obtained before any data was collected at the bar. On the eight pre-determined testing nights, bar patrons were approached and asked to participate in a study examining the effects of alcohol on cognitive and motor functions. Patrons were also told the study would take between 2025 minutes and that there were no incentives for participating. Those who agreed were asked to sign an informed consent document.

Consenting patrons were escorted to a secondary room inside the bar void of other guests. Inside this secluded area participants had their BAC levels measured and provided a subjective rating of their intoxication. Afterwards, they were given instructions for their first task, the Cornhole game adaptation. Midway through this task each participant was interrupted by a confederate (Alex). Following this interruption each participant finished one more round of Cornhole and provided a second BAC and subjective intoxication measurement. Participants were then escorted to another room inside the bar that was also void of guests and outside noises.

Participants were informed that the purpose of this additional testing room was to provide a quiet space for their cognitive assessments. However, before completing these assessments each participant was asked to provide a statement about the Cornhole disturbance. Statements were collected in an interview format and was given under the 
pretense that disturbances at the bar needed to be recorded using a generic incident report provided by the university. Responses to these questions were audio-recorded under the pretense that the university might need to verify the participant's statement should consequences arise from the incident. Those who agreed were provided with a microphone headset to speak into and were interviewed by a research assistant in a neutral manner. Following the interview, participants were randomly assigned to view a showup or lineup in which the confederate was either pictured or not pictured. Prior to viewing their respective photos, participants were asked to state whether the girl who disrupted their Cornhole game was pictured, and if so, to identify her. Participants were also given the option to reject the photos or state they were not sure whether the girl's picture was present.

After the interview and identification portion of the study, participants were informed of the deception. That is, they were told the confederate intrusion was staged and that the true purpose of the study was to examine the effects of alcohol on eyewitness memory. Participants were then escorted to a final testing room inside the bar void of other guests to complete a Drinking History Questionnaire and provide believability measures for the experimental manipulations. Finally, participants were dismissed from the testing area and repeatedly asked not to discuss the study with anyone who might be a future participant. Research assistants in charge of recruiting listened for discussions regarding the study around the bar and none were heard. 


\section{Scoring}

Event memory. The video-recorded witness interviews were first transcribed and broken down into units of information. A unit of information was defined as the smallest piece of information that could be coded as accurate, inaccurate, I don't know, subjective, or irrelevant in its relation to the eyewitness interaction. For example, the sentence "she came in with a red sweater and a beer can" was broken down into 3 units (1- she came in, 2- with a red sweater, 3- and a beer can). One research assistant unitized all the transcripts to ensure consistency. The first 20 unitized transcripts were examined by Dr. Nadja Schreiber Compo and the primary investigator to ensure the assistant broke down each statement in a similar fashion. After verifying witness information was broken down correctly the remaining 112 transcriptions were unitized. All remaining transcripts were randomly checked by the primary investigator to ensure consistency.

Using a detailed set of scoring instructions 3 trained research assistants independently scored each unit of the first 20 transcripts. These units were scored as accurate (contained information from the interaction), inaccurate (contained inaccurate or modified information about the interaction), I don't know (IDK; participant said some variation of the phrase "I don't know"), subjective (non-verifiable information; e.g., "I [the participant] told the intruder to leave" or "I [the participant] felt weird"), or irrelevant (did not include information related to the question or event; e.g., "last weekend I was really drunk). It was also possible for units to fit into multiple categories. For example, the phrase "last weekend I was really drunk" could be scored as irrelevant and subjective because the information did not pertain to the event or question and it 
could not be verified for accuracy. After scoring the first 20 transcripts a meeting was held to discuss discrepancies among the classification of certain units. These discrepancies were settled by a majority vote which included the scorers, Dr. Nadja Schreiber Compo, and the primary investigator. After this meeting, adjustments were made to the scoring checklist and each assistant continued to independently score the remaining transcripts. Inter-class correlations across all 132 scored transcripts were high for accurate (.99), inaccurate (.97), IDK (.93), subjective (.96), and irrelevant (.82) information. Given the high inter-class correlations between the three scorers, only the scored transcripts of the rater with the highest inter-class correlation to the other two scorers was used to conduct all analyses.

Memory quantity was examined using the total number of units reported by each participant. Memory quality was assessed using the proportion of accurate, inaccurate, and IDK units reported by each participant. These proportions were calculated by dividing the number of units in each category by the total number of accurate, inaccurate, and IDK units provided by the participant throughout the interview. For example, the proportion of accurate information was calculated by dividing the number of accurate units reported by the participant by the total number of accurate, inaccurate, and IDK units reported by that same participant. Subjective and irrelevant information was not included in the denominator because it could not be verified as accurate or inaccurate. Similar scoring procedures have been used in the past to examine intoxicated witnesses recall (Altman et al., 2018; Schreiber Compo et al., 2012; Yuille \& Tollestrup, 1990). 
Memory for faces. Participants' identification decisions were coded

dichotomously in several different ways to allow for the examination of different research questions. These dichotomous classifications were used so the data could be analyzed using logistic regressions. Logistic regressions allowed for a well-powered simultaneous examination of both the continuous (i.e., BAC level) and categorical (i.e., ID format) variables in the study (Flowe et al., 2017; Molinaro et al., 2013) and have been shown to be an effective method of analyzing binomial data in the eyewitness literature (Altman et al., 2018; Dysart et al., 2002; Molinaro et al., 2013; Wright \& McDaid, 1996).

The goal of this study was to examine how alcohol and identification format affect witnesses' identification decisions in a target-present and target-absent situation, not to examine the diagnostic value of each format using intoxicated witnesses. Given that choosing and accuracy rates are heavily dependent on the target's presence and that alcohol is expected to differentially affect decisions in each situation it was decided that the target-present and target-absent data would be analyzed separately. This analytic approach is similar to Molinaro et al. (2013).

Choosing behavior. To examine whether alcohol and identification format affected participants' choosing behavior, responses were separated by whether the participant positively identified a photo (i.e., choosers) or did not make an identification (i.e., non-choosers). That is, participants who stated the confederate's picture was present were labeled as choosers. Those who rejected the photos or responded "not sure" were labeled as non-choosers. 
Target-present accuracy. Of interest in the target-present condition was the effect of alcohol and identification format on the number of correct perpetrator identifications and the number of incorrect rejections (Molinaro et al., 2013). To examine these questions responses were categorized in two ways. First, participants were separated by whether they correctly identified the confederate's photo or provided any other alternative response (i.e., rejection, not sure, filler identification). Second, participants were classified by whether they incorrectly rejected the photos or provided an alternative response (i.e., identified a photo, not sure).

Target-absent accuracy. Of interest in the target-absent condition was the effect of alcohol and identification format on the number of correct rejections and false identifications (Molinaro et al., 2013). To examine these questions responses were categorized in two ways. First, participants were separated by whether they correctly rejected the photos or provided an alternative response (i.e., identified a photo, not sure). Second, to examine the likelihood of a false identification from the lineup condition, filler D was designated as the innocent suspect. Filler D was designated as the innocent suspect because she was (incorrectly) chosen most often across all the lineups and showups in which she appeared (see Table 3). This allowed for the examination of a 'worst case scenario' (WCS) in which a photo that highly resembles the perpetrator was presented to the witness in the absence of the perpetrator's photo (Clark et al., 2009; Pryke et al., 2004). To examine this, participants' responses in the lineup condition were separated by whether they identified filler D (i.e., made a false identification) or provided an alternative response false (i.e., identified a filler, rejected the lineup, not sure). This false identification rate was compared to the aggregate false identification rate of all the 
photos used in the showup condition. To properly compare the false identification rate of the innocent suspect across identification formats, only the showups in which the innocent suspect appeared should be used; however, the design of this study did not warrant that analysis given that filler D only appeared in approximately one-sixth $(N=8)$ of the target-absent showups. This limitation is explored further in the discussion section.

\section{CHAPTER V}

\section{RESULTS}

\section{Intoxication Measurements and Procedure Believability}

Before analyzing the interview and identification data, the number of participants at each BAC level was charted and analyses were performed to examine how well their responses to the Drinking History Questionnaire were correlated with their subjective and objective drinking measures. Additional analyses were conducted to examine the believability of the interaction, interview, and identification procedure.

Intoxication measurements. To examine whether participants reached elevated BAC levels associated with en bloc and fragmentary blackouts, participants' BAC levels were first charted (see Figure 1). Of the 132 participants tested, 73 (55.3\%) recorded a BAC level below the U.S. legal driving limit (i.e., BAC <.08\%). The remaining 59 (44.7\%) participants recorded a BAC level of .08\% or higher, rendering them legally intoxicated according to U.S. standards. Furthermore, 45 participants recorded a BAC level above $.10 \%$, the lowest BAC level at which signs of fragmentary and en bloc blackouts are expected to occur. The highest BAC level recorded was .24\%. 
Point-biserial correlations were used to examine the relationship between participants' BAC measurements and their responses to questions about their current and previous levels of intoxication (see Table 4 for complete correlation matrix). Participants' first BAC measure was strongly and significantly correlated with their second BAC measure $(r=.97, p<.01)$, first subjective BAC measure $(r=.68, p<.01)$, second subjective BAC measure $(r=.68, p<.01)$, drinking occasions per week $(r=.35, p<.01)$, number of drinks per week $(r=.39, p<.01)$, time drinking on the night of the experiment $(r=.64, p<.01)$, and drinks consumed on the night of the experiment $(r=.68, p<.01)$. These correlations show that the higher participants' reported alcohol consumption (in general and the night of the study), the higher their actual measured breath alcohol level. Age and gender were also significantly correlated with participants' first BAC measure ( $r$ $=.34, p<.01$ and $r=-.20, p<.05$, respectively), such that younger participants and males presented higher BAC measures than older participants and females.

Procedure believability. Participants' believability ratings were given on scales ranging from 0 (not believable at all) to 10 (extremely believable). Paired Samples T-tests revealed that participants were more inclined to believe the staged eyewitness interaction $(M=7.15, S D=3.04)$ than the identification photos presumably provided by the bar $(M=$ 4.87, $S D=3.73), t(126)=6.20, p<.01)$. Participants were also more likely to believe the eyewitness interview $(M=7.10,2.96)$ than they were the identification photos, $t(126)$ $=6.14, p<.01$. No difference was found between the believability of the eyewitness interaction and the interview, $t(126)=.35, p=.73$. Point-biserial correlations revealed that participants' first BAC measure was not significantly correlated with their belief in the staged eyewitness interaction $(r=-.09, p=.31)$, interview $(r=-.04, p=.69)$, or 
identification photos $(r=-.02, p=.86)$. One-way ANOVA's revealed that participants' believability ratings did not vary significantly between the lineup and showup condition for the intrusion $(p=.68)$, interview $(p=.93)$, and photos $(p=.83)$.

\section{Memory For The Event}

First, the effects of alcohol on event memory were analyzed using a series of linear regressions. For each regression BAC level was the predictor variable and the quantity (number of accurate, inaccurate, IDK, subjective, and irrelevant units reported) or quality (proportion of accurate, inaccurate, or IDK responses) of information provided during the participant interviews was used as the outcome variables.

Quantity. A linear regression showed that BAC level was not a significant predictor of recall quantity, $F(1,128)=1.60, p=.21, \mathrm{R}^{2}=.01, \beta=-.11$ (see Figure 1). However, when irrelevant and subjective information was excluded from the number of units reported, $\mathrm{BAC}$ level was a significant predictor of recall quantity, $F(1,128)=$ 25.35, $p<.01, \mathrm{R}^{2}=.17, \beta=-.41$. That is, as BAC levels increased the number of relevant informational units reported decreased (see Figure 2).

\section{Quality.}

Accuracy. A linear regression revealed that BAC level was a significant predictor of recall accuracy $F(1,128)=44.37, p<.01, \mathrm{R}^{2}=.26, \beta=-.51$. As BAC levels increased the proportion of accurate units reported by participants decreased (see Figure 3).

Inaccuracies. A second linear regression further revealed that BAC level was also a significant predictor of recall inaccuracies, $F(1,128)=23.87, p<.01, \mathrm{R}^{2}=.16, \beta=.40$. 
That is, as BAC levels increased the proportion of inaccurate units reported also increased (see Figure 4).

I don't know responses. A third linear regression showed that BAC level was also a significant predictor of the proportion of IDK responses provided, $F(1,128)=14.87, p$ $<.01, \mathrm{R}^{2}=.10, \beta=.32$. Specifically, as BAC levels increased the proportion of IDK responses reported also increased (see Figure 5).

Additional measures. In addition to the quantity and quality measures above, the effect of alcohol on the amount of subjective and irrelevant information reported was also examined. This information was examined using the proportion of information reported in each category. These proportions were calculated by dividing the number of subjective units or irrelevant units reported by the total number of units provided (i.e., accurate, inaccurate, I don't know, subjective, and irrelevant units) by that participant.

Irrelevant information. A linear regression showed that BAC level was a significant predictor of the proportion of irrelevant information reported, $F(1,128)=$ $6.95, p<.01, \mathrm{R}^{2}=.05, \beta=.23$. As BAC levels increased so did the proportion of irrelevant information reported (see Figure 6).

Subjective information. A linear regression showed that BAC level was a significant predictor of the proportion of subjective information reported, $F(1,128)=$ 27.60, $p<.01, \mathrm{R}^{2}=.18, \beta=.42$. As BAC levels increased so did the proportion of subjective information reported (see Figure 7). 


\section{Memory For Faces}

Choosing behavior. Regardless of target-presence, of the 132 participants in this study 63 participants $(47.70 \%)$ identified one of the photos displayed as the perpetrator. The other 69 participants $(52.30 \%)$ either rejected the photos or could not determine if the perpetrator's photo was present. Of the 61 participants in the target-present condition $41(67.20 \%)$ made an identification, 17 of those participants were in the lineup condition while the other 24 were in the showup condition. Of the 71 participants in the targetabsent condition $28(39.40 \%)$ made an identification, 19 of those participants were in the lineup condition and 9 were in the showup condition (see Table 5).

Target-present. A logistic regression was used to examine whether BAC level, identification format, or the interaction between the two variables (predictors) helped classify witnesses' choosing behavior in the target-present condition. A model with these predictors was able to classify $68.90 \%$ of participants' decisions to identify a photo. This was not significantly more than the $67.20 \%$ of cases classified by a model with no predictors, $\chi^{2}(3)=2.28, p=.52$, Nagelkerke $R^{2}=.05$. Participants' BAC level $(p=.22)$, identification format $(p=.87)$, and the interaction between the two $(p=.80)$ were not significant predictors of choosing behavior.

Target-absent. A logistic regression was then used to examine whether BAC level, identification format, or the interaction between the two variables (predictors) helped classify witnesses' choosing behavior in the target-absent condition. A model with these predictors was able to classify $70.80 \%$ of participants' decisions to identify a photo; this was significantly more than the $60.60 \%$ of cases classified by a model with no 
predictors, $\chi^{2}(3)=12.52, p<.01$, Nagelkerke $R^{2}=.22$. Identification format was the only significant predictor in the model, $\beta=1.97, S E=.91$, Wald $(1)=4.73, p<.05, \operatorname{Exp}(B)=$ 7.19. That is, participants in the lineup condition were nearly two times more likely to make an identification than those in the showup condition. Participants' BAC level $(p=$ $.44)$ and the interaction $(p=.69)$ were not significant predictors of choosing behavior.

Accuracy. Of the 61 participants in the target-present condition 35 (57.38\%) correctly identified the perpetrator, 11 in the lineup condition and 24 in the showup condition. Of the remaining $26(42.62 \%)$ participants in the target-present condition 9 rejected the photos, 2 in the lineup condition and 7 in the showup condition. The remaining 17 of the 26 either identified a filler photo $(N=6$; all in the lineup condition) or could not make a decision from the lineup $(N=5)$ or showup $(N=6)$ they viewed (see Table 5). Of importance in this target-present condition was the number of correct perpetrator identifications and the number of incorrect rejections.

Of the 71 participants in the target-absent condition $22(31.00 \%)$ accurately rejected the photos presented, 4 in the lineup condition and 18 in the showup condition. Of the remaining 49 participants $15(30.61 \%)$ made a false identification, 6 in the lineup condition (i.e., identified filler D) and 9 in the showup condition. The remaining 34 participants $(69.39 \%)$ in the target-absent condition either identified a filler photo $(N=$ 13; all in the lineup condition) or could not make a decision from the lineup $(N=9)$ or showup $(N=12)$ they viewed (see Table 5). Of importance in this target-absent condition was the number of correct rejections and the number of false identifications. 
Correct perpetrator identifications. In the next set of analyses, a logistic regression was used to examine whether $\mathrm{BAC}$ level, identification format, or the interaction between the two variables (predictors) helped classify correct perpetrator identifications in the target-present condition. A model with these predictors was able to classify $63.90 \%$ of witnesses who identified the perpetrator. This was not significantly different from the $57.40 \%$ of cases classified by the model with no predictors, $\chi^{2}(3)=$ $4.46, p=.22$, Nagelkerke $R^{2}=.10$. Participants' BAC level $(p=.22)$, identification format $(p=.37)$, and the interaction $(p=.87)$ were not significant predictors of whether participants identified the perpetrator.

Incorrect rejections. Incorrect rejection in the target-present condition could not be analyzed due to the low cell counts (T. Hayes, personal communication, February 16, 2018). That is, the maximum likelihood estimation of the regression failed to converge given the few participants who rejected the photos in the target-present condition. The model was also unable to distinguish the regression line from zero after bootstrapping techniques were used to simulate more data and the number of iterations was increased. Based on this information the data was rendered uninterpretable.

Correct rejections. Correct rejections in the target-absent condition could also not be calculated due to the limited number of participants who rejected the lineup in this condition (T. Hayes, personal communication, February 16, 2018). Bootstrapping techniques and iteration enhancements were again performed to try and simulate more data but the regression line in the model still could not be distinguished from zero. Based on this information data was again rendered uninterpretable. 
False identifications. A logistic regression was used to examine whether BAC level, identification format, or the interaction between the two variables (predictors) helped classify false identifications in the target-absent condition. A model with these predictors was able to classify $85.90 \%$ of false identifications, the same percentage as a model with no predictors, rendering the model non-significant, $\chi^{2}(3)=6.82, p=.08$, Nagelkerke $R^{2}=.16$. Participants' BAC level ( $\left.p=.17\right)$, identification format $(p=.10)$, and the interaction $(p=.83)$ were not significant predictors of whether participants made a false identification.

Testimony relevant judgements. Next, a series of linear regressions were used to examine how BAC level and choosing behavior impacted participants' testimony relevant judgements (i.e., identification certainty, distance to the perpetrator, view of the perpetrator, and incident length). For each regression BAC level, choosing behavior, and the interaction between the two variables acted as the predictors while the respective testimony relevant judgement acted as the outcome variables. Participants did not have to provide a response to each judgement so samples sizes vary across each analysis.

Identification certainty. A linear regression revealed that BAC level and choosing behavior did not predict identification certainty, $F(3,99)=.87, p=.46, \mathrm{R}^{2}=.03$. There was also no significant interaction between the variables, $p=.37$.

Distance to the perpetrator. Next, a linear regression was conducted and revealed that BAC level and choosing behavior significantly predicted participants' estimates of how far away the perpetrator was, $F(3,121)=3.65, p=.02, \mathrm{R}^{2}=.08$. The model also suggested a significant interaction between the variables, $\beta=-62.65, S E=24.29, t=-$ 
$2.58, p<.05$, such that for choosers there was a negative relationship between BAC and participants' estimates of how far away the perpetrator was $(r=-.22)$. For non-choosers, there was a positive relationship between BAC level and participant's estimates of how far away the perpetrator was $(r=.23)$.

View of the perpetrator. Another linear regression showed that BAC level and choosing behavior significantly predicted participants' view of the perpetrator, $F(3,123)$ $=5.65, p<.01, \mathrm{R}^{2}=.12$. Participants' BAC level was the only significant predictor, $\beta=-$ $.34, S E=4.51, t=-3.02, p<.01$ such that as BAC levels increased participants' ratings of view of the perpetrator decreased.

Length of the incident. Lastly, a linear regression showed that BAC level and choosing behavior significantly predicted how long participants thought the incident lasted, $F(3,123)=3.04, p<.05, \mathrm{R}^{2}=.07$. The model revealed a significant interaction between the variables, $\beta=-690.68, S E=230.63, t=-3.00, p<.01$, such that for choosers there was a negative relationship between alcohol and the length of the incident $(r=-$ .29). For non-choosers there was a positive relationship between BAC level and the length of the incident $(r=.24)$.

\section{CHAPTER VI}

\section{DISCUSSION}

The aim of this study was to examine witnesses' event memory for a live-staged interaction at elevated BAC levels and examine how identification format might impact these witnesses' identification decisions. Two central findings emerged from this project: 1) alcohol significantly affected witnesses event memory by reducing both the quantity 
and quality of relevant information reported; and 2) alcohol (even at elevated BAC levels) had no effect on witnesses' identification abilities, regardless of identification format.

\section{Event Memory}

In line with my hypotheses and some prior research (Altman et al., 2018;

Crossland et al., 2016), elevated BAC levels reduced both the quantity and quality of relevant information reported by intoxicated individuals. That is, the higher participants' BAC levels were, the lower both the quantity and accuracy of relevant information they reported and the higher the proportion of inaccurate information they reported. These findings are in line with other quasi-experimental field studies that have examined witness memory for events at elevated BAC levels, suggesting detrimental effects of higher BACs on witnesses' memory for events (Altman et al., 2018; Crossland et al., 2016).

One unique finding in the present study is that alcohol did not have an effect on the quantity of information reported by participants when all information was considered, regardless of relevance. Only after irrelevant and subjective information was excluded from participants' reports did the quantity of (relevant) information witnesses reported decrease as BAC levels increased. This finding lends support to the attentional AMT, suggesting that increases in BAC level reduce the amount of attentional resources people can devote toward information in the environment and subsequently decrease the amount of information encoded and later recalled. In the context of the present study, as BAC levels increased witnesses had fewer attentional resources to allocate to the confederate 
intrusion, reducing the amount of (relevant) information later reported in relation to those at lower BAC levels. When relevance of information was not considered, however, there was no relationship between participants' BAC levels and recall quantity. This is consistent with prior research and suggests that intoxicated individuals may compensate for their limited memory by incorporating more subjective and irrelevant information into their reports (Schreiber Compo et al., 2011). Therefore, although witnesses at higher BAC levels may report as much information as those at lower BAC levels, the informational value of such reports appears to be somewhat diluted.

The present findings are also in line with quasi-experimental field studies that have examined how elevated BAC levels affect offenders' memory for criminal events (Read, Yuille, \& Tollestrup, 1992; van Oorsouw et al., 2015; van Oorsouw \& Smeets, 2012). That is, when participants are asked to take the perspective of the perpetrator in a mock crime event, highly intoxicated individuals also report less plentiful and less accurate information. In two of these studies, participants also took part in engaging livestaged interactions (Read et al., 1992; van Oorsouw et al., 2015). Furthermore, Read et al. (1992) also found a positive relationship between mock offenders' BAC levels and the amount of subjective information reported (i.e., thoughts, feelings, emotions). Together with the present set of findings, this further suggests that while participants at elevated BAC levels are less likely to recall relevant information they appear to have full access to memory for their emotional states during the event. This information is then reported in lieu of memory for the actual event along with irrelevant information (Schreiber Compo et al., 2011). In the van Oorsouw et al (2015) study participants' recall was compared to a pre-determined list of items created by the investigators; therefore, the authors were 
unable to determine the amount of subjective and irrelevant information reported by participants.

Together with prior research, the present set of findings on witnesses' memory for events at elevated BAC levels further support the notion that the null/inconsistent findings throughout the literature may be at least partially explained by the low-tomoderate BAC levels frequently tested in laboratory settings (Flowe et al., 2016; Hagsand et al., 2013a; 2017; Schreiber Compo et al., 2011). Specifically, at low-tomoderate BAC levels the effects of alcohol may not be powerful enough to consistently expose cognitive impairments in witnesses' perceptual and consolidation abilities. As BAC levels increase however, pyramidal cell activity continues to slow down (Lee et al., 2009; Perry et al., 2006; White, 2003) and drinkers' ability to attend to peripheral information in the environment is reduced further (Josephs \& Steele, 1990; Steele \& Josephs, 1990). At elevated BAC levels alcohol-induced memory deficits are therefore more readily apparent and consistent because less information is encoded and transferred to LTM (Lee et al., 2009; Perry et al., 2006; White, 2003). In addition to reducing the quantity of information transferred to LTM, the present data suggest that elevated BAC levels simultaneously yield more irrelevant and subjective information about events experienced to compensate for limited memory and increase output.

Taken together, the event memory data in this study highlight the importance of testing witness memory across a broader BAC spectrum given that the low-to-moderate BAC levels frequently tested may fall short of capturing the full effect of alcohol on memory for events. The present findings also suggest that tests of witness memory should 
involve detail-rich and interactive environments like those witnesses might encounter given that a majority of the studies utilizing an interactive and engaging event with intoxicated participants found that witnesses reported more subjective and/or irrelevant information under those conditions. Although engaging and non-engaging events are processed by similar memory systems, the way in which these events are encoded and stored is notably different (Cabeza \& St. Jacques, 2007; Greenberg \& Verfaellie, 2010; Read, Yuille, and Tollestrup, 1992). Tests using interactive environments will therefore allow researchers to account for the encoding, storage, and retrieval differences between events in which intoxicated and sober witnesses are actively engaged and those in which they passively observe (Altman et al., in press; Lane \& Meissner, 2008; Read et al., 1992). Testing these laboratory-based theories under more applied and ecologically valid conditions will also strengthen peoples' theoretical understanding of how alcohol affects witness memory and arguably render the findings more transferable to real-world contexts (Carlson, 2013; Lane \& Meissner, 2008).

\section{Memory for Faces}

In contrast to alcohol's effect on witnesses' memory for the event, alcohol and identification format had no effect on witnesses' lineup or showup decisions in the targetpresent condition - in line with my hypotheses. In the target-absent condition alcohol was expected to produce a more liberal decision making criterion, increasing choosing and false identification rates in the showup condition; however, the liberal decision-making criterion created by alcohol was expected to be offset by the fillers in the lineup condition. That is, lineup fillers were expected to provide intoxicated individuals 
alternative options to consider, reducing their ability to locate a best match suspect given the overlapping features between the various photos (Colloff \& Flowe, 2016). This would lead intoxicated individuals to render more rejections and 'not sure' responses. In addition, false selections from the lineup would be dispersed across the fillers and reduce the false identification rate (Wells, 2001). Contrary to my hypothesis, participants who viewed a target-absent lineup were more likely to make an identification than those who viewed a target-absent showup. Worth noting, however, is that despite increased choosing rates in the lineup condition there was no accompanying increase in false identifications. This suggests that the fillers satisfied their intended purpose and siphoned away would-be false identifications. Also important in the context of the present study, alcohol was not a significant factor in any of the witnesses' identification decisions.

There are several reasons why witnesses in the target-absent lineup condition might have made more identifications than those in the target-absent showup condition. It is possible that there were simply more options available in the lineup condition, which naturally increases the likelihood that a witness identifies an individual who resembles the perpetrator (Steblay et al., 2003). This is why all-suspect lineups are not recommended (see Steblay et al., 2003; Wells \& Turtle, 1996 for reviews). Alternatively, as predicted by the original AMT, given their reduced cognitive resources intoxicated individuals are more likely than sober or less intoxicated individuals to act on impulse rather than deliberative thought (Josephs \& Steele, 1990; Steele \& Josephs, 1990). That is, intoxicated individuals may have identified a lineup member that resembled the perpetrator rather quickly without much consideration for alternative lineup members whose purpose was to yield a more conservative decision-making criterion. Despite these 
potential explanations for the increased choosing rate in the target-absent lineup condition, perhaps the best explanation for the present set of identification results is that choosing and false identification rates in the target-absent showup condition were simply not as high as expected given the variety of fillers presented to witnesses. That is, the predictions for the target-absent showup condition were based largely on the findings in Dysart et al. (2002). In the Dysart et al. (2002) study all witnesses in the target-absent condition were shown the same filler who also highly resembled the target. This degree of similarity between the innocent suspect in the target-absent condition and target in the target-present condition, combined with the liberal decision making criterion created by alcohol, likely resulted in a high rate of false identifications in the Dysart study. This notion is supported by the findings in the present study in that fillers who highly resembled the confederate were often falsely identified by participants in the targetabsent showup condition (see Table 3). For example, filler D (the designated innocent suspect) was falsely identified in 4 of the 8 showups in which she appeared. However, other fillers who were viewed as less similar to the perpetrator (e.g., fillers B \& E) were never falsely identified in the target-absent showup condition. Thus, choosing and false identification rates in the target-absent showup condition were lowered by these less similar fillers. Had filler D been shown to all witnesses in the target-absent condition, the choosing and false identification rate would have likely been higher. Because an aggregate of the fillers was used in the showup condition these data therefore cannot be directly compared to the findings in Dysart et al. (2002).

Taken together the present data highlight the importance of filler similarity when examining identification decisions, including those made by intoxicated individuals. 
While this issue may not be important in situations where a lineup is administered, the current data, and the findings in Dysart et al. (2002), suggest that it can have a significant impact on witnesses' decisions when presented with a showup. Specifically, if a highly intoxicated individual is presented with a showup photo that highly resembles the perpetrator immediately following a crime, then the likelihood of a false identification may be inflated (Dysart et al., 2002). This increase in false identifications is even more likely when other biasing factors associated with the showup procedure are present (Dysart \& Lindsay, 2007; Sjöberg, 2016). For example, in Dysart et al.’s study participants also viewed the filler in a live presentation format just outside the testing location, a manipulation that enhances the suggestiveness of the showup procedure (Sjöberg, 2016; Steblay et al., 2003). It is thus recommended that investigators utilize a full lineup whenever possible, including when dealing with intoxicated witnesses (Altman et al., in press; Steblay et al., 2003; Wells, 2001). Although these lineups take more time to assemble, they can decrease the likelihood of a false identification without reducing correct perpetrator identifications (Agricola, 2009; Steblay et al., 2003).

\section{Limitations}

While it is recommended that future research on intoxicated witnesses include participants across a broad BAC spectrum, these quasi-experimental field studies come at the expense of several limitations (Altman et al., in press). Mainly, testing participants in the field eliminates the ability to ethically manipulate BAC levels. No causal inferences can therefore be made about the effects of alcohol on memory; instead, data only lend support to questions about the relationship between memory and participants' BAC 
levels. Within this context, the present data indicate a clear negative relationship between elevated BAC levels and witnesses' event memory, with no clear relationship between BAC level and witnesses' identification decisions.

Another limitation with quasi-experimental field research involving intoxicated individuals is that participants often visit the bar in groups (Altman et al., in press). This enhances the likelihood that patrons who have already been tested will return to their group and divulge information about the study manipulations. The high believability ratings reported in this study, however, suggest that there was a low level of crossgermination of information across participants, possibly due to research assistants at the bar being instructed to listen for information being shared between prior and future participants. No such communication was overheard by the research assistants. Also worth noting is that this potential limitation is not reserved to field research as students in laboratory-based studies may also divulge study manipulations to their friends or classmates after participating.

Finally, the availability and price of the testing location limited our ability to collect as many participants as needed to conduct all possible analyses. Although recruitment across the 8 testing nights was successful, we were only able to test a total of 132 participants. This provided sufficient power for the recall analyses but given the various conditions and response options in the identification portion of the study, analyses may have been somewhat under-powered. As a result, some of the effects of alcohol and identification format on witnesses' decisions might not have been detected. Despite this limitation, valuable information (i.e., choosing behavior, perpetrator 
identifications, and false identifications) was still gathered from witnesses' identification decisions. Also worth noting is that this limitation (i.e., low number of participants) is a challenge across past studies investigating the effects of alcohol on witness memory and is not unique to the present study (Altman et al., 2018; Dysart et al., 2002).

\section{Future Directions}

Future research should explore ways to monitor participants' alcohol consumption in bar settings to better understand how consumption rate and alcohol type (i.e., wine, liquor, beer) might differentially affect witness memory. For example, Crossland et al. (2016) had participants visit the campus bar and engage in their normal drinking behavior before exposing them to the study procedure inside the psychology lab on campus. While this approach does not offer researchers the ability to manipulate alcohol type or consumption rate, it does allow for a better opportunity to assess participants' drinking behaviors via security cameras or research assistants placed at the bar. Recording this information will help researchers better understand how alcohol type and consumption rate affect witness memory at elevated BAC levels. This paradigm would also allow researchers to manipulate the time participants have to consume alcohol at the bar, potentially providing researchers more control over intoxication levels in field settings.

Future field studies examining the relationship between memory and elevated BAC levels should also explore venues in which participants' actions can be video recorded throughout the duration of the study. For example, in Read et al.'s (1992) first study, participants' actions, outside of those they were instructed to perform, could not be verified. In the second experiment however, Read et al. (1992) placed a camera inside the 
testing location so that participants' actions, including those outside of what they were told to perform, could later be verified. This allowed for a more thorough examination of the offenders' reports. In the present study the layout of the room did not allow for a camera to be positioned outside of the participants' sight. Fearing that a camera would raise suspicion for the interview and identification procedure, we opted against a video recording. As such, there was information reported during the interviews that could have been verified for accuracy if the event had been recorded.

For ethical reasons the study team was also unable to collect participants' contact information, which would have allowed for the collection of data after a time delay and assess the impact of a sobering delay on witnesses' memory. Collecting this information is important because even witnesses who are interviewed immediately (while intoxicated) are often re-interviewed at a later time in a sober state (Altman et al., in press; Palmer et al., 2013). Therefore, examining witnesses recall at various time points and at different intoxication points is of crucial applied relevance. This recommendation is of even greater importance in the context of identifications, given the time it takes to generate a fair lineup (Agricola, 2009; Cicchini \& Easton, 2010). As such, asking intoxicated witnesses to make an identification at a later time, in a less intoxicated or sober state, is a likely scenario. Showups, however, are often administered when a suspect is apprehended within hours of the crime (Agricola, 2009) and witnesses are more likely to still be intoxicated. In addition to examining identification decisions and different time delays, future research should examine how other identification formats (e.g., the sequential lineup) impact intoxicated witnesses' identification decisions given the different thought processes associated with each identification format (Steblay et al., 2003; Wells, 2001). 


\section{Concluding Remarks}

Taken together, the present data suggest that the experts' and mock jurors' opinions in the Kassin et al (2001) survey and the Evans and Schreiber Compo (2010) study were premature given the dearth of research on alcohol's effect on witness memory at the time. The data also suggest that the negative effects of alcohol on memory for simple stimuli do not extrapolate well onto witness memory, an assumption many of the experts and jurors likely made. Since these studies were published, a substantial amount of research shows that low-to-moderate BAC levels have little-to-no effect on participants' event memory and no effect on witnesses' ability to make an accurate identification decision. Only at elevated BAC levels do impairments in event memory emerge consistently while deficits in identification ability seem to remain absent; the potential exception to this latter conclusion being when highly intoxicated witnesses' are administered a showup in which the target is absent and highly similar to the perpetrator. In this instance, alcohol may inflate false identifications. As such, investigators should err on the side of caution and administer a lineup whenever possible when gathering identification data from intoxicated witnesses.

As it stands, the present study constitutes an important piece to a very large and still largely incomplete puzzle. To gain a more complete understanding of how alcohol can potentially affect witnesses' memory for events and faces, more research is needed in both areas. These studies should be carried out in both field and laboratory settings utilizing engaging and non-engaging events to better mimic real-world conditions. Only 
then will we be able to fully understand the still elusive effects of alcohol on witness memory. 
Table 1.

Overview of the general findings and procedures used in the studies examining the effects of alcohol on eyewitnesses' memory for events. Breath alcohol concentrations (BACs) not published in \% format were converted using the Lion Units Converter and recorded as approximations (www.lionlaboratories.com).

\begin{tabular}{|c|c|c|c|c|c|c|c|c|}
\hline $\begin{array}{c}\text { Authors/ } \\
\text { Journal }\end{array}$ & $\begin{array}{c}\text { Lab } \\
\text { vs. } \\
\text { Field }\end{array}$ & Participants & $\begin{array}{c}\text { Presentation } \\
\text { Mode/ } \\
\text { Stimuli }\end{array}$ & DV Measure & Delay & BAC Range & $\begin{array}{l}\text { Mean } \\
\text { BACs }\end{array}$ & Effects of Alcohol \\
\hline $\begin{array}{c}\text { Yuille \& } \\
\text { Tollestrup } \\
\text { (1990) } \\
\text { Journal of } \\
\text { Applied } \\
\text { Psychology }\end{array}$ & $\mathrm{Lab}$ & $\begin{array}{c}N=120 \\
\text { Gender } \\
\text { All Male } \\
\text { M Age (SD) } \\
21.2(\mathrm{~N} / \mathrm{A})\end{array}$ & $\begin{array}{l}\text { Live-Staged } \\
\text { Event } \\
\text { Staged } \\
\text { robbery }\end{array}$ & $\begin{array}{l}\text { Quantity \& } \\
\text { Quality } \\
\text { Verbal free } \\
\text { and cued } \\
\text { recall }\end{array}$ & $\begin{array}{c}\text { Immediate } \\
(30 \text { mins }) \\
N=58 \\
1 \text { Week } \\
N=120 \\
\text { (sober) } \\
\text { Both } \\
N=58\end{array}$ & $\begin{array}{c}.06-.12 \\
\text { (Only } 12 \\
\text { intoxicated } \\
\text { participants } \\
\text { were } \\
\text { breathalyzed) }\end{array}$ & $\begin{array}{c}* \text { Control } \\
N=27 \\
.00 \\
* \text { Placebo } \\
N=46 \\
.00 \\
\text { High Intox. } \\
N=47 \\
.10\end{array}$ & $\begin{array}{l}\frac{\text { Effect }}{\text { - Quantity }} \\
\text { - Quality } \\
\frac{\text { No Effect }}{- \text { No null effects found }} \\
\text { *Control and placebo } \\
\text { participants combined for } \\
\text { analyses }\end{array}$ \\
\hline
\end{tabular}




\begin{tabular}{|c|c|c|c|c|c|c|c|c|}
\hline $\begin{array}{l}\text { Schreiber } \\
\text { Compo et al. } \\
\text { (2011) } \\
\text { Memory }\end{array}$ & $\mathrm{Lab}$ & $\begin{array}{c}N=94 \\
\text { Gender } \\
55 \mathrm{~F} ; 39 \mathrm{M} \\
\\
M \text { Age (SD) } \\
24 \text { (N/A) }\end{array}$ & $\begin{array}{l}\text { Live } \\
\text { Interaction } \\
\text { Alcohol } \\
\text { consumed at } \\
\text { laboratory } \\
\text { bar }\end{array}$ & $\begin{array}{l}\text { Quantity } \\
\text { Written free } \\
\text { recall }\end{array}$ & $\begin{array}{c}\text { Immediate } \\
(1-2 \text { mins }) \\
N=94\end{array}$ & N/A & $\begin{array}{c}\text { Control } \\
N=27 \\
.00 \\
\text { Placebo } \\
N=37 \\
.01 \\
\text { Mod Intox. } \\
N=30 \\
.07\end{array}$ & $\begin{array}{l}\frac{\text { Effect }}{\text { - Quantity: Subj information }} \\
\text { and peripheral details } \\
\text { No Effect } \\
\text { - Quantity: Number of } \\
\text { statements and accurate } \\
\text { statements }\end{array}$ \\
\hline $\begin{array}{l}\text { Schreiber } \\
\text { Compo et al. } \\
\text { (2012) } \\
\text { Law \& } \\
\text { Human } \\
\text { Behavior }\end{array}$ & Lab & $\begin{array}{c}N=93 \\
\text { Gender } \\
59 \mathrm{~F} ; 34 \mathrm{M} \\
\\
M \text { Age (SD) } \\
24(4.6)\end{array}$ & $\begin{array}{c}\text { Live } \\
\text { Interaction } \\
\text { Alcohol } \\
\text { consumed at } \\
\text { laboratory } \\
\text { bar followed } \\
\text { by staged } \\
\text { theft }\end{array}$ & $\begin{array}{l}\text { Quality } \\
\text { Open-ended } \\
\text { questions, } \\
\text { cued } \\
\text { questions, or } \\
\text { mixed }\end{array}$ & $\begin{array}{c}\text { Immediate } \\
(20 \text { mins }) \\
\quad N=93\end{array}$ & $\approx .04-.13$ & $\begin{array}{c}\text { Control } \\
N=25 \\
.00 \\
\text { Placebo } \\
N=38 \\
.00 \\
\text { Mod Intox. } \\
N=30 \\
\approx .07\end{array}$ & $\begin{array}{l}\frac{\text { Effect }}{\text { - Quality: Cued recall }} \\
\frac{\text { No Effect }}{\text { - Quality: Accurate \& mis- }} \\
\quad \text { information }\end{array}$ \\
\hline
\end{tabular}




\begin{tabular}{|c|c|c|c|c|c|c|c|c|}
\hline \multirow{3}{*}{$\begin{array}{l}\text { Hagsand et } \\
\text { al. (2013a) } \\
\text { Scandinavian } \\
\text { Journal of } \\
\text { Psychology }\end{array}$} & \multirow{3}{*}{ Lab } & \multirow{3}{*}{$\begin{array}{c}N=126 \\
80 \mathrm{~F} ; 46 \mathrm{M} \\
M \text { Age (SD) } \\
26(3.26)\end{array}$} & \multirow{3}{*}{$\begin{array}{c}\text { Video } \\
\text { Mock } \\
\text { kidnapping }\end{array}$} & \multirow{3}{*}{$\begin{array}{l}\text { Quantity \& } \\
\text { Quality } \\
\text { Verbal free } \\
\text { and cued } \\
\text { recall }\end{array}$} & \multirow{3}{*}{$\begin{array}{c}1 \text { Week } \\
N=126 \\
\text { (sober) }\end{array}$} & \multirow{3}{*}{$.00-.12$} & $\begin{array}{c}\text { Control } \\
N=42 \\
.00\end{array}$ & \\
\hline & & & & & & & \multirow{2}{*}{$\begin{array}{c}\text { Low Intox. } \\
\begin{array}{c}N=40 \\
.04\end{array} \\
\text { Mod. } \\
\text { Intox. } \\
\begin{array}{c}N=44 \\
.06\end{array}\end{array}$} & $\frac{\text { Effect }}{- \text { Quantity }}$ \\
\hline & & & & & & & & $\frac{\text { No Effect }}{\text { - Quality }}$ \\
\hline \multirow{3}{*}{$\begin{array}{l}\text { Harvey et al. } \\
\qquad(2013 \mathrm{a})\end{array}$} & \multirow{3}{*}{ Lab } & & Photos & \multirow{3}{*}{$\begin{array}{l}\text { Quantity } \\
\text { Free recall }\end{array}$} & \multirow{3}{*}{$\begin{array}{c}1 \text { Day } \\
N=106 \\
\text { (sober) }\end{array}$} & \multirow{3}{*}{$.00-.10$} & & \\
\hline & & $\begin{array}{c}N=106 \\
80 \mathrm{~F} ; 26 \mathrm{M}\end{array}$ & $\begin{array}{l}\text { Riot (high } \\
\text { salience) or }\end{array}$ & & & & $\begin{array}{c}N=60 \\
.00\end{array}$ & $\frac{\text { Effect }}{\text { - Quantity }}$ \\
\hline & & $\begin{array}{l}M \text { Age (SD) } \\
21.7(4.4)\end{array}$ & $\begin{array}{l}\text { two } \\
\text { violinists } \\
\text { (low } \\
\text { salience) }\end{array}$ & & & & $\begin{array}{l}\text { High Intox. } \\
\qquad \begin{array}{l}N=52 \\
\approx .06\end{array}\end{array}$ & $\frac{\text { No Effect }}{\text { - No null effects found }}$ \\
\hline \multirow{3}{*}{$\begin{array}{l}\text { Harvey et al. } \\
\text { (2013b) } \\
\text { Applied } \\
\text { Cognitive } \\
\text { Psychology }\end{array}$} & \multirow{3}{*}{ Lab } & $N=120$ & & $\begin{array}{l}\text { Quantity, } \\
\text { Confidence }\end{array}$ & & & Control & \\
\hline & & $78 \mathrm{~F} ; 42 \mathrm{M}$ & $\begin{array}{l}\text { Slideshow of } \\
\text { Photos }\end{array}$ & $\begin{array}{c}16 \mathrm{~T} / \mathrm{F} \\
\text { statements }(8\end{array}$ & $\begin{array}{c}1 \text { Day } \\
N=120\end{array}$ & $.05-.17$ & .00 & - Quantity \\
\hline & & $\begin{array}{c}M \text { Age (SD) } \\
19.7(2.74)\end{array}$ & Mock theft & $\begin{array}{l}\text { peripheral } \\
\text { details) about } \\
\text { the event. }\end{array}$ & (sober) & & $\begin{array}{l}\text { High Intox. } \\
\qquad \begin{array}{c}N=60 \\
.11\end{array}\end{array}$ & $\frac{\text { No Effect }}{\text { - Confidence }}$ \\
\hline
\end{tabular}




\begin{tabular}{|c|c|c|c|c|c|c|c|c|}
\hline $\begin{array}{l}\text { La Rooy et } \\
\text { al. (2013) } \\
\text { Open Journal } \\
\text { of Medical } \\
\text { Psychology }\end{array}$ & Lab & $\begin{array}{c}\quad N=58 \\
30 \mathrm{~F} ; 28 \mathrm{M} \\
M \text { Age }(\mathrm{SD}) \\
21.5(2.2)\end{array}$ & $\begin{array}{c}\text { Video } \\
\text { Mock armed } \\
\text { robbery }\end{array}$ & $\begin{array}{c}\text { Quantity, } \\
\text { Errors } \\
\text { Written free } \\
\text { recall }\end{array}$ & $\begin{array}{c}\text { Immediate } \\
\begin{array}{c}(30 \text { mins }) \\
N=58\end{array} \\
\text { AND } \\
1 \text { Day } \\
N=58 \\
\text { (sober) }\end{array}$ & $.00-.07$ & $\begin{array}{l}\text { Placebo } \\
\begin{array}{c}N=\mathrm{N} / \mathrm{A} \\
.00\end{array} \\
\text { Low Intox. } \\
\begin{array}{c}N=\mathrm{N} / \mathrm{A} \\
\approx .02\end{array} \\
\text { Mod Intox. } \\
\begin{array}{c}N=\mathrm{N} / \mathrm{A} \\
\approx .06\end{array}\end{array}$ & $\begin{array}{l}\frac{\text { Effect }}{- \text { No effects of alcohol }} \\
\frac{\text { No Effect }}{\text { - Quantity }} \\
\text { - Errors }\end{array}$ \\
\hline $\begin{array}{l}\text { Flowe et al. } \\
\text { (2015) } \\
\text { Memory }\end{array}$ & $\mathrm{Lab}$ & $\begin{array}{l}\quad N=88 \\
\text { All Female } \\
M \text { Age (SD) } \\
20.42(2.27)\end{array}$ & $\begin{array}{l}\text { Narrative } \\
\text { Hypothetical } \\
\text { interactive } \\
\text { rape scenario }\end{array}$ & $\begin{array}{l}\text { Quantity \& } \\
\text { Quality } \\
30 \text { item } \\
\text { multiple } \\
\text { choice test }\end{array}$ & $\begin{array}{c}1 \text { Day } \\
N=88 \\
\text { (sober) } \\
\text { AND } \\
4 \text { Months } \\
N=64 \\
\text { (sober) }\end{array}$ & N/A & $\begin{array}{c}\text { Placebo } \\
N=\mathrm{N} / \mathrm{A} \\
.00 \\
\text { Low Intox. } \\
N=\mathrm{N} / \mathrm{A} \\
.05 \\
\\
\text { Mod Intox. } \\
N=\mathrm{N} / \mathrm{A} \\
.08\end{array}$ & $\begin{array}{l}\frac{\text { Effect }}{\text { - Quantity: Central details }} \\
\text { - Quality: Accurate details } \\
\frac{\text { No Effect }}{\text { - No null effects found }}\end{array}$ \\
\hline
\end{tabular}




\begin{tabular}{|c|c|c|c|c|c|c|c|c|}
\hline $\begin{array}{l}\text { Hildebrand } \\
\text { Karlén et al. } \\
\quad(2015) \\
\text { Psychology, } \\
\text { Crime, \& } \\
\text { Law }\end{array}$ & $\mathrm{Lab}$ & $\begin{array}{c}N=86 \\
42 \mathrm{~F} ; 44 \mathrm{M} \\
M \text { Age (SD) } \\
\text { N/A }\end{array}$ & $\begin{array}{l}\text { Video } \\
\text { Staged } \\
\text { argument } \\
\text { between a } \\
\text { male and } \\
\text { female } \\
\text { depicting } \\
\text { intimate } \\
\text { partner } \\
\text { violence }\end{array}$ & $\begin{array}{l}\text { Quantity \& } \\
\text { Quality } \\
\text { Verbal free } \\
\text { recall }\end{array}$ & $\begin{array}{c}\text { Immediate } \\
(10 \text { mins }) \\
\quad N=86\end{array}$ & $.04-.10$ & $\begin{array}{c}\text { Control } \\
N=43 \\
21 \mathrm{~F} ; 22 \mathrm{M} \\
.00 \\
\text { Mod Intox. } \\
(\mathrm{M}) \\
N=22 \\
.07 \\
\text { Mod Intox. } \\
(\mathrm{F}) \\
N=21 \\
.08\end{array}$ & $\begin{array}{l}\frac{\text { Effect }}{\text { - Quantity: For females }} \\
\frac{\text { No Effect }}{\text { - Quality }} \\
\text { - Quantity: For males }\end{array}$ \\
\hline $\begin{array}{l}\text { Crossland } \\
\text { et al. (2016) } \\
\text { Experiment } 1 \\
\text { Applied } \\
\text { Cognitive } \\
\text { Psychology }\end{array}$ & Lab & $\begin{array}{c}N=88 \\
56 \mathrm{~F} ; 32 \mathrm{M} \\
M \text { Age (SD) } \\
20.92(6.22)\end{array}$ & $\begin{array}{c}\text { Video } \\
\text { Mock theft }\end{array}$ & $\begin{array}{l}\text { Confidence, } \\
\text { Quantity, } \\
\text { Quality, \& } \\
\text { Item Salience } \\
\text { Written free } \\
\text { recall and } 40 \\
\text { item } \\
\text { recognition } \\
\text { test. } \\
\text { Confidence in } \\
\text { each item } \\
\text { assessed }\end{array}$ & $\begin{array}{l}1 \mathrm{Week} \\
N=88 \\
\text { (sober) }\end{array}$ & $.03-.11$ & $\begin{array}{c}\text { Control } \\
N=22 \\
.00 \\
\text { Placebo } \\
N s=22 \\
.00 \\
\text { Mod Intox } \\
N=23 \\
.06 \\
\text { Mod Intox. } \\
N=21 \\
.09\end{array}$ & $\begin{array}{l}\text { Effect } \\
\text { - Confidence } \\
\text { No Effect } \\
\text { - Quantity } \\
\text { - Quality } \\
\text { - Item Salience }\end{array}$ \\
\hline
\end{tabular}




\begin{tabular}{|c|c|c|c|c|c|c|c|c|}
\hline $\begin{array}{l}\text { Crossland et } \\
\text { al. }(2016) \\
\text { Experiment } 2 \\
\text { Applied } \\
\text { Cognitive } \\
\text { Psychology }\end{array}$ & Field & $\begin{array}{c}N=54 \\
42 \mathrm{~F} ; 12 \mathrm{M} \\
M \text { Age (SD) } \\
19.5(1.27)\end{array}$ & $\begin{array}{l}\text { Video } \\
\text { Mock theft. } \\
\text { (Same video } \\
\text { as Study 1) }\end{array}$ & $\begin{array}{l}\text { Recognition, } \\
\text { Quantity \& } \\
\text { Quality } \\
\text { Semi- } \\
\text { structured } \\
\text { interview and } \\
\text { recognition } \\
\text { task from } \\
\text { experiment } 1\end{array}$ & $\begin{array}{l}1 \text { Week } \\
N=54 \\
\text { (sober) }\end{array}$ & $.00-.23$ & $\begin{array}{c}\text { Low Intox } \\
\qquad \begin{array}{c}N=26 \\
.05\end{array} \\
\text { High Intox. } \\
\begin{array}{c}N=28 \\
.14\end{array}\end{array}$ & $\begin{array}{l}\text { Effect } \\
\text { - Quality: Free recall accuracy. } \\
\text { Cued accuracy and "I don't } \\
\text { know" responses. } \\
\text { - Quantity x Confidence: Cued } \\
\text { recall accuracy and "I don't } \\
\text { know" responses } \\
\text { - Confidence } \\
\text { No Effects } \\
\text { - Quantity: Cued recall } \\
\text { - Quality: Inaccurate responses }\end{array}$ \\
\hline $\begin{array}{l}\text { Hagsand et } \\
\text { al. (2017) } \\
\text { Memory }\end{array}$ & $\mathrm{Lab}$ & $\begin{array}{c}N=99 \\
\text { Gender } \\
57 \mathrm{~F} ; 42 \mathrm{M} \\
\\
M \text { Age (SD) } \\
24.76(4.19)\end{array}$ & $\begin{array}{l}\text { Video } \\
\text { Staged } \\
\text { robbery }\end{array}$ & $\begin{array}{c}\text { Quantity \& } \\
\text { Quality } \\
\text { Free and cued } \\
\text { recall }\end{array}$ & $\begin{array}{c}\text { Immediate } \\
\text { (15 mins) } \\
N=47 \\
1 \text { Week } \\
N=99 \\
\text { (sober) } \\
\text { Both } \\
N=47\end{array}$ & $.00-.11$ & $\begin{array}{c}\text { Control } \\
\begin{array}{c}N=48 \\
.00\end{array} \\
\text { Low Intox. } \\
\begin{array}{c}N=51 \\
.05\end{array}\end{array}$ & $\begin{array}{l}\frac{\text { Effect }}{\text { - Quantity: Free recall }} \\
\frac{\text { No Effect }}{\text { - Quality }} \\
\text { - Quantity: Overall recall }\end{array}$ \\
\hline
\end{tabular}




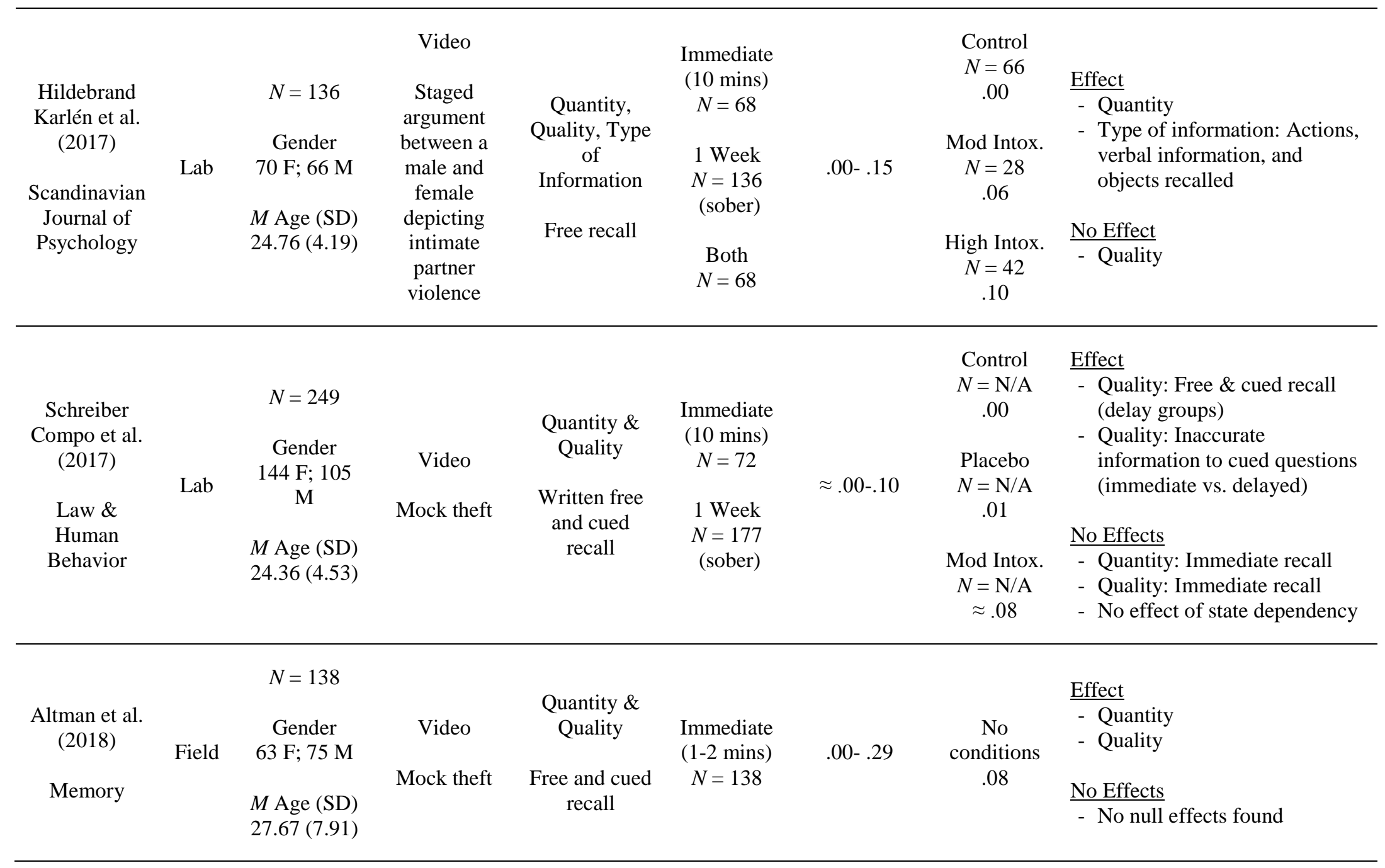


Table 2

Overview of the general findings and procedures used in the studies examining the effects of alcohol on eyewitnesses'facial identification abilities. Breath alcohol concentrations (BACs) not published in \% format were converted using the Lion Units Converter and recorded as approximations (www.lionlaboratories.com).

\begin{tabular}{|c|c|c|c|c|c|c|c|c|}
\hline Authors & $\begin{array}{c}\text { Lab } \\
\text { vs. } \\
\text { Field } \\
\end{array}$ & Participants & Stimuli & $\begin{array}{c}\text { DV Measure/ } \\
\text { Presentation } \\
\text { Mode }\end{array}$ & Delay & $\begin{array}{c}\text { BAC } \\
\text { Range } \\
\end{array}$ & $\begin{array}{c}\text { BAC } \\
\text { Averages } \\
\end{array}$ & Effects of Alcohol \\
\hline $\begin{array}{l}\text { Yuille \& } \\
\text { Tollestrup } \\
\quad(1990) \\
\text { Journal of } \\
\text { Applied } \\
\text { Psychology }\end{array}$ & $\mathrm{Lab}$ & $\begin{array}{c}N=120 \\
\text { All Male } \\
\text { M Age (SD) } \\
21.2(\mathrm{~N} / \mathrm{A})\end{array}$ & $\begin{array}{l}\text { Live-staged } \\
\text { event } \\
\text { Staged } \\
\text { robbery }\end{array}$ & $\begin{array}{c}\text { Lineup ID (TA } \\
\text { \&TP) \& } \\
\text { Confidence } \\
\text { Simultaneous }\end{array}$ & $\begin{array}{c}1 \text { Week } \\
N=120 \\
\text { (sober) }\end{array}$ & $.06-.12$ & $\begin{array}{c}\text { Control } \\
\begin{array}{c}N=73 \\
.00\end{array} \\
\text { High Intox. } \\
\begin{array}{c}N=47 \\
.10\end{array}\end{array}$ & $\begin{array}{l}\text { Effect } \\
\text { - Confidence } \\
\begin{array}{l}\text { No Effect } \\
\text { - TP } \\
\text { - TA }\end{array}\end{array}$ \\
\hline $\begin{array}{l}\text { Dysart et al. } \\
\text { (2002) } \\
\text { Journal of } \\
\text { Applied } \\
\text { Psychology }\end{array}$ & Field & $\begin{array}{l}\quad N=103 \\
42 \mathrm{~F} ; 61 \mathrm{M} \\
M \text { Age (SD) } \\
\text { N/A (N/A) }\end{array}$ & $\begin{array}{c}\text { Live } \\
\text { Interaction } \\
\text { Brief } \\
\text { interaction } \\
\text { with a female } \\
\text { confederate }\end{array}$ & $\begin{array}{l}\text { Show-up ID } \\
\text { (TA \& TP) \& } \\
\text { Confidence } \\
\text { Show-up } \\
\text { photograph }\end{array}$ & $\begin{array}{c}\text { Immediate } \\
(12 \text { mins }) \\
N=103\end{array}$ & $.00-.20$ & $\begin{array}{l}\text { Low Intox. } \\
\begin{array}{c}N=55 \\
.02 \\
\text { Mod Intox } \\
N=48 \\
.09\end{array}\end{array}$ & $\begin{array}{l}\frac{\text { Effect }}{\text { - TA: False identifications }} \\
\frac{\text { No Effect }}{\text { - TP }} \\
\text { - Confidence }\end{array}$ \\
\hline
\end{tabular}




\begin{tabular}{|c|c|c|c|c|c|c|c|c|}
\hline $\begin{array}{l}\text { Hagsand et } \\
\text { al. (2013b) } \\
\text { European } \\
\text { Journal of } \\
\text { Psychology } \\
\text { Applied to } \\
\text { Legal } \\
\text { Context }\end{array}$ & $\mathrm{Lab}$ & $\begin{array}{c}N=123 \\
74 \mathrm{~F} ; 49 \mathrm{M} \\
M \text { Age (SD) } \\
25.07(3.45)\end{array}$ & $\begin{array}{c}\text { Video } \\
\text { Mock } \\
\text { kidnapping }\end{array}$ & $\begin{array}{c}\text { Lineup ID (TA } \\
\text { \& TP) \& } \\
\text { Confidence } \\
\text { Simultaneous }\end{array}$ & $\begin{array}{c}1 \text { Week } \\
N=123 \\
\text { (sober) }\end{array}$ & $.00-.09$ & $\begin{array}{c}\text { Control } \\
\begin{array}{c}N=41 \\
.00\end{array} \\
\text { Low Intox. } \\
\begin{array}{c}N=42 \\
\approx .04\end{array} \\
\text { Mod Intox. } \\
\quad N=40 \\
\approx .08\end{array}$ & $\begin{array}{l}\frac{\text { Effect }}{\text { - No effects of alcohol found }} \\
\frac{\text { No Effect }}{\text { - TP }} \\
\text { - TA } \\
\text { - Confidence }\end{array}$ \\
\hline $\begin{array}{l}\text { Harvey et } \\
\text { al. (2013b) } \\
\text { Applied } \\
\text { Cognitive } \\
\text { Psychology }\end{array}$ & $\mathrm{Lab}$ & $\begin{array}{c}N=120 \\
78 \mathrm{~F} ; 42 \mathrm{M} \\
M \text { Age (SD) } \\
19.7(2.74)\end{array}$ & $\begin{array}{l}\text { Slideshow of } \\
\text { Photos } \\
\text { Mock theft }\end{array}$ & $\begin{array}{c}\text { Lineup ID (TA } \\
\text { \& TP) \& } \\
\text { Confidence } \\
\text { Simultaneous }\end{array}$ & $\begin{array}{c}1 \text { Day } \\
N=120 \\
\text { (sober) }\end{array}$ & $.05-.17$ & $\begin{array}{c}\text { Control } \\
\begin{array}{c}N=60 \\
.00\end{array} \\
\text { High Intox. } \\
\begin{array}{c}N=60 \\
.11\end{array}\end{array}$ & $\begin{array}{l}\text { Effect } \\
\text { - Confidence } \\
\frac{\text { No Effect }}{\text { - TP }} \\
\text { - TA }\end{array}$ \\
\hline $\begin{array}{l}\text { Kneller et } \\
\text { al. (2015) } \\
\text { European } \\
\text { Journal of } \\
\text { Psychology } \\
\text { Applied to } \\
\text { Legal } \\
\text { Context }\end{array}$ & Lab & $\begin{array}{c}N=120 \\
97 \mathrm{~F} ; 23 \mathrm{M} \\
M \text { Age (SD) } \\
20.4(4.12)\end{array}$ & $\begin{array}{c}\text { Video } \\
\text { Staged auto } \\
\text { theft }\end{array}$ & $\begin{array}{l}\text { Lineup ID (TA } \\
\text { \& TP) \& } \\
\text { Confidence } \\
\text { Simultaneous }\end{array}$ & $\begin{array}{c}1 \text { Week } \\
N=120 \\
\text { (sober) }\end{array}$ & $\approx .02-.08$ & $\begin{array}{c}\text { Control } \\
\begin{array}{c}N=40 \\
.00\end{array} \\
\text { Placebo } \\
N=40 \\
.00 \\
\text { Low Intox. } \\
N=40 \\
\approx .05\end{array}$ & $\begin{array}{l}\frac{\text { Effect }}{\text { - No effects of alcohol found }} \\
\frac{\text { No Effect }}{\text { - TP }} \\
\text { - TA } \\
\text { - Confidence }\end{array}$ \\
\hline
\end{tabular}




\begin{tabular}{|c|c|c|c|c|c|c|c|c|}
\hline $\begin{array}{l}\text { Flowe et al. } \\
\qquad \begin{array}{l}\text { (2017) } \\
\text { Applied } \\
\text { Cognitive } \\
\text { Psychology }\end{array}\end{array}$ & $\mathrm{Lab}$ & $\begin{array}{l}\quad N=153 \\
\text { All Female } \\
M \text { Age (SD) } \\
20.53(2.28)\end{array}$ & $\begin{array}{l}\text { Narrative } \\
\text { Hypothetical } \\
\text { interactive } \\
\text { sexual } \\
\text { assault } \\
\text { scenario }\end{array}$ & $\begin{array}{l}\text { Lineup ID (TA } \\
\text { \&TP), } \\
\text { Confidence, \& } \\
\text { Expectancy } \\
\text { Simultaneous }\end{array}$ & $\begin{array}{l}1 \text { Day } \\
N=80 \\
1 \text { Week } \\
N=73\end{array}$ & $.00-.10$ & $\begin{array}{c}\text { Placebo } \\
\mathrm{N}=75 \\
.00 \\
\text { Intoxicated } \\
\mathrm{N}=80 \\
.08\end{array}$ & $\begin{array}{l}\frac{\text { Effect }}{\text { - Confidence }} \\
\frac{\text { No Effect }}{\text { - TP }} \\
\text { - TA } \\
\text { Expectancy }\end{array}$ \\
\hline $\begin{array}{l}\text { Altman et } \\
\text { al. (2018) } \\
\text { Memory }\end{array}$ & Field & $\begin{array}{c}N=138 \\
\text { Gender } \\
63 \mathrm{~F} ; 75 \mathrm{M} \\
\text { M Age (SD) } \\
27.67(7.91)\end{array}$ & $\begin{array}{c}\text { Video } \\
\text { Mock theft }\end{array}$ & $\begin{array}{c}\text { Lineup ID (TA } \\
\text { \& TP) \& } \\
\text { Confidence } \\
\text { Simultaneous }\end{array}$ & $\begin{array}{l}\text { Immediate } \\
(5-10 \\
\text { mins }) \\
N=138\end{array}$ & $.00-.29$ & $\begin{array}{c}\text { No } \\
\text { conditions } \\
.08\end{array}$ & $\begin{array}{l}\frac{\text { Effect }}{\text { - No effects of alcohol found }} \\
\frac{\text { No Effect }}{- \text { TP }} \\
\text { - TA } \\
\text { - Confidence }\end{array}$ \\
\hline
\end{tabular}


Table 3

Number of times each filler was identified from a lineup or showup.

\begin{tabular}{cccccc}
\hline & \multicolumn{5}{c}{ Identification Format } \\
\cline { 2 - 6 } & $\begin{array}{c}\text { Lineup } \\
\text { Target- } \\
\text { present }\end{array}$ & $\begin{array}{c}\text { Target- } \\
\text { absent }\end{array}$ & $\begin{array}{c}\text { Target- } \\
\text { present }\end{array}$ & $\begin{array}{c}\text { Target- } \\
\text { absent }\end{array}$ & $\begin{array}{c}\text { Total } \\
\text { selections }\end{array}$ \\
\hline Filler A & 2 & 2 & - & 2 & 6 \\
Filler B & 1 & 0 & - & 0 & 1 \\
Filler C & 0 & 1 & - & 1 & 2 \\
Filler D & $\mathbf{2}$ & $\mathbf{6}$ & - & $\mathbf{4}$ & $\mathbf{1 2}$ \\
Filler E & 1 & 4 & - & 0 & 5 \\
Filler F & 0 & 6 & - & 2 & 8 \\
\hline
\end{tabular}

A

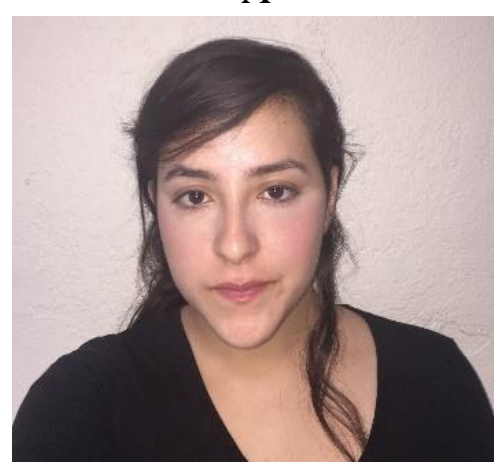

D

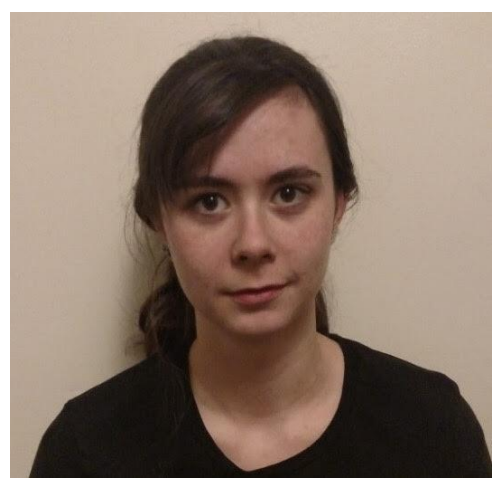

B

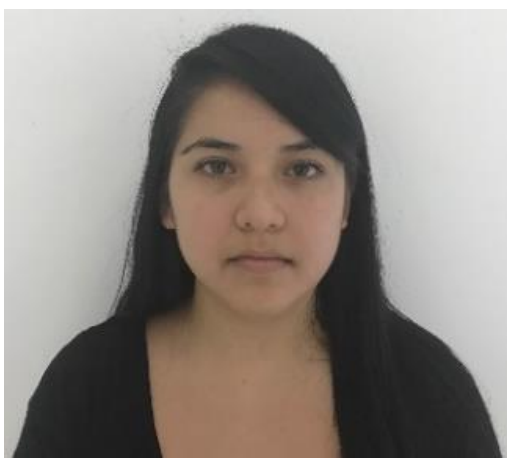

E

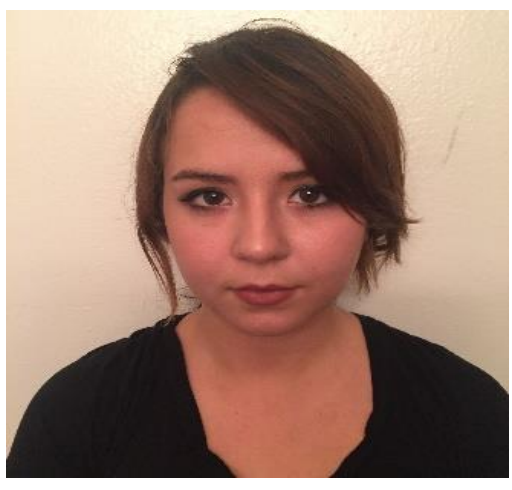

C

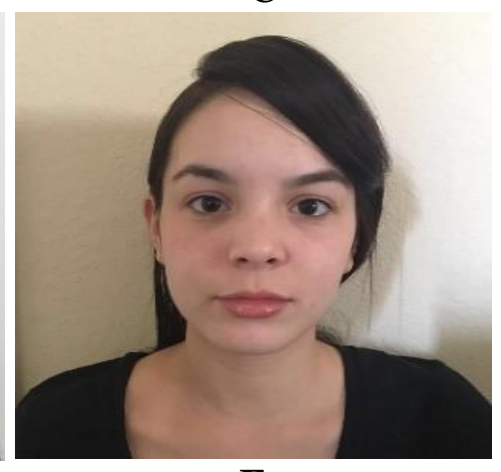

$\mathbf{F}$

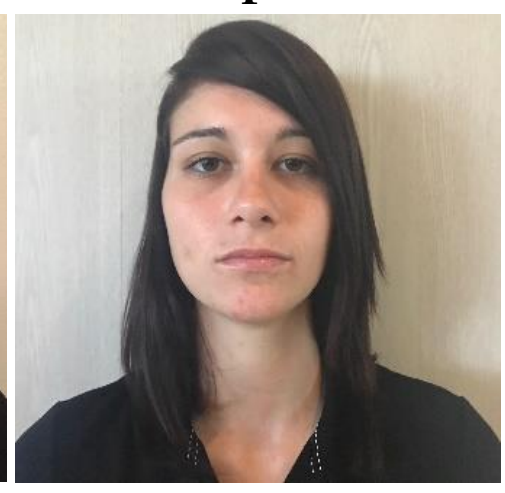


Table 4

Correlations between participants' objective and subjective drinking measures, responses to the drinking history questionnaire, and believability in the study manipulations.

\begin{tabular}{|c|c|c|c|c|c|c|c|c|c|c|c|c|c|c|}
\hline & BAC 1 & BAC 2 & $\begin{array}{c}\text { Subj } \\
\text { BAC1 }\end{array}$ & $\begin{array}{c}\text { Subj } \\
\text { BAC2 }\end{array}$ & $\begin{array}{c}\text { ID } \\
\text { Certainty }\end{array}$ & $\begin{array}{l}\text { Intrusio } \\
\text { n Belief }\end{array}$ & $\begin{array}{c}\text { Interview } \\
\text { Belief }\end{array}$ & $\begin{array}{c}\text { Photos } \\
\text { Belief }\end{array}$ & $\begin{array}{l}\text { Drinkin } \\
\text { g Occas }\end{array}$ & $\begin{array}{l}\text { Weekly } \\
\text { Drinks }\end{array}$ & $\begin{array}{c}\text { Drinking } \\
\text { Time }\end{array}$ & $\begin{array}{l}\text { Drinks } \\
\text { Tonight }\end{array}$ & Gender & Age \\
\hline $\begin{array}{l}\text { BAC } 1 \\
\text { BAC 2 }\end{array}$ & $.972^{* *}$ & 1 & & & & & & & & & & & & \\
\hline Subj BAC1 & $.678^{* *}$ & $.710^{* *}$ & 1 & & & & & & & & & & & \\
\hline Subj BAC2 & $.675^{* *}$ & $.696^{* *}$ & $.976^{* *}$ & 1 & & & & & & & & & & \\
\hline ID certainty & -.045 & -.062 & -.012 & .022 & 1 & & & & & & & & & \\
\hline Intrusion Belief & -.089 & -.088 & .063 & .041 & .064 & 1 & & & & & & & & \\
\hline Interview Belief & .035 & .041 & .068 & .032 & -.010 & $.493^{* *}$ & 1 & & & & & & & \\
\hline Photos Belief & -.016 & .008 & .050 & .033 & .061 & $.265^{* *}$ & $.307^{* *}$ & 1 & & & & & & \\
\hline Drinking Occas & $.350^{* *}$ & $.355^{* *}$ & $.364^{* *}$ & $.347^{* *}$ & .096 & -.154 & .092 & -.083 & 1 & & & & & \\
\hline Weekly Drinks & $.392^{* *}$ & $.365^{* *}$ & $.263^{* *}$ & $.227^{* *}$ & .109 & .023 & .084 & -.048 & $.260^{* *}$ & 1 & & & & \\
\hline Drinking Time & $.638^{* *}$ & $.637^{* *}$ & $.454^{* *}$ & $.427^{* *}$ & -.064 & -.117 & .063 & -.060 & $.232^{* *}$ & $.436^{* *}$ & 1 & & & \\
\hline Drinks Tonight & $.680^{* *}$ & $.696^{* *}$ & $.580^{* *}$ & $.549^{* *}$ & .026 & -.007 & .069 & -.080 & $.381^{* *}$ & $.564^{* *}$ & $.740^{* *}$ & 1 & & \\
\hline Gender & $-.196^{*}$ & $-.182^{*}$ & $-.187^{*}$ & $-.194^{*}$ & .023 & .041 & .058 & $.205^{*}$ & $-.196^{*}$ & $-.291^{* *}$ & $-.235^{* *}$ & $-.319^{* *}$ & 1 & \\
\hline Age & $-.343^{* *}$ & $-.320^{* *}$ & $-.242^{* *}$ & $-.232^{* *}$ & $-.229^{*}$ & -.017 & -.050 & .047 & .005 & $-.345^{* *}$ & $-.260^{* *}$ & $-.265^{* *}$ & .126 & 1 \\
\hline
\end{tabular}

**. Correlation is significant at the 0.01 level (2-tailed).

*. Correlation is significant at the 0.05 level (2-tailed). 
Table 5

Identification decisions across lineup and showup conditions (N, \%)

\begin{tabular}{|c|c|c|c|c|c|}
\hline & & \multicolumn{4}{|c|}{ Identification Format } \\
\hline & & \multicolumn{2}{|c|}{ Lineup } & \multicolumn{2}{|c|}{ Showup } \\
\hline & & $\begin{array}{l}\text { Target- } \\
\text { present }\end{array}$ & $\begin{array}{l}\text { Target- } \\
\text { absent }\end{array}$ & $\begin{array}{l}\text { Target- } \\
\text { present }\end{array}$ & $\begin{array}{l}\text { Target- } \\
\text { absent }\end{array}$ \\
\hline & $\mathrm{N}$ & 24 & 32 & 37 & 39 \\
\hline \multirow{2}{*}{$\begin{array}{l}\text { Choosing } \\
\text { Behavior }\end{array}$} & Made selection & $17(70.80 \%)$ & $19(59.40 \%)$ & $24(64.90 \%)$ & $9(23.10 \%)$ \\
\hline & No selection & $7(29.20 \%)$ & $13(40.60 \%)$ & $13(35.10 \%)$ & $30(76.90 \%)$ \\
\hline \multirow{5}{*}{$\begin{array}{c}\text { ID } \\
\text { Accuracy }\end{array}$} & Perpetrator IDs & $11(45.83 \%)$ & & $24(64.86 \%)$ & \\
\hline & Filler IDs & $6(25.00 \%)$ & $13(40.63 \%)$ & & \\
\hline & Rejections & $2(8.33 \%)$ & $4(12.50 \%)$ & $7(18.91 \%)$ & $18(46.15 \%)$ \\
\hline & False IDs & & $6(18.75 \%)$ & & $9(23.08 \%)$ \\
\hline & Not sure & $5(20.84 \%)$ & $9(28.13 \%)$ & $6(16.23 \%)$ & $12(30.77 \%)$ \\
\hline
\end{tabular}

Note. The decisions in the target-absent lineup reflect when filler D was chosen as the innocent suspect. 


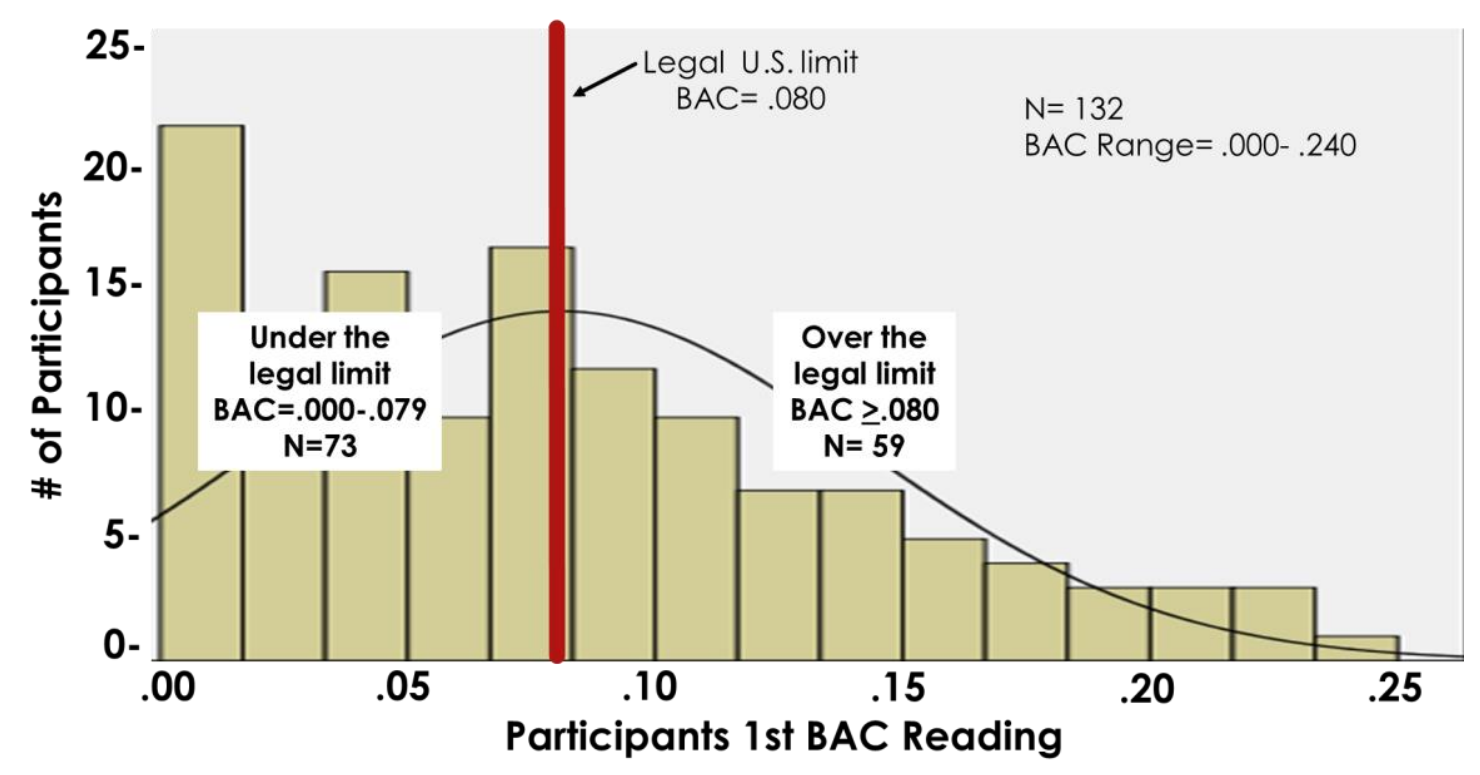

Figure 1. Number of participants (X-axis) at the various BAC levels recorded (Y-axis). 


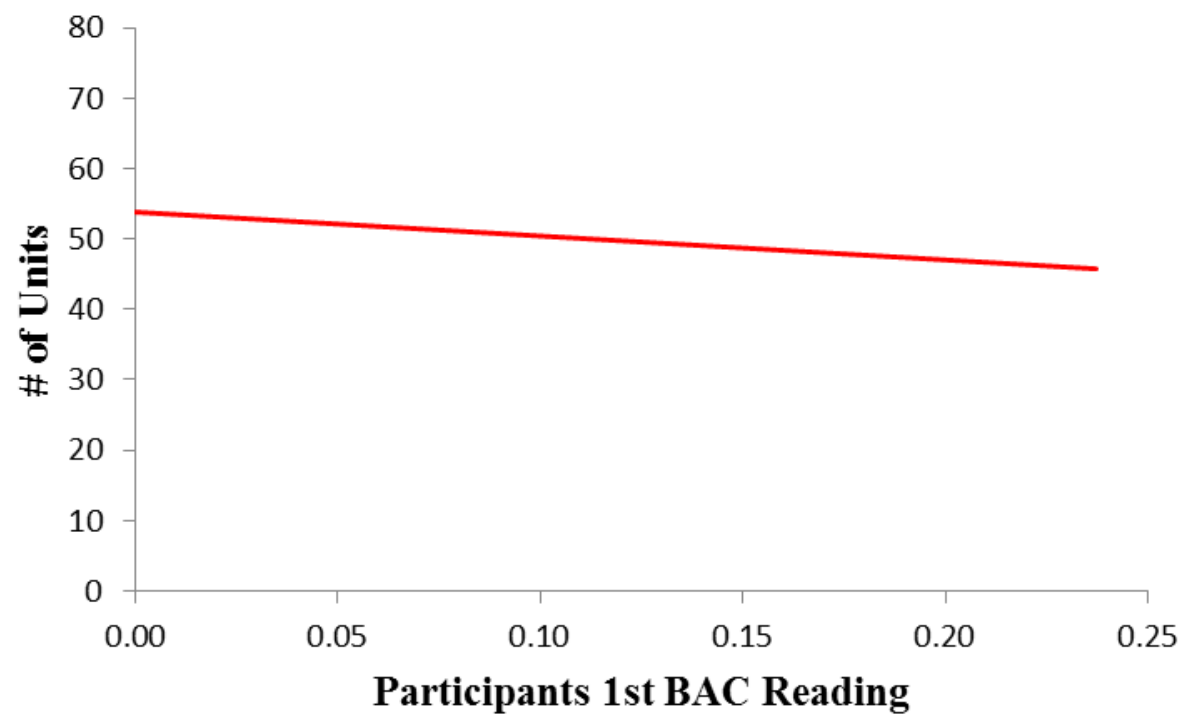

Figure 2. Relationship between BAC level (X-axis) and the total number of units reported (Y-axis). This figure includes subjective and irrelevant information reported. 


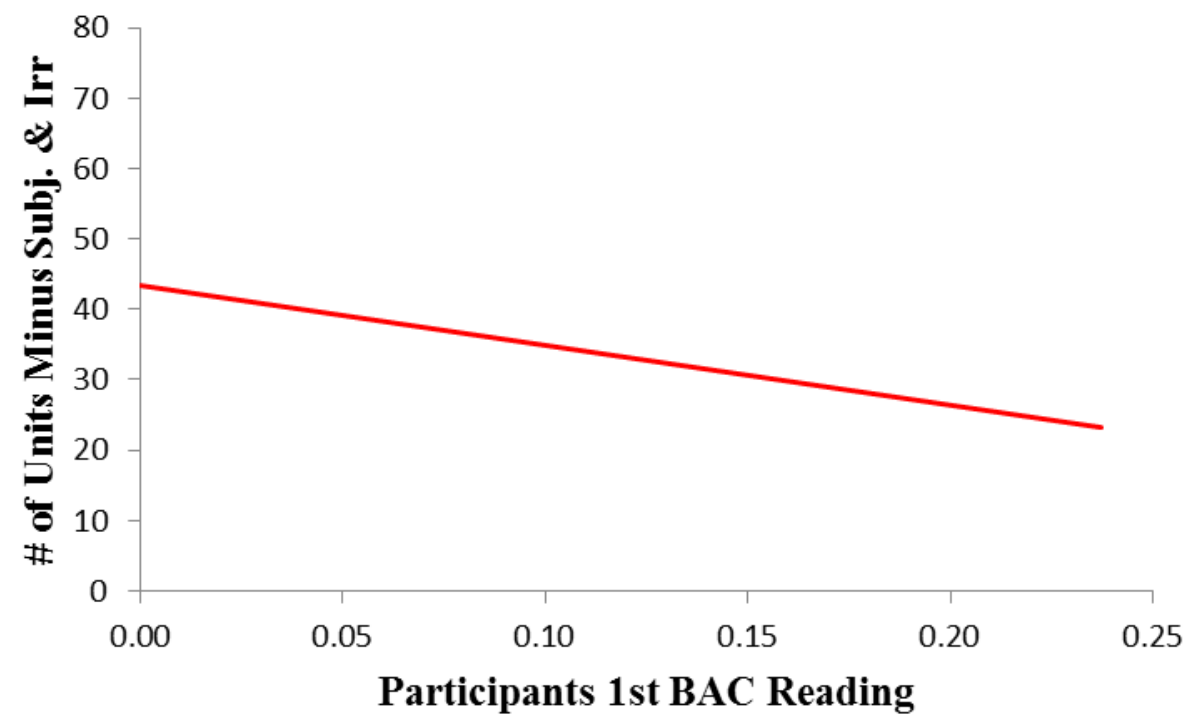

Figure 3. Relationship between BAC level (X-axis) and the total number of units reported (Y-axis). This figure excludes subjective and irrelevant information reported. 


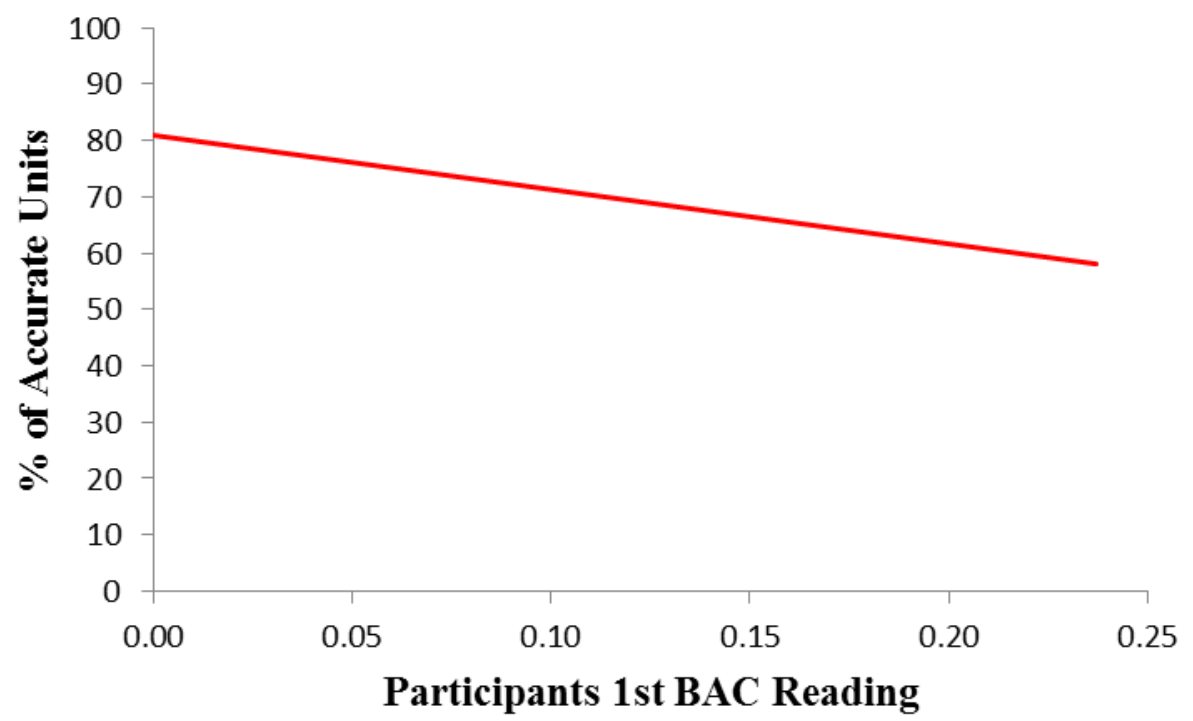

Figure 4. Relationship between BAC level (X-axis) and the proportion of accurate units reported (Y-axis). 


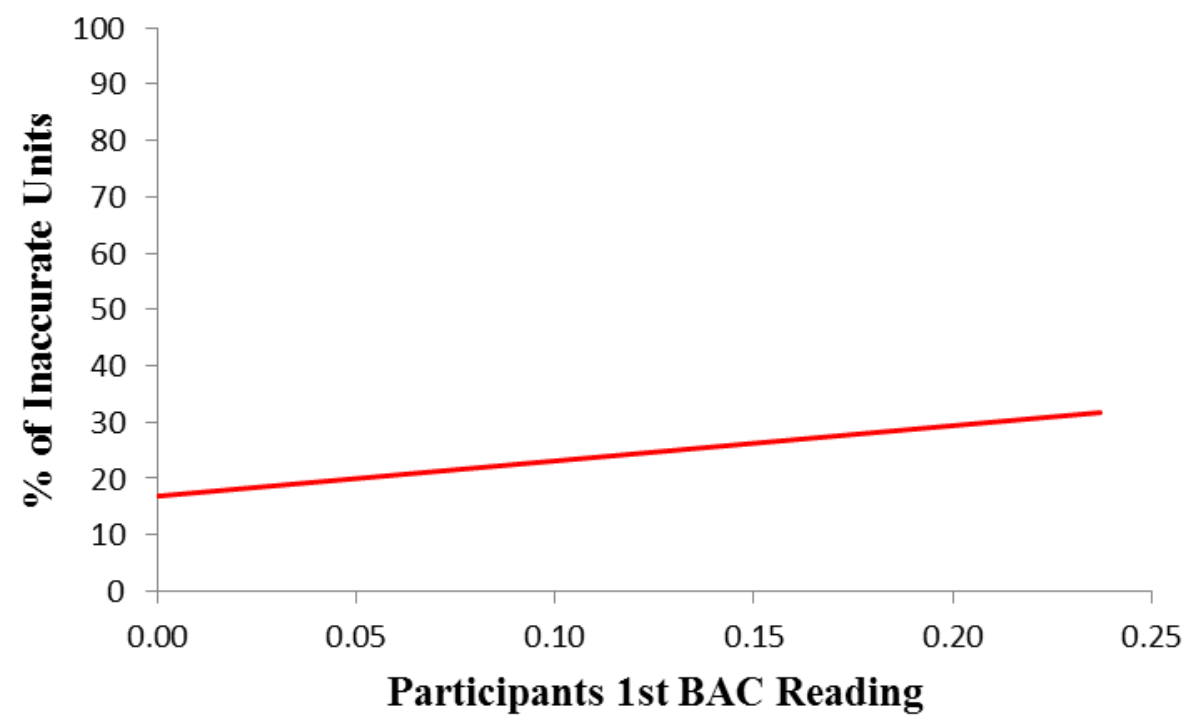

Figure 5. Relationship between BAC level (X-axis) and the proportion of inaccurate units reported (Y-axis). 


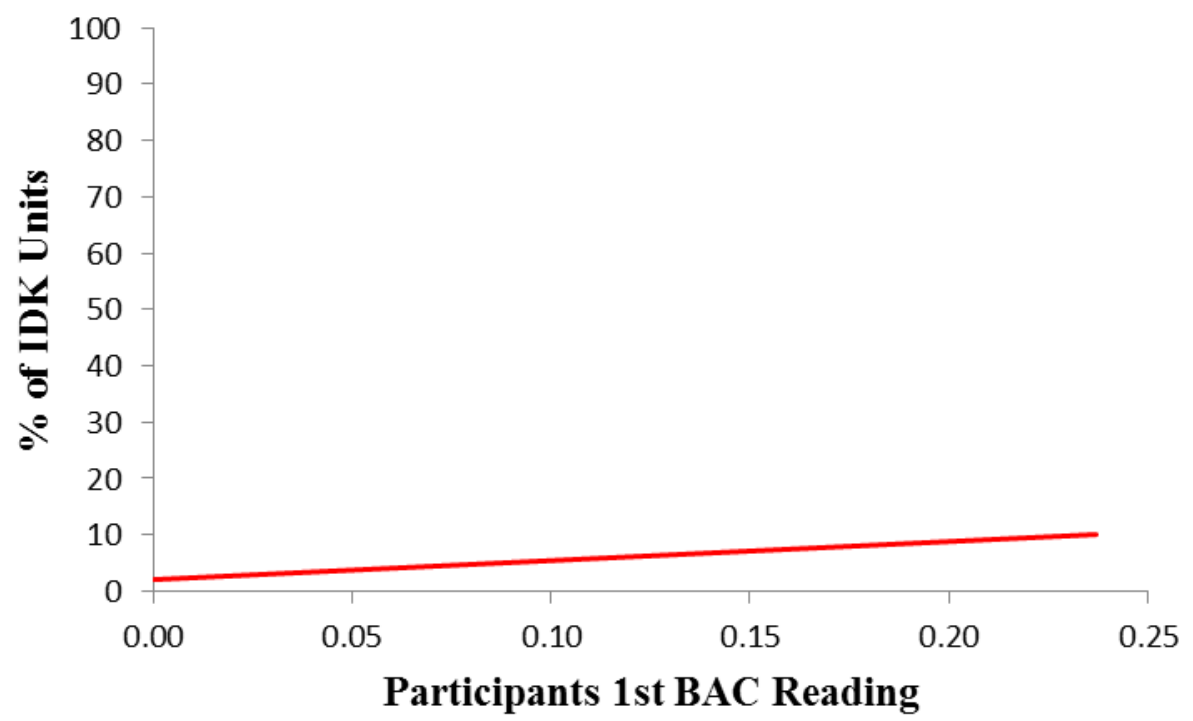

Figure 6. Relationship between BAC level (X-axis) and the proportion of 'I don't know' units reported (Y-axis). 


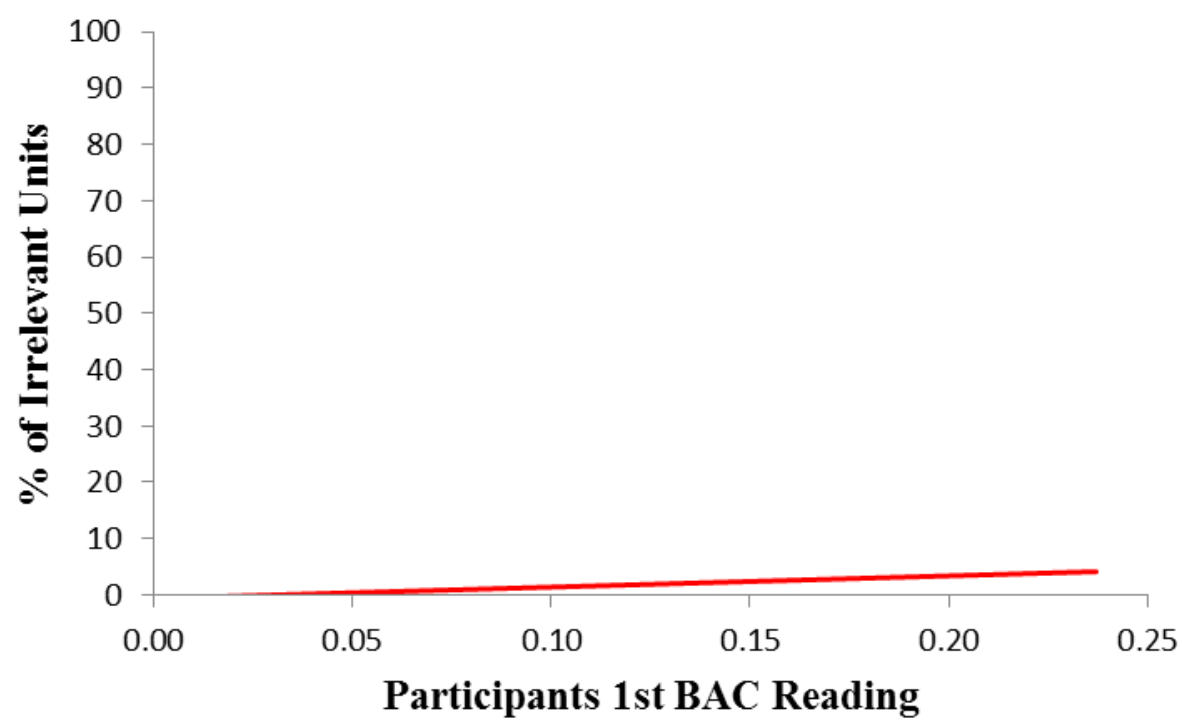

Figure 7. Relationship between BAC level (X-axis) and the proportion of irrelevant units reported (Y-axis). 


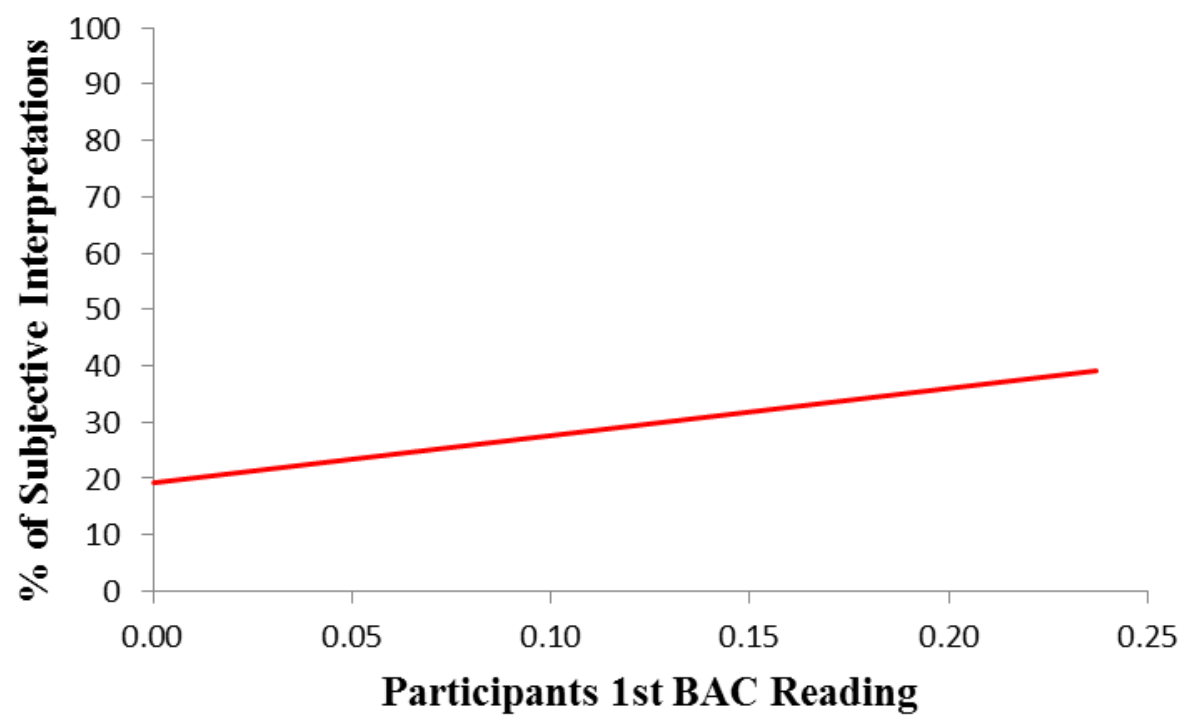

Figure 8. Relationship between BAC level (X-axis) and the proportion of subjective units reported (Y-axis). 


\section{REFERENCES}

Abbey, A. (2002). Alcohol-related sexual assault: A common problem among college students. Journal of Studies on Alcohol, 14(3), 118-128. doi: 10.15288/jsas.2002.s14.118

Abbey, A., Saenz, C., \& Buck, P. O. (2005). The cumulative effects of acute alcohol consumption, individual differences and situational perceptions on sexual decision making. Journal of Studies on Alcohol, 66(1), 82-90. doi: /10.15288/jsa.2005.66.82

Abbey, A., Saenz, C., Buck, P. O., Parkhill, M. R., \& Hayman, L. W. (2006). The effects of acute alcohol consumption, cognitive reserve, partner risk, and gender on sexual decision making. Journal of Studies on Alcohol, 67(1), 113-121. doi: 10.15288/jsa.2006.67.113

Abbey, A., Wegner, R., Woerner, J., Pegram, S. E., \& Pierce, J. (2014). Review of survey and experimental research that examines the relationship between alcohol consumption and men's sexual aggression perpetration. Trauma, Violence, \& Abuse, 15(4), 265-282. doi: 10.1177/1524838014521031

Agricola, B. H. (2009). The psychology of pretrial identification procedures: The showup is showing out and undermining the criminal justice system. Law and Psychology Review, 33, 125-137. doi: 10.1005/622169289-2009-17811-006

Altman, C., Schreiber Compo, N., Hagsand, A. V., \& Evans, J. R. (in press). State of Intoxication: A Review of the Effects of Alcohol on Witnesses Memory. In Dickinson, J., Schreiber Compo, N., Carol, R. N., McCauley, M., \& Schwartz, B. (Ed). Evidence-based investigative interviewing (Chapter 5). New York, NY: Routledge

Altman, C., Schreiber Compo, N., McQuiston, D. E., Hagsand, A. V., \& Cervera, J. (2018). Witnesses memory for events and faces under elevated levels of intoxication Memory, Advanced Online Publication. doi: 10.1080/09658211.2018.1445758

American Cornhole Association [ACA]. (2016). How To Play Cornhole/ Corn Toss. Retrieved from http://www.playcornhole.org/rules.shtml

Atkinson, R. C., \& Shiffrin, R. M. (1968). Human memory: A proposed system and its control processes. In Sternberg, R. J. (Ed). The psychology of learning and motivation: II (Chapter 9, pp. 115-118). New York, NY: Cambridge University Press

Bauer, P. J. (2013). Memory. In Zelazo, P. D. (Ed.). The Oxford handbook of developmental psychology (Vol 1): Body and mind (pp. 505-541). New York, NY. Oxford University Press 
Birnbaum, I. M., \& Parker, E. S. (1977). Alcohol and human memory. Oxford, England: Lawrence Erlbaum Associates

Brown, J., Brignell, C. M., Dhiman, S. K., Curran, H. V., \& Kamboj, S. K. (2010). Acute effects of alcohol on memory: Impact of emotional context and serial position. Neurobiology of Learning and Memory, 93(3), 428-434. doi: 10.1016/j.nlm.2009.12.010

Cabeza, R., \& St Jacques, P. (2007). Functional neuroimaging of autobiographical memory. Trends in Cognitive Sciences, 11(5), 219-227. /10901/70459213

Carlson, C. A. (2013). From science to reform: A long and winding road. PsycCRITIQUES, 58(31). doi: /10.1037/a0033382

Cicchini, M. D., \& Easton, J. G. (2010). Reforming the law on show-up identifications. The Journal of Criminal Law and Criminology, 100(2), 381-414. doi: /10/100020381

Clark, S. E. (2003). A memory and decision model for eyewitness identification. Applied Cognitive Psychology, 17(6), 629-654. doi: /10.1002/acp.891

Clark, S. E., Marshall, T. E., \& Rosenthal, R. (2009). Lineup administrator influences on eyewitness identification decisions. Journal of Experimental Psychology: Applied, 15(1), 63-75. doi:/10.1037/a0015185

Colflesh, G. J. H., \& Wiley, J. (2013). Drunk, but not blind: The effects of alcohol intoxication on change blindness. Consciousness and Cognition: An International Journal, 22(1), 231-236. doi: 10.1016/j.concog.2013.01.001

Colloff, M. F., \& Flowe, H. D. (2016). The effects of acute alcohol intoxication on the cognitive mechanisms underlying false facial recognition. Psychopharmacology, 233(11), 2139-2149. doi: 10.1007/s00213-016-4263-4

Craik, F. I., \& Lockhart, R. S. (1972). Levels of processing: A framework for memory research. Journal of Verbal Learning \& Verbal Behavior, 11(6), 671-684. doi: 10.1016/S0022-5371(72)80001-X

Crossland, D., Kneller, W., \& Wilcock, R. (2016). Intoxicated witnesses: Testing the validity of the alcohol myopia theory. Applied Cognitive Psychology, 30(2), 270281. doi: $10.1002 /$ acp.3209

Curran, H. V., \& Hildebrandt, M. (1999). Dissociative effects of alcohol on recollective experience. Consciousness and Cognition, 8(4), 497-509. doi: 1053-8100/99

Department of Justice [DOJ], Office of Justice Programs, Bureau of Justice Statistics. (1998). An analysis of national data on the prevalence of alcohol involvement in crime (NCJ Publication No. 168632). Retrieved from http//www.ojp.usdoj.gov/bjs/ 
Department of Transportation [DOT]. (2012). Conforming Products List of Alcohol Screening Devices. Federal Register, 77(115). (DOT Publication No. 35747). Washington, DC: DOT.

Dougherty, D. M., Marsh, D. M., Moeller, F. G., Chokshi, R. V., \& Rosen, V. C. (2000). Effects of moderate and high doses of alcohol on attention, impulsivity, discriminability, and response bias in immediate and delayed memory task performance. Alcoholism: Clinical and Experimental Research, 24(11), 17021711. doi: 10.1111/j.1530-0277.2000.tb01972.x

Dysart, J. E., \& Lindsay, R. C. L. (2007). Show-up identifications: Suggestive technique or reliable method? In Lindsay, R. C. L., Ross, D. F., Read, J. D., \& Toglia, M. P. (Ed.). The handbook of eyewitness psychology (Vol 2): Memory for people (Chapter 12, pp. 137-153). Mahwah, NJ: Lawrence Erlbaum Associates

Dysart, J. E., Lindsay, R. C. L., MacDonald, T. K., \& Wicke, C. (2002). The intoxicated witness: Effects of alcohol on identification accuracy from showups. Journal of Applied Psychology, 87(1), 170-175. doi: 10.1037/0021-9010.87.1.170

Evans, J. R., \& Schreiber Compo, N. (2010). Mock jurors' perceptions of identifications made by intoxicated eyewitnesses. Psychology, Crime and Law, 16(3), 191-210. doi: $10.1080 / 10683160802612890$

Evans, J. R., Schreiber Compo, N., \& Russano, M. (2009). Intoxicated witnesses and suspects: Procedures and prevalence according to law enforcement. Psychology, Public Policy, and Law, 15(3), 194-221. doi: 10.1037/a0016837

Fife, D., Perry, C., \& Gronlund, S. D. (2014). Revisiting absolute and relative judgments in the WITNESS model. Psychonomic Bulletin \& Review, 21(2), 479-487. doi: /10.3758/s13423-013-0493-1

Fillmore, M. T., \& Vogel-Sprott, M. (2000). Response inhibition under alcohol: Effects of cognitive and motivational conflict. Journal of Studies on Alcohol, 61(2), 239246. doi: $10.15288 /$ jsa.2000.61.239

Fillmore, M. T., Vogel-Sprott, M., \& Gavrilescu, D. (1999). Alcohol effects on intentional behavior: Dissociating controlled and automatic influences. Experimental and Clinical Psychopharmacology, 7(4), 372-378. doi: 10.1037/1064-1297.7.4.372

Flowe, H. D., Colloff, M. F., Karoğlu, N., Zelek, K., Ryder, H., Humphries, J. E., \& Takarangi, M. K. T. (2017). The effects of alcohol intoxication on accuracy and the confidence-accuracy relationship in photographic simultaneous line-ups. Applied Cognitive Psychology, 31(4), 379-391. doi: 10.1002/acp.3332

Flowe, H. D., Takarangi, M. K. T., Humphries, J. E., \& Wright, D. S. (2015). Alcohol and remembering a hypothetical sexual assault: Can people who were under the influence of alcohol during the event provide accurate testimony? Memory, 24(8), 1042-1061. doi: 10.1080/09658211.2015.1064536 
Garfinkel, S. N., Dienes, Z., \& Duka, T. (2006). The effect of alcohol and repetition at encoding on implicit and explicit false memories. Psychopharmacology, 188(4), 498-508. doi: 10.1007/s00213-006-0480-6

George, S., Rogers, R. D., \& Duka, T. (2005). The acute effect of alcohol on decision making in social drinkers. Psychopharmacology, 182(1), 160-169. doi: 10.1037/t00696-000

Goodwin, D. W., Powell, B., Bremer, D., Hoine, H., \& Stern, J. (1969). Alcohol and recall: State-dependent effects in man. Science, 163(3873), 1358-1360. doi: 10.1126/science.163.3873.1358

Greenberg, D. L., \& Verfaellie, M. (2010). Interdependence of episodic and semantic memory: Evidence from neuropsychology. Journal of the International Neuropsychological Society, 16(5), 748-753. doi: /10.1017/S1355617710000676

Hagsand, A., Roos af Hjelmsäter, E, Granhag, P., Fahlke, C., \& Söderpalm Gordh, A. (2013a). Bottled memories: On how alcohol affects eyewitness recall. Scandinavian Journal of Psychology, 54(3), 188-195. doi: 10.1111/sjop.12035

Hagsand, A., Roos af Hjelmsäter, E., Granhag, P., Fahlke, C., \& Söderpalm Gordh, A. (2013b). Do sober eyewitnesses outperform alcohol intoxicated eyewitnesses in a lineup? The European Journal of Psychology Applied to Legal Context, 5(1), 2347. Retrieved from www.usc.es/sepjf

Hagsand, A., Roos af Hjelmsäter, E., Granhag, P. A., Fahlke, C., \& Söderpalm Gordh, A. (2017). Witnesses stumbling down memory lane: The effects of alcohol intoxication, retention interval, and repeated interviewing. Memory, 25, 531-543. doi: 10.1080/09658211.2016.1191652

Harrison, E. L. R., \& Fillmore, M. T. (2005). Are bad drivers more impaired by alcohol? Sober driving precision predicts impairment from alcohol in a simulated driving task. Accident Analysis and Prevention, 37(5), 882-889. doi: /10.1016/j.aap.2005.04.005

Harvey, A. J. (2014). Some effects of alcohol and eye movements on cross-race face learning. Memory, 22(8), 1126-1138. doi: 10.1080/09658211.2013.872278

Harvey, A. J., Kneller, W., \& Campbell, A. C. (2013a). The effects of alcohol intoxication on attention and memory for visual scenes. Memory, 21(8), 969-980. doi: 10.1080/09658211.2013.770033

Harvey, A. J., Kneller, W., \& Campbell, A. C. (2013b). The elusive effects of alcohol intoxication on visual attention and eyewitness memory. Applied Cognitive Psychology, 27(5), 617. doi: 10.1002/acp.2940

Hildebrand Karlén, M., Roos-af-Hjelmsäter, E., Fahlke, C., Granhag, P. A., \& Söderpalm Gordh, A. (2015). Alcohol intoxicated eyewitnesses' memory of intimate partner violence. Psychology, Crime \& Law, 21(2), 156-171. doi:

10.1080/1068316X.2014.951644 
Hildebrand Karlén, M., Roos-af-Hjelmsäter, E., Fahlke, C., Granhag, P. A., \& Söderpalm Gordh, A. (2017). To wait or not to wait? Improving results when interviewing intoxicated witnesses to violence. Scandinavian Journal of Psychology, 58(1), 1522. doi: $10.1111 /$ sjop. 12345

Hilliar, K. F., Kemp, R. I., \& Denson, T. F. (2010). Now everyone looks the same: Alcohol intoxication reduces the own-race bias in face recognition. Law and Human Behavior, 34(5), 367-378. doi: 10.1007/s10979-009-9204-X

Jarosz, A. F., Colflesh, G. J. H., \& Wiley, J. (2012). Uncorking the muse: Alcohol intoxication facilitates creative problem solving. Consciousness and Cognition: An International Journal, 21(1), 487-493. doi: 10.1016/j.concog.2012.01.002

Josephs, R. A., \& Steele, C. M. (1990). The two faces of alcohol myopia: Attentional mediation of psychological stress. Journal of Abnormal Psychology, 99(2), 115126. doi: 10.1037/0021-843X.99.2.115

Kassel, J. D., Wardle, M. C., Heinz, A. J., \& Greenstein, J. E. (2010). Cognitive theories of drug effects on emotion. In J. D. Kassel (Ed.). Substance abuse and emotion (Chapter 12, pp. 61-82). Washington, DC: American Psychological Association

Kassin, S. (2004). Psychology (4th ed.). Auckland, New Zealand: Pearson Education

Kassin, S. M., Tubb, V. A., Hosch, H. M., \& Memon, A. (2001). On the "general acceptance" of eyewitness testimony research: A new survey of the experts. American Psychologist, 56(5), 405-416. doi: 10.1037/0003066X.56.5.405

KHN Solutions (2016). Breathalyzer.net: The trusted source for personal and professional alcohol breathalyzers. Retrieved from www.breathalyzer.net/

Kneller, W., \& Harvey, A. J. (2015). Lineup identification accuracy: The effects of alcohol, target presence, confidence ratings, and response time. The European Journal of Psychology Applied to Legal Context, 8(1), 11-18. doi: 10.1016/j.ejpal.2015.09.001

Lane, S. M., \& Meissner, C. A. (2008). A 'middle road' approach to bridging the basicapplied divide in eyewitness identification research. Applied Cognitive Psychology, 22(6), 779-787. doi: /10.1002/acp.1482

La Rooy, D., Nicol, A., \& Terry, P. (2013). Intoxicated eyewitnesses: The effects of alcohol on eyewitness recall across repeated interviews. Open Journal of Medical Psychology, 2(3), 107-114. doi: 10.4236/ojmp.2013.23017

Laude, J. R., \& Fillmore, M. T. (2015). Simulated driving performance under alcohol: Effects on driver-risk versus driver-skill. Drug and Alcohol Dependence, 154, 271-277. doi: 10.1016/j.drugalcdep.2015.07.012 
Lee, H., Roh, S., \& Kim, D. J. (2009). Alcohol-induced blackout. International Journal of Environmental Research and Public Health, 6(11), 2783-2792. doi: 10.3390/ijerph6112783

Littleton, H., Grills-Taquechel, A., \& Axsom, D. (2009). Impaired and incapacitated rape victims: Assault characteristics and post-assault experiences. Violence and Victims, 24(4), 439-457. doi: 10.1891/0886-6708.24.4.439

Loftus, E. F. (2005). Planting misinformation in the human mind: A 30-year investigation of the malleability of memory. Learning \& Memory, 12(4), 361-366. doi: /10.1101/lm.94705

Lombardi, W. J., Sirocco, K. Y., Andreason, P. J., \& George, D. T. (1997). Effects of triazolam and ethanol on proactive interference: Evidence for an impairment in retrieval inhibition. Journal of Clinical and Experimental Neuropsychology, 19(5), 698-712. doi: 10.1080/01688639708403755

Marczinski, C. A., Harrison, E. L. R., \& Fillmore, M. T. (2008). Effects of alcohol on simulated driving and perceived driving impairment in binge drinkers.

Alcoholism: Clinical and Experimental Research, 32(7), 1329-1337. doi: 10.1111/j.1530-0277.2008.00701.x

Maylor, F. A., \& Rabbit, P. M. (1987). Effect of alcohol on rate of forgetting. Psychopharmacology, 91(2), 230-235. doi: 10.1007/BF00217069

Maylor, E. A., \& Rabbitt, P. M. (1993). Alcohol, reaction time and memory: A metaanalysis. British Journal of Psychology, 84(3), 301-317. doi: 10.1111/j.20448295.1993.tb02485.x

Mintzer, M. Z. (2007). The acute effects of alcohol on memory: A review of laboratory studies in healthy adults. International Journal on Disability and Human Development, 6(4), 397-403. doi: 10.1515/IJDHD.2007.6.4.397

Mohler-Kuo, M., Dowdall, G. W., Koss, M. P., \& Wechsler, H. (2004). Correlates of rape while intoxicated in a national sample of college women. Journal of Studies on Alcohol, 65(1), 37-45. doi: 10.15288/jsa.2004.65.37

Molinaro, P. F., Arndorfer, A., \& Charman, S. D. (2013). Appearance-change instruction effects on eyewitness lineup identification accuracy are not moderated by amount of appearance change. Law and Human Behavior, 37(6), 432-440. doi:/10.1037/lhb0000049

Molnár, M., Boha, R., Czigler, B., \& Gaál, Z. A. (2010). The acute effect of alcohol on various memory processes. Journal of Psychophysiology, 24(4), 249-252. doi: 10.1027/0269-8803/a000038

Morewedge, C. K., Krishnamurti, T., \& Ariely, D. (2014). Focused on fairness: Alcohol intoxication increases the costly rejection of inequitable rewards. Journal of Experimental Social Psychology, 50, 15-20. doi: 10.1016/j.jesp.2013.08.006 
Moulton, P. L., Petros, T. V., Apostal, K. J., Park, R.V., Ronning, E. A., King, B. M., \& Penland, J. G. (2005). Alcohol-induced impairment and enhancement of memory: A test of the interference theory. Physiology \& Behavior, 85(3), 240-245. doi: 10.1016/j.physbeh.2005.03.011

National Council on Alcoholism and Drug Defense [NCADD]. (April, 2016). Alcohol, Drugs, and Crime. Retrieved from: https://ncadd.org/about-addiction/alcoholdrugs-and-crime

National Institute of Health [NIH], National Institute on Drug Abuse, Maryland Collaborative to Reduce College Drinking and Related Problems. (2016). Sexual assault and alcohol: What the research evidence tells us. Retrieved from https://www.drugabuse.gov/sites/default/files/sexualassault.pdf

National Institute of Justice [NIJ], Police Executive Research Reform, Office of Justice Programs, U.S. Department of Justice. (2013). A national survey of eyewitness identification procedures in law enforcement agencies (NIJ Publication No. 2010IJ-CX0032). Retrieved from https://www.ncjrs.gov/pdffiles 1/nij/grants/242617.pdf

Nordby, K., Watten, R. G., Raanaas, R. K., \& Magnussen, S. (1999). Effects of moderate doses of alcohol on immediate recall of numbers: Some implications for information technology. Journal of Studies on Alcohol, 60(6), 873-878. doi: 10.15288/jsa.1999.60.873

Palmer, F. T., Flowe, H. D., Takarangi, M. K. T., \& Humphries, J. E. (2013). Intoxicated witnesses and suspects: An archival analysis of their involvement in criminal case processing. Law and Human Behavior, 37(1), 54-59. doi: 10.1037/lhb0000010

Parker, E. S., Birnbaum, I. M., \& Noble, E. P. (1976). Alcohol and memory: Storage and state dependency. Journal of Verbal Learning \& Verbal Behavior, 15(6), 691702. doi: 10.1016/0022-5371(76)90061-X

Perry, P. J., Argo, T. R., Barnett, M. J., Liesveld, J. L., Liskow, B., Hernan, J. M.,... Brabson, M. A. (2006). The association of alcohol-induced blackouts and grayouts to blood alcohol concentrations. Journal of Forensic Sciences, 51(4), 896-899. doi: 10.1111/j.1556-4029.2006.00161.x

Pryke, S., Lindsay, R. C. L., Dysart, J. E., \& Dupuis, P. (2004). Multiple independent identification decisions: A method of calibrating eyewitness identifications. Journal of Applied Psychology, 89(1), 73-84. doi: /10.1037/0021-9010.89.1.73

Rape, Abuse, and Incest National Network [RAINN]. (2016). Reporting Results. Retrieved from https://rainn.org/get-information/statistics/reporting-rates

Read, J. D., Yuille, J. C., \& Tollestrup, P. (1992). Recollections of a robbery: Effects of arousal and alcohol upon recall and person identification. Law and Human Behavior, 16(4), 425-446. doi: /10.1007/BF02352268 
Schreiber Compo, N., Carol, R. N., Evans, J. R., Pimentel, P., Holness, H., NicholsLopez, K., Rose, S., Furton, K. G. (2017). Witness memory and alcohol: The effects of state-dependent recall. Law and Human Behavior, 41(2), 202-215. doi:/10.1037//hb0000224

Schreiber Compo, N., Evans, J. R., Carol, R. N., Kemp, D., Villalba, D., Ham, L. S., \& Rose, S. (2011). Alcohol intoxication and memory for events: A snapshot of alcohol myopia in a real-world drinking scenario. Memory, 19(2), 202-210. doi: 10.1080/09658211.2010.546802

Schreiber Compo, N., Evans, J. R., Carol, R. N., Villalba, D., Ham, L. S., Garcia, T., \& Rose, S. (2012). Intoxicated eyewitnesses: Better than their reputation? Law and Human Behavior, 36(2), 77-86. doi: 10.1037/h0093951

Simons, D. J., \& Rensink, R. A. (2005). Change blindness: Past, present, and future. Trends in Cognitive Sciences, 9(1), 16-20. doi: /10.1016/j.tics.2004.11.006

Sjöberg, M.P. (2016) The show-up identification procedure: A literature review. Open Journal of Social Sciences, 4, 86-95. doi: 10.4236/jss.2016.41012

Smith, A. M., Bertrand, M., Lindsay, R. C. L., Kalmet, N., Grossman, D., \& Provenzano, D. (2014). The impact of multiple show-ups on eyewitness decision-making and innocence risk. Journal of Experimental Psychology: Applied, 20(3), 247-259. doi: 10.1037/xap0000018

Smith, E. E., \& Kosslyn, S. M. (2007). Cognitive psychology: Mind and brain. Upper Saddle River, N.J: Pearson/Prentice Hall.

Söderlund, H., Parker, E. S., Schwartz, B. L., \& Tulving, E. (2005). Memory encoding and retrieval on the ascending and descending limbs of the blood alcohol concentration curve. Psychopharmacology, 182(2), 305-317. doi: 10.1007/s00213-005-0096-2

Soutschek, A., Strobach, T., \& Schubert, T. (2013). Working memory demands modulate cognitive control in the stroop paradigm. Psychological Research, 77(3), 333-347. doi: 10.1007/s00426-012-0429-9

Steblay, N., Dysart, J., Fulero, S., \& Lindsay, R.C.L. (2003). Eyewitness accuracy rates in police showup and lineup presentations: A meta-analytic comparison. Law and Human Behavior, 27(5), 523-40. doi: 10.1023/A:1025438223608

Steblay, N., Wells, G. L., \& Douglass, A. B. (2014). The eyewitness post identification feedback effect 15 years later: Theoretical and policy implications. Psychology, Public Policy, and Law, 20(1), 1-18. doi: 10.1037/law0000001

Steele, C. M., \& Josephs, R. A. (1990). Alcohol myopia: Its prized and dangerous effects. American Psychologist, 45(8), 921-933. doi: 10.1037/0003-066X.45.8.921

Technical Working Group: Eyewitness Evidence (1999). Eyewitness evidence: A guide for law enforcement. US Department of Justice, Office of Justice Programs, 
National Institute of Justice. NCJ 178240. Retrieved from:

https://www.ncjrs.gov/pdffiles 1/nij/178240.pdf

Testa, M., Hoffman, J. H., \& Livingston, J. A. (2010). Alcohol and sexual risk behaviors as mediators of the sexual victimization-revictimization relationship. Journal of Consulting and Clinical Psychology, 78(2), 249-259. doi: 10.1037/a0018914

Testa, M., \& Livingston, J. A. (2009). Alcohol consumption and women's vulnerability to sexual victimization: Can reducing women's drinking prevent rape? Substance Use \& Misuse, 44(9-10), 1349-1376. doi: 10.1080/10826080902961468

Tracy, J. I., \& Bates, M. E. (1999). The selective effects of alcohol on automatic and effortful memory processes. Neuropsychology, 13(2), 282-290. doi:10.1037/08944105.13.2.282

van Oorsouw, K., \& Merckelbach, H. (2012). The effects of alcohol on crime-related memories: A field study. Applied Cognitive Psychology, 26(1), 82-90. doi: /10.1002/acp.1799

van Oorsouw, K., Merckelbach, H., \& Smeets, T. (2015). Alcohol intoxication impairs memory and increases suggestibility for a mock crime: A field study. Applied Cognitive Psychology, 29(4), 493-501. doi: /10.1002/acp.3129

Weissenborn, R., \& Duka, T. (2000). State-dependent effects of alcohol on explicit memory: The role of semantic associations. Psychopharmacology, 149(1), 98106. doi: $10.1007 / \mathrm{s} 002139900349$

Wells, G. L. (2001). Police lineups: Data, theory, and policy. Psychology, Public Policy, and Law, 7(4), 791-801. doi:10.1037/10768971.7.4.791

Wells, G. L., \& Bradfield, A. L. (1998). "Good, you identified the suspect": Feedback to eyewitnesses distorts their reports of the witnessing experience. Journal of Applied Psychology, 83(3), 360-376. doi: /10.1037/0021-9010.83.3.360

Wells, G. L., \& Bradfield, A. L. (1999). Distortions in eyewitnesses' recollections: Can the postidentification-feedback effect be moderated? Psychological Science, 10(2), 138-144. doi:/10.1111/1467-9280.00121

Wells, G. L., \& Luus, C. E. (1990). The diagnosticity of a lineup should not be confused with the diagnostic value of nonlineup evidence. Journal of Applied Psychology, 75(5), 511-516. doi: /10.1037/0021-9010.75.5.511

Wells, G. L., \& Turtle, J.W. (1986). Eyewitness identification: The importance of lineup models. Psychological Bulletin, 99(3), 320-329. doi:10.1037/0033-2909.99.3.320

Wetherill, R. R., \& Fromme, K. (2016). Alcohol-induced blackouts: A review of recent clinical research with practical implications and recommendations for future studies. Alcoholism: Clinical and Experimental Research, 40(5), 922-935. doi: 10.1111/acer.13051 
White, A. M. (2003). What happened? alcohol, memory blackouts, and the brain. Alcohol Research \& Health, 27(2), 186-196. doi: 10.127/620454420

Wright, D. B., \& McDaid, A. T. (1996). Comparing system and estimator variables using data from real line-ups. Applied Cognitive Psychology, 10(2), 75- 84. doi: 10.1002/(SICI)1099-0720(199602)10:1_75::AIDACP3643.0.CO;2-E

Yuille, J. C., \& Tollestrup, P. A. (1990). Some effects of alcohol on eyewitness memory. Journal of Applied Psychology, 75(3), 268-273. doi: 10.1037/00219010.75.3.268

Zawacki, T. (2011). Effects of alcohol on women's risky sexual decision making during social interactions in the laboratory. Psychology of Women Quarterly, 35(1), 107118. doi: $10.1177 / 0361684310384106$ 
APPENDICES 
Appendix A

\section{Chronological List of Studies Examining the Effect of Alcohol in a Criminal Context}

$\underline{\text { Alcohol \& Eyewitness Memory }}$

1) Yuille \& Tollestrup (1990)

2) Dysart, Lindsay, MacDonald, \& Wicke (2002)

3) Schreiber-Compo, Evans, Carol, Kemp, Villalba, Ham, \& Rose (2011)

4) Schreiber-Compo, Evans, Carol, Villalba, Ham, Garcia, \& Rose (2012)

5) Hagsand, Roos af Hjelmsäter, Granhag, Fahlke, \& Söderpalm Gordh (2013a)

6) Hagsand, Roos af Hjelmsäter, Granhag, Fahlke, \& Söderpalm Gordh (2013b)

7) Harvey, Kneller, \& Campbell (2013a)

8) Harvey, Kneller, \& Campbell (2013b)

9) La Rooy, Nicol, \& Terry (2013)

10) Flowe, Takarangi, Humphries, \& Wright (2015)

11) Hildebrand Karlén, Roos af jelmsäter, Fahlke, Granhag, \& Söderpalm Gordh (2015)

12) Kneller \& Harvey (2015)

13) Crossland, Kneller, \& Wilcock (2016)

14) Hagsand, Roos af Hjelmsäter, Granhag, Fahlke, \& Söderpalm Gordh (2017)

15) Hildebrand Karlén, Roos af Hjelmsäter, Fahlke, Granhag, \& Söderpalm Gordh (2017)

16) Schreiber Compo, Carol, Evans, Pimentel, Holness, Nichols-Lopez, Rose, \& Furton (2017) 
17) Flowe, Colloff, Karoglu, Zelek, Ryder, Humphries, \& Takarangi (2017)

18) Altman, Schreiber Compo, McQuiston, Hagsand, \& Cervera (2018)

$\underline{\text { Alcohol \& Offender Memory }}$

1) Read, Yuille, \& Tollestrup (1992)

2) Van Oorsouw \& Merckelbach (2012)

3) Van Oorsouw, Merckelbach, \& Smeets (2015)

Note: There is considerable overlap between the eyewitness studies and the three studies examining offender memory (i.e., Read, Yuille, \& Tollestrup, 1992; van Oorsouw \& Merckelbach, 2012; van Oorsouw, Merckelbach, Smeets, 2015); however, the offender studies were excluded from the literature review because the differences were considered substantial. For example, Read et al. (1992) and van Oorsouw et al. (2015) had participants remember a complex procedure (locate a room, search a coat pocket, unlock drawers, look out for visitors, etc.) while subsequently encoding additional information about their surroundings. This altered cognitive load would disproportionality affect intoxicated participants given their limited cognitive resources and differ from participants in eyewitness studies who are often unburdened (mentally) during the stimulus/event presentation. Detailed instructions in the offender studies also provide a primary goal for participants to achieve. According to the AMT, alcohol lowers inhibition and causes people to seek out initial goals/desires without utilizing higher level cognitive processes to consider alternative things in the environment. These offender studies therefore focus participants' attention on one aspect of the situation (i.e., the robbery), an intense lure for those who are intoxicated, whereas most of the eyewitness studies allow the participant to determine where they would like to allocate attentional resources. For example, in Altman et al. (2018) participants watched a 2 minute video depicting a convenient store robbery. Throughout this event participants had to consistently determine whether they wanted to attend to the perpetrator, other characters, actions, etc. This seems like a subtle difference but given the importance of attention in the alcohol literature we feel it is an important distinguisher.

The procedure used in Van Oorsouw and Smeets' (2012) study more closely resembles an eyewitness experiment; however, the suspect view used in this video still focuses participants' attention toward specific items (i.e., the hands) instead of allowing them to determine where to devote attention. Again, since focus and attention allocation are major concerns in the alcohol- eyewitness literature it was determined that this difference was substantial enough to exclude it from the literature review. 
Overall, we did not believe the differences between offender and witness studies were worth noting in the literature review as they would distract from the other information provided. We believe the authors of the offender studies hold a similar opinion, which is why they distinguish their findings from the eyewitness findings. Reviews of the alcoholeyewitness literature (e.g., Altman et al. in press) have also made this distinction. Links between the offender studies and the present study are however made in the discussion section. 
Appendix B

\section{Objective and Subjective BAC Charts}

\section{Subjective Rating 1:}

"Please rate on a scale of 0 (meaning not at all) to 100 (meaning extremely) how drunk you currently feel:"

Not at all

0

$10 \quad 20$

$30 \quad 40$

50

$60 \quad 70$
Extremely 100

\section{First BAC Recording:}

\section{Subjective Rating 2:}

"Please rate on a scale of 0 (meaning not at all) to 100 (meaning extremely) how drunk you currently feel:"

Not at all

Extremely

$\begin{array}{lllllllllll}0 & 10 & 20 & 30 & 40 & 50 & 60 & 70 & 80 & 90 & 100\end{array}$

Second BAC Recording: 


\section{Appendix C}

\section{Staged Eyewitness Interaction}

\section{Cornhole Instructions}

I'm going to give you these 5 bean bags and have you stand at that line. When I say so, you are going to throw one bag at the board, any one you want. I am going to mark your score for that toss, take that bag off the board, and then tell you to throw another bag. Then I'll mark your score for that bag, take it off the board, and tell you to throw another. And so on and so forth until you have thrown all 5 bags.

For each of these pink bags you land on the board you will get 5 points. Every time you get a pink bag inside the hole you will get 10 points. The blue bag is worth double the points, so 10 on the board and 20 in the hole. The goal is to get as many points as possible, but don't worry about keeping track, I'll do that here.

Okay, lets get started. You get one practice round to throw all the bean bags and get used to the distance. After that I'm going to give you 3 rounds to earn points.

Participant is directed to the throwing line. Once everyone is in place, participant is told to throw the first bag [see Cornhole Scoring Sheet]

[If the participant asks for clarification/repetition tell them not to worry. They will get the hang of it as they proceed]

\section{Cornhole Scoring Sheet}

\begin{tabular}{|c|c|cc|cc|c|}
\hline Round & Toss & \multicolumn{2}{|c|}{ Pink } & \multicolumn{2}{|c|}{ Blue } & Praise/Script \\
\hline & 1 & 5 & 10 & 10 & 20 & "Okay, throw the first bag" \\
\cline { 2 - 8 } & 2 & 5 & 10 & 10 & 20 & "Okay, throw the second bag" \\
\cline { 2 - 8 } Practice Round & 3 & 5 & 10 & 10 & 20 & "Okay, throw the third bag" \\
\cline { 2 - 8 } & 4 & 5 & 10 & 10 & 20 & "Okay, throw the fourth bag" \\
\cline { 2 - 8 } & 5 & 5 & 10 & 10 & 20 & "Okay, throw the fifth bag" \\
\hline
\end{tabular}




\begin{tabular}{|c|c|c|c|c|c|c|}
\hline \multirow{5}{*}{2} & 6 & 5 & 10 & 10 & 20 & $\begin{array}{c}\text { "That was the practice round. } \\
\text { Now you get } 3 \text { scored } \\
\text { rounds." }\end{array}$ \\
\hline & 7 & 5 & 10 & 10 & 20 & \\
\hline & 8 & 5 & 10 & 10 & 20 & \\
\hline & 9 & 5 & 10 & 10 & 20 & \\
\hline & 10 & 5 & 10 & 10 & 20 & \\
\hline \multirow{5}{*}{3} & 11 & 5 & 10 & 10 & 20 & $\begin{array}{l}\text { "That was your first scored } \\
\text { round. Two more to go." }\end{array}$ \\
\hline & 12 & 5 & 10 & 10 & 20 & \\
\hline & 13 & 5 & 10 & 10 & 20 & $\begin{array}{c}\text { "Txt/call confederate to } \\
\text { come" }\end{array}$ \\
\hline & 14 & 5 & 10 & 10 & 20 & \\
\hline & 15 & 5 & 10 & 10 & 20 & \\
\hline \multirow{5}{*}{4} & 16 & 5 & 10 & 10 & 20 & $\begin{array}{c}\text { "Confederate enters after toss } \\
\text { 15. See next page." }\end{array}$ \\
\hline & 17 & 5 & 10 & 10 & 20 & \\
\hline & 18 & 5 & 10 & 10 & 20 & \\
\hline & 19 & 5 & 10 & 10 & 20 & \\
\hline & 20 & 5 & 10 & 10 & 20 & $\begin{array}{l}\text { Move on to } 2^{\text {nd }} B A C \\
\text { measurement. }\end{array}$ \\
\hline \multirow{5}{*}{ Totals } & $\begin{array}{c}\text { Practice } \\
\text { Round }\end{array}$ & & & & & \\
\hline & Round 2 & & & & & \\
\hline & Round 3 & & & & & \\
\hline & Round 4 & & & & & \\
\hline & $\begin{array}{l}\text { Overall } \\
\text { Score }\end{array}$ & & & & & \\
\hline
\end{tabular}

On Board/In Hole = Circle Correct \# Miss= Line Through Toss \& Points 


\title{
Appendix D
}

\section{Confederate Intrusion}

\author{
$\mathbf{R A}=$ Research Assistant $\quad$ Alex $=$ Confederate Intruder \\ [Confederate (Alex) enters the secondary bar holding a beer]
}

RA: Whoa, whoa, whoa.... you can't be back here right now.

Alex: Whoa, whoa, whoa.... Why not? This some sort of undercover Cornhole game or something?

RA: Ya, it kind of is [somewhat sarcastically]. We're conducting a research experiment right now.

[Alex sits down at the table]

Alex: Hmmm, interesting. I've been in research experiments before at school! Sign me up to play the winner. My names Alex, with an X.

[Alex starts playing with the breathalyzer]

RA: [In an assertive tone] Put that down, you can't play with that stuff!!

[Alex looks at the RA in surprise]

RA: [Still in an assertive tone] Listen girl, you're not grasping the point. We rented this room so we could have privacy. Do you need me to have the bar manager come escort you out?

[Alex stands up]

Alex: First, I'm not your girl. Second, you can go fuck yourself! I didn't drive 30 minutes to stand here and get yelled at!

RA: Okay, leave then.

Alex: What does it look like I'm doing. See, [grabbing chair] chairs empty [pushes chair over toward the researcher while turning and leaving]

RA: [to participant] Wow, I'm sorry about that. Lets finish up your last round and get you on to the next part of the study.

Return to $4^{\text {th }}$ round of the Cornhole game. 


\section{Appendix E}

\section{Eyewitness Interview}

The University gave us specific guidelines for documenting disturbances. I'm just going to read through each of these questions. Please answer them to the best of your ability.

1) In as much detail as possible, please tell me everything you can remember about what happened, starting from the time you entered the room where you played cornhole?

[Allow the participant an adequate amount of time to finish his/her story, do not cut him/her off or interrupt in any way]

2) Okay, is there anything else you can remember about what happened?

(once participant has exhausted their free narrative account move on to next section)

The questions below ask about things you might have already said. Just to make sure we have the complete story don't worry about repeating any information.

3) About how far away were you from the intruder?

4) On a scale from 0 (not good) to 10 (very good) how good a view did you have of the intruder?

5) How tall was the intruder?

6) How much do you think the intruder weighed?

7) Please describe any distinct facial features the intruder had, if they had any?

8) Please describe what the intruder was wearing?

9) What did the intruder say, if anything?

10) What was the intruder drinking, if anything?

11) How long would you say the entire interaction with the intruder lasted?

12) Did the research assistant have any physical contact with the intruder, if so can you describe it?

13) Please tell me what else you remember about the setting, such as the walls or cornhole boards? 
Appendix F

Confederate's Target-Present Photo

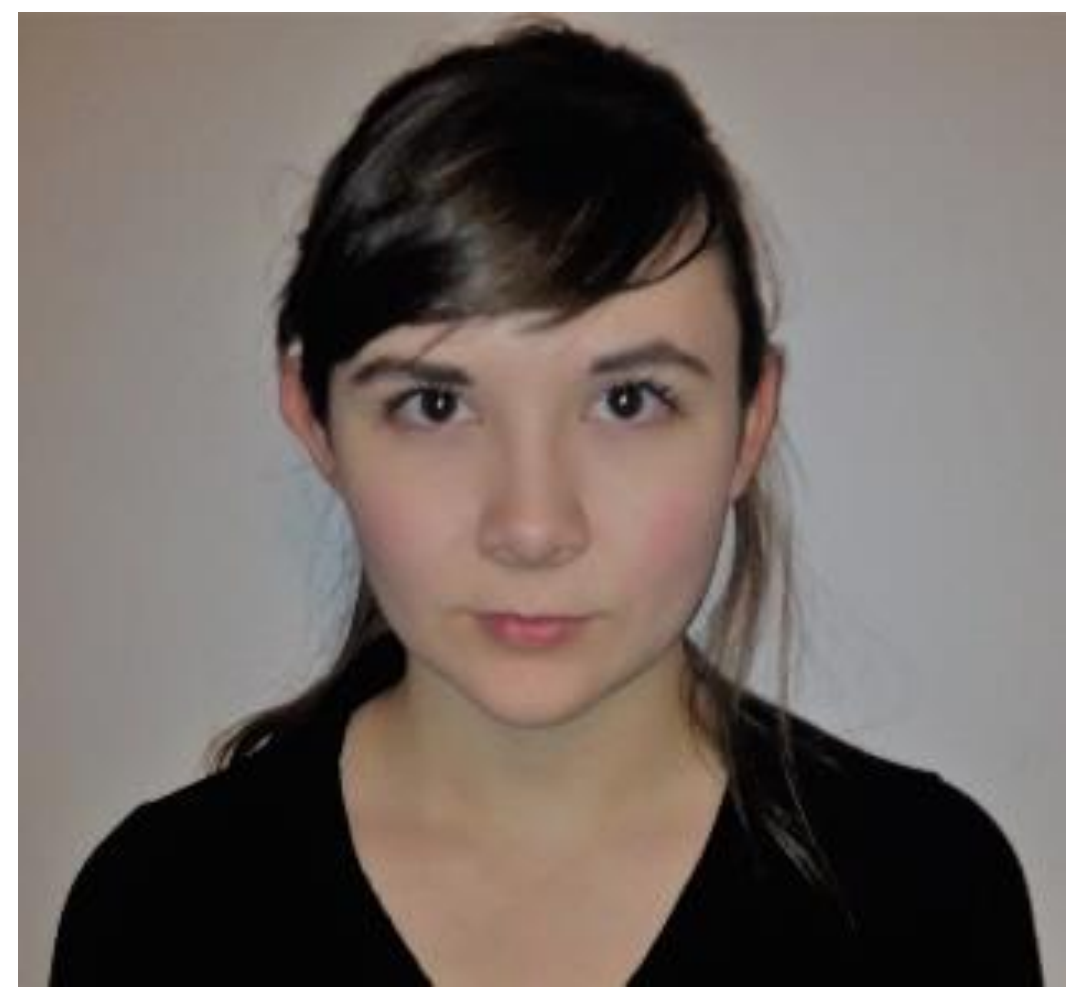


Appendix G

\section{Confederate's Initial Composite Description}

RA 1: White/Caucasian female (could be Hispanic) pale complexion, between 18 and 25 years old, petit/small frame, heart-shaped face, small and pointy chin, blushed cheeks, dark brown hair, thin lips, short and full brown eyebrows, dark brown eyes, hooded eyes (droopy eyes), one ear stands out more than the other, slightly protruding tip of nose, elongated nose bridge, medium sized ears (flushed/rosy), no earrings, bangs combed to the side, messy pony tail, natural make-up, long eyelashes (mascara), neutral face expression, birthmark on left cheek, rosy lips, and black v-neck long sleeved shirt.

RA 2: The woman appears to be of Caucasian decent. She has medium length dark chocolate hair with side swept bangs. In the picture, she has hers straight and pulled back and some random pieces fallen out. This woman's eyes are dark chocolate accompanied with long lashes. She contains a structural jaw line with an oval-shaped face and pointed chin. She has high, wide cheekbones and rosy cheeks. Her eye browns are thick and pointed up towards the middle of the brow. Her mouth appears to be small and narrow from her slight smirk, and her top lip seems thinner than her bottom lip. Lastly, she has a straight, flat and slightly wide nose.

RA 3: She looks like a young girl, 20-25. She is White/Caucasian, pretty pale. Probably American but could be Hispanic. She has dark hair, dark bron maybe black. Her hair is straight and pulled back in a ponytail with a few pieces sticking out. Her side swooped bangs are a very defining feature. Her eyebrows match her hair color. Looks like she has brown eyes that are kind of big. Her face is thin at the bottom but kind of wide at the top because she has chubby cheeks. She has pretty thin lips. Other than that she doesn't have many defining features (makeup, scars, pimples). Looks kind of skinny in the photo.

Initial Composite Description: White/Caucasian female with a pale complexion, could possibly be Hispanic. Looks to be between 20-25 years old and has a small/petite build. Her face is round at the top (chubby cheeks) and thinner at the bottom (pointier chin). She has long-straight dark brown-blackish hair that is pulled into a pony tail in the back and her bangs are combed to the side. She has brown eyes, brown eyebrows, and thin lips. 
Appendix $\mathrm{H}$

\section{Potential Fillers}
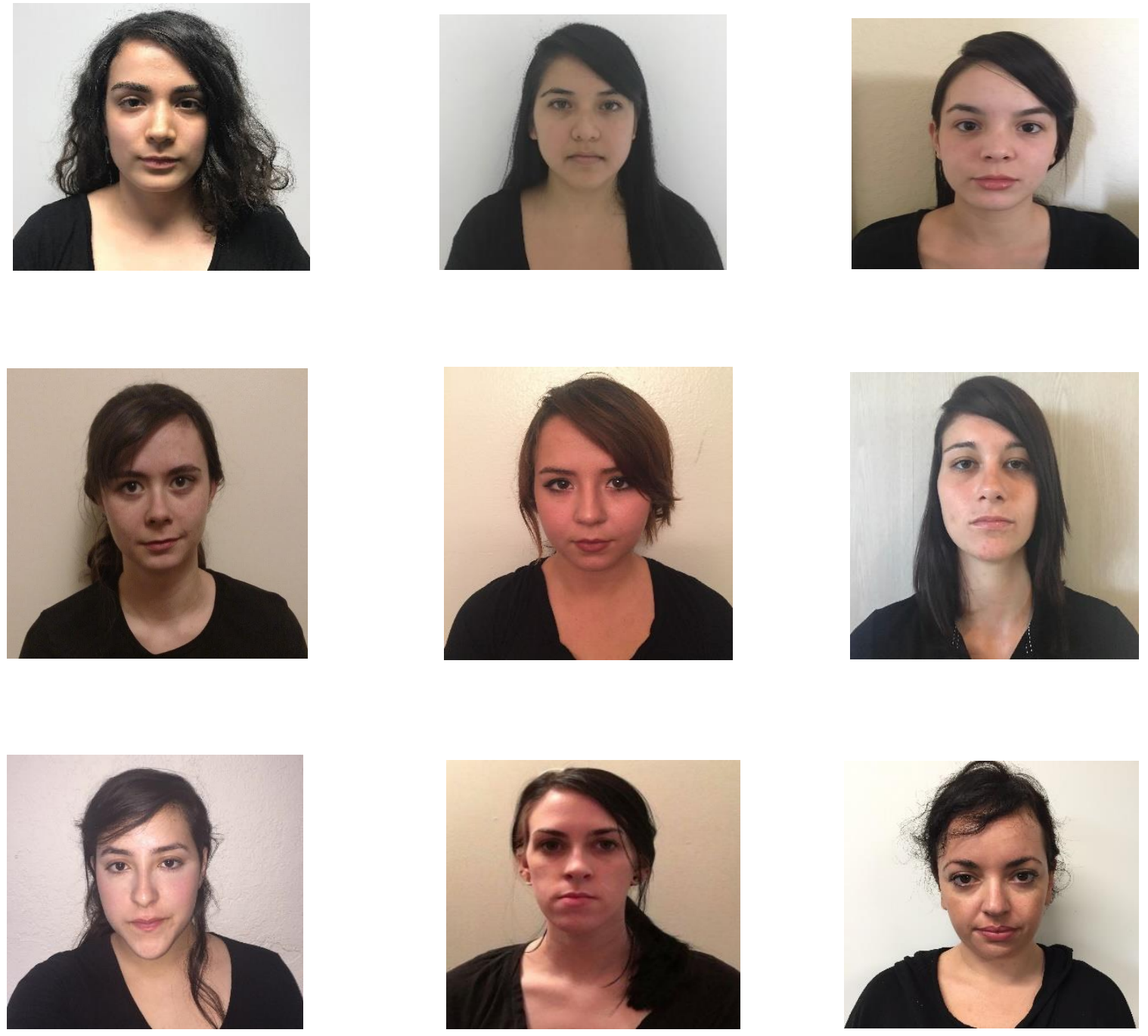
Appendix I

\section{Confederate's Final Composite Description}

Student 1- Causation, American, height about 5,4, 124 pounds, average build, long brown hair straight at the top wavy toward the bottom with side bangs, brown color eyes, pal skin tone

Student 2- The person that I just witnessed in a video was a white female, around 130$145 \mathrm{lbs}$, probably between $\mathbf{5} \mathbf{f t} \mathbf{2}$ inch - 5ft $\mathbf{6}$ inches tall but definitely not a "tall woman" or above $5 \mathrm{ft} 6$ inches. long dark brown/black hair with bangs combed to the side, she had a side pony tale. She looked like she could have been between 19-27 years old, chubby/full face (very youthful), thicker physique but not heavy/over weight and had rosy cheeks.

Student 3- White, Caucasian, about 5'6, dark brown hair with bangs, petite build, about 120 pounds, low to mid-20s

Student 4- White, about 20- 25 years old, 5'7, 150 lbs, dark brown hair, brown eyes, medium build

Student 5- The female seemed to be of average height and a medium build (arms maybe a little toned). She seemed to be skinny, but since she had on a flowly shirt she could potentially be chubby. Somewhere around $\mathbf{1 2 5}$ lbs. Her looks to be Caucasian. She had light brown, long straight hair with side swept bangs. Her brown eyes seemed to be squinty; small. She had chubby cheeks and a round face. Her lips were thin. Small nose.

Student 6- The girl was white/Caucasian. She average height for a girl, like 5' 2" or 5' 4". She wasn't a big girl judging by her arms, but it was hard to tell because she had a fuller/round face. If I had to guess I would say she was about 120 pounds, no more than 135 pounds, so like a medium build. She had dark brown/black hair that was straight and her bangs were swooped down in front of her face, I can't remember which way. Didn't look like she had any distinct facial features (scars/pimples) on her face but it was hard to tell. She looked like your typical American girl, kinda skinny.

Final Composite Description: White/Caucasian female in her early-mid 20s (20-25 years old). Stands about 5 foot 4 inches tall and weighs between 120 and 130 pounds. She has long dark brown hair that is straight with her bangs swooped to the side. She has a fuller face with 'chubby' cheeks and brown eyes. Her build has been described as average/petite. 
Appendix $\mathbf{J}$

\section{Similarity Ratings}

Means and standard deviations for how similair each photo was to the final confederate description given on a 0 (not at all) to 10 (perfect match) scale. Photo A depicts the confederate followed by the fillers from the highest to the lowest rated.

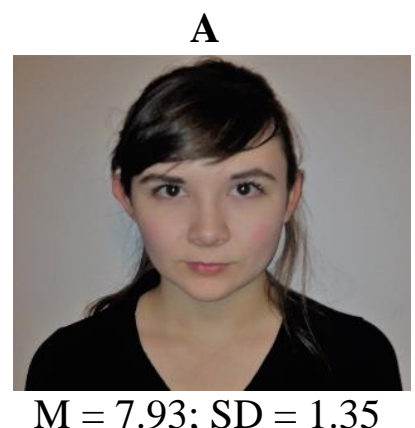

D

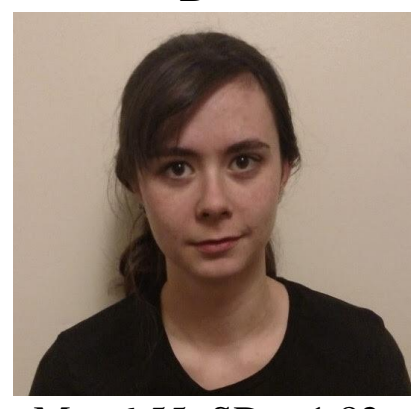

$\mathrm{M}=6.55 ; \mathrm{SD}=1.82$

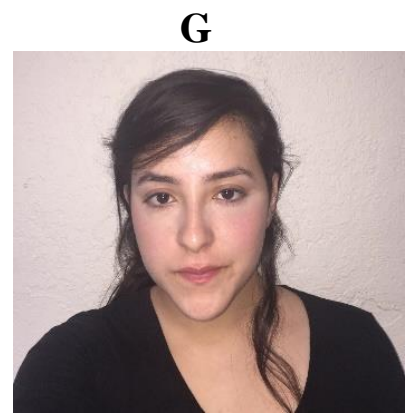

$\mathrm{M}=5.48 ; \mathrm{SD}=2.08$
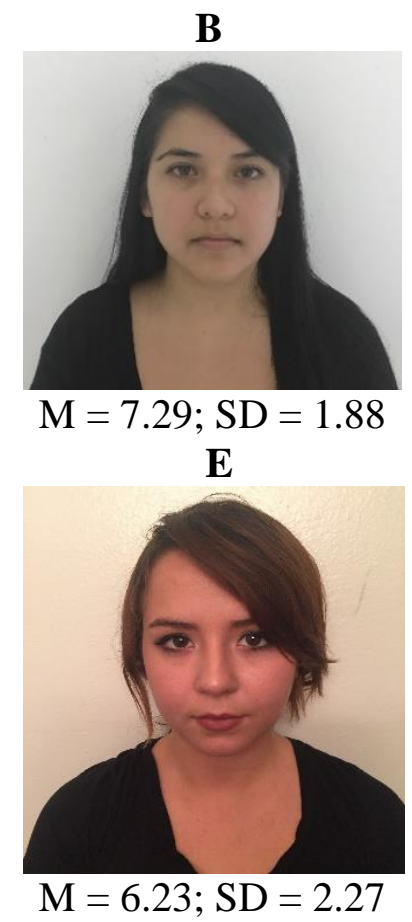

$\mathbf{H}$

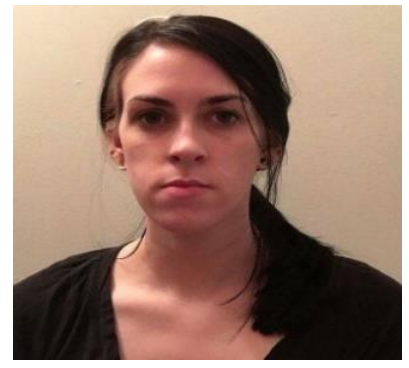

$\mathrm{M}=4.36 ; \mathrm{SD}=2.02$

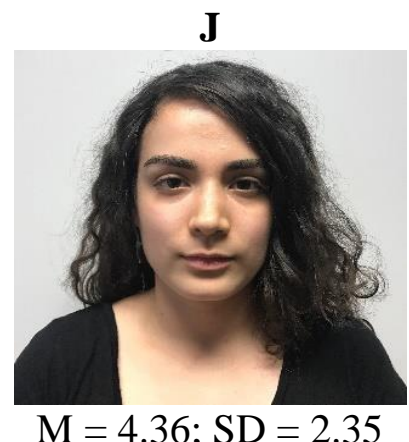

C

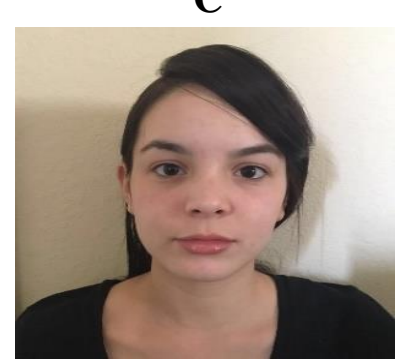

$\mathrm{M}=6.80 ; \mathrm{SD}=1.90$

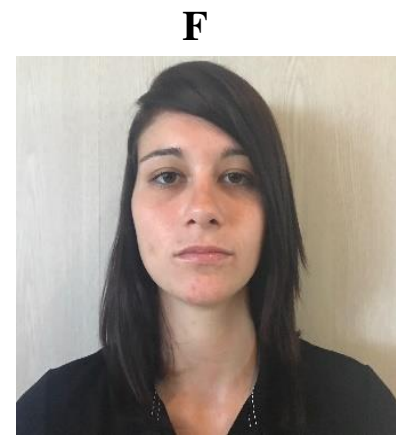

$\mathrm{M}=5.59 ; \mathrm{SD}=2.20$

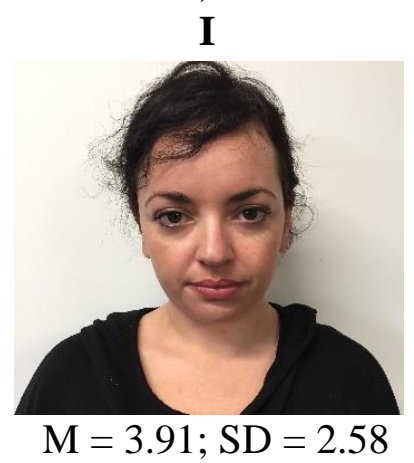


Appendix K

\section{Target-absent Showups}

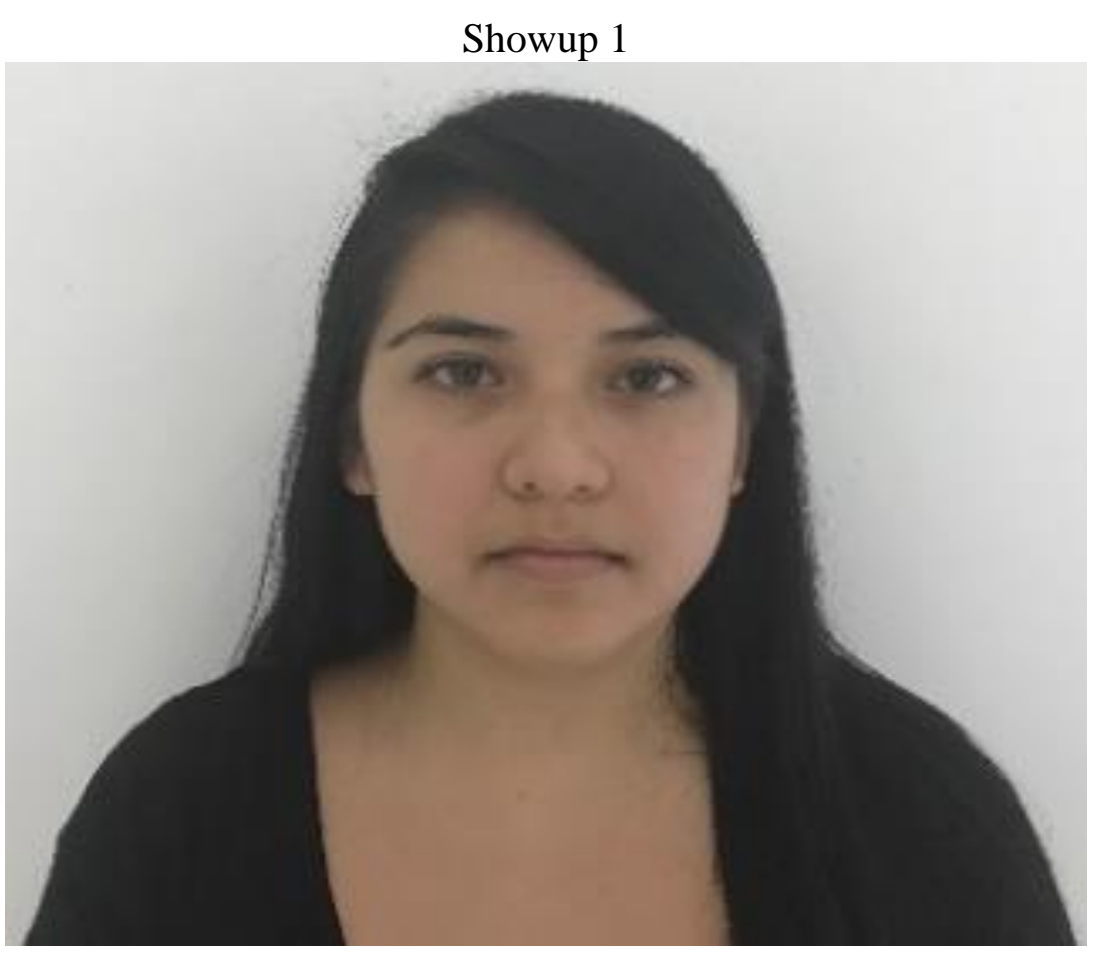

Showup 2

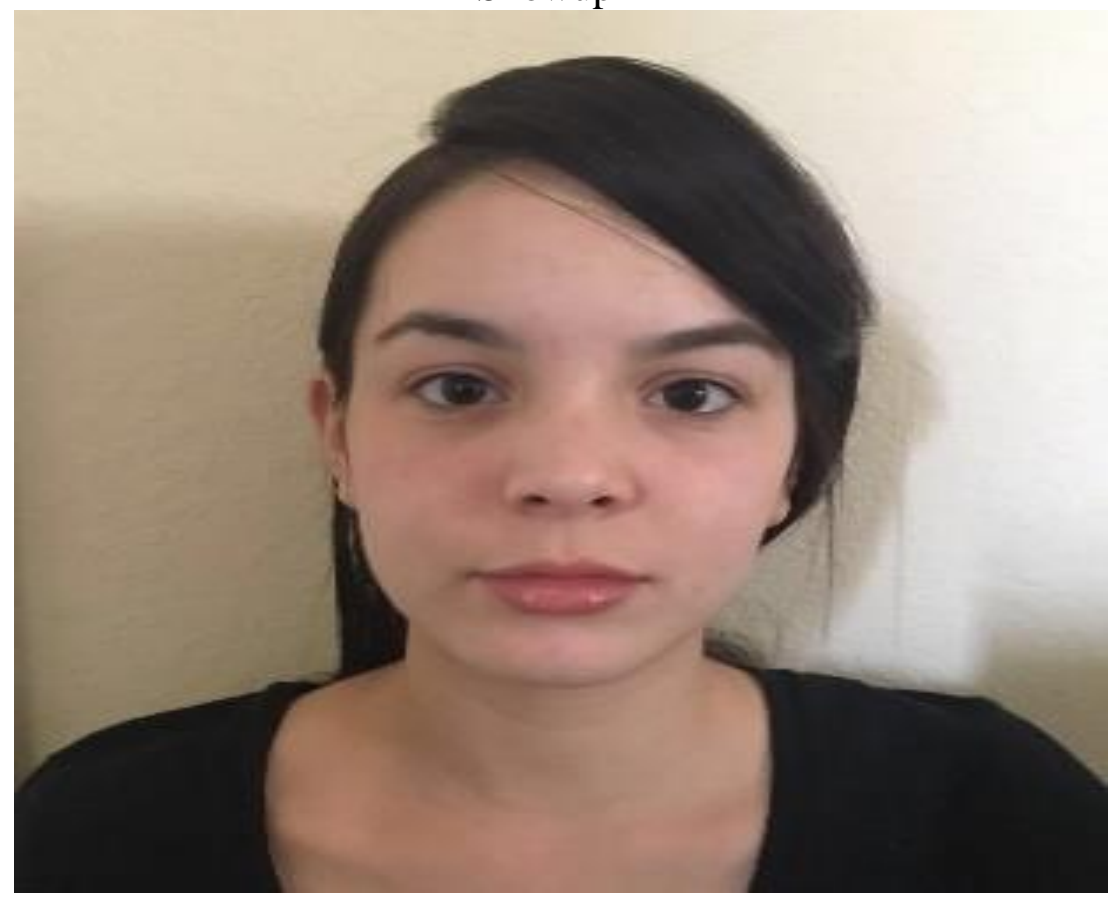


Showup 3

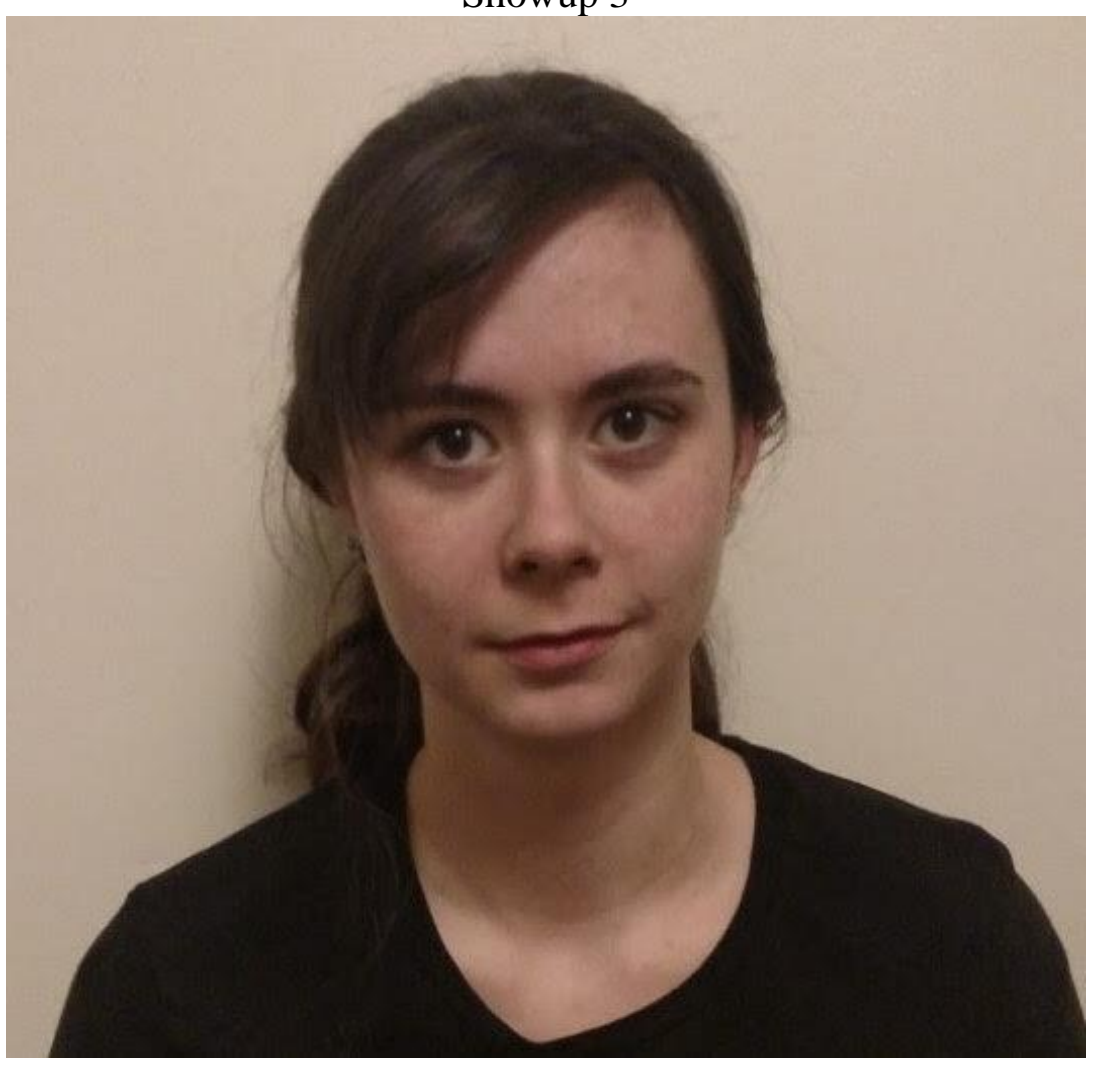

Showup 4

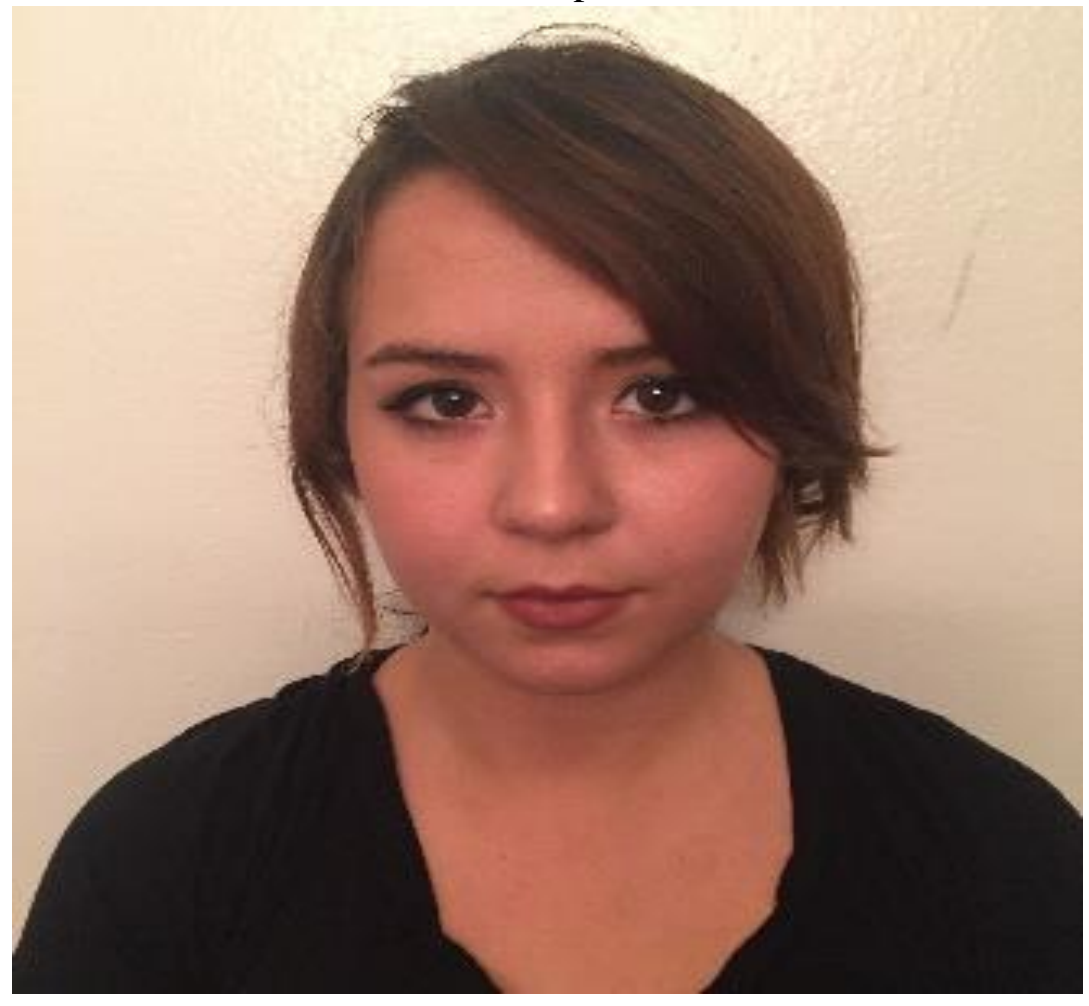




\section{Showup 5}

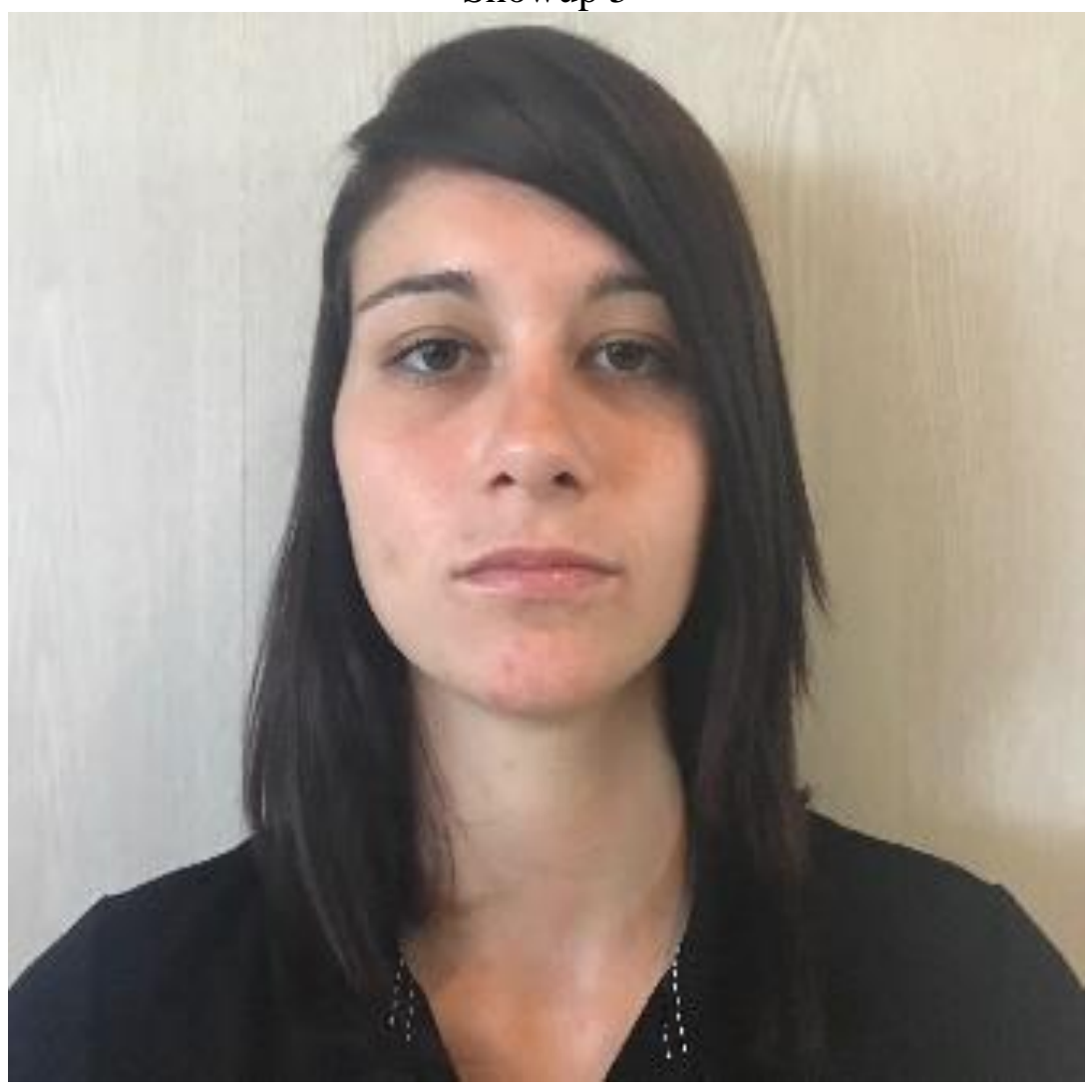

Showup 6

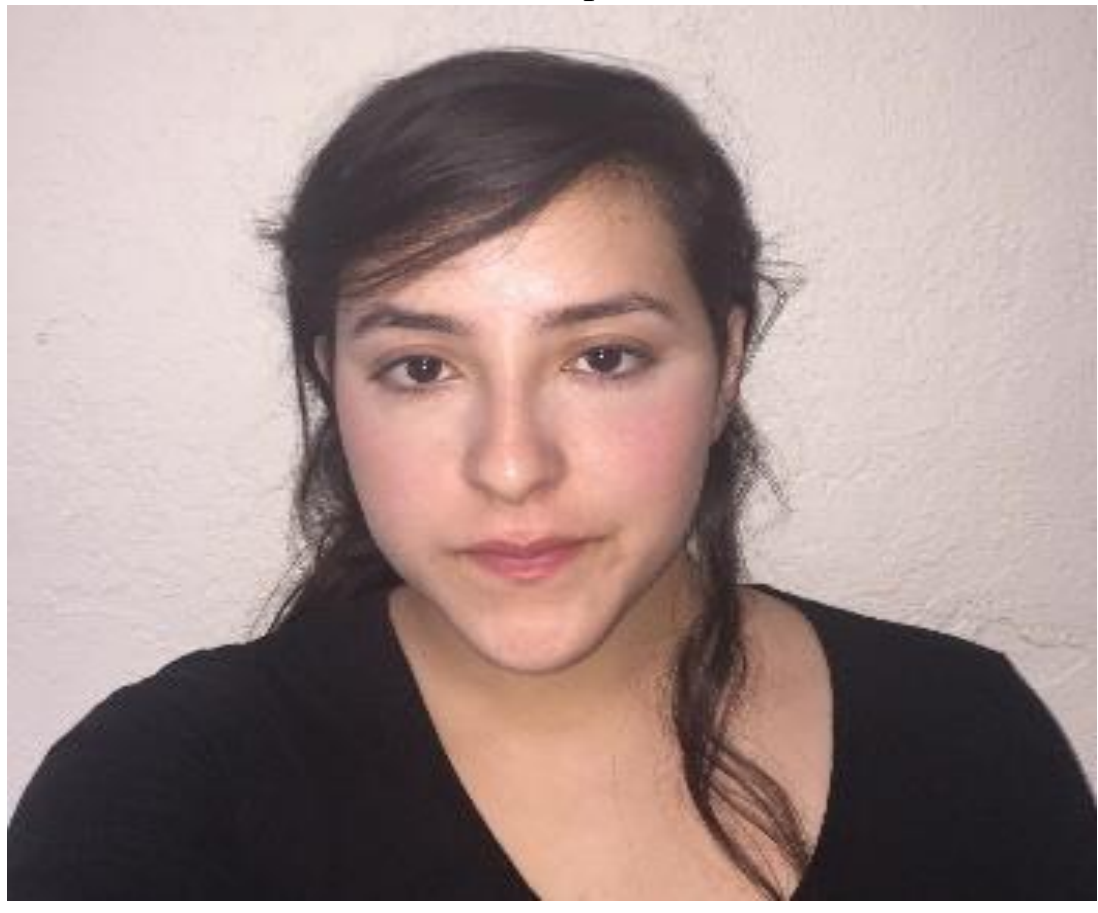


Appendix L

\section{Target-absent Lineup}

Note: Lineup photos were the same size as the photos used in the showup condition.
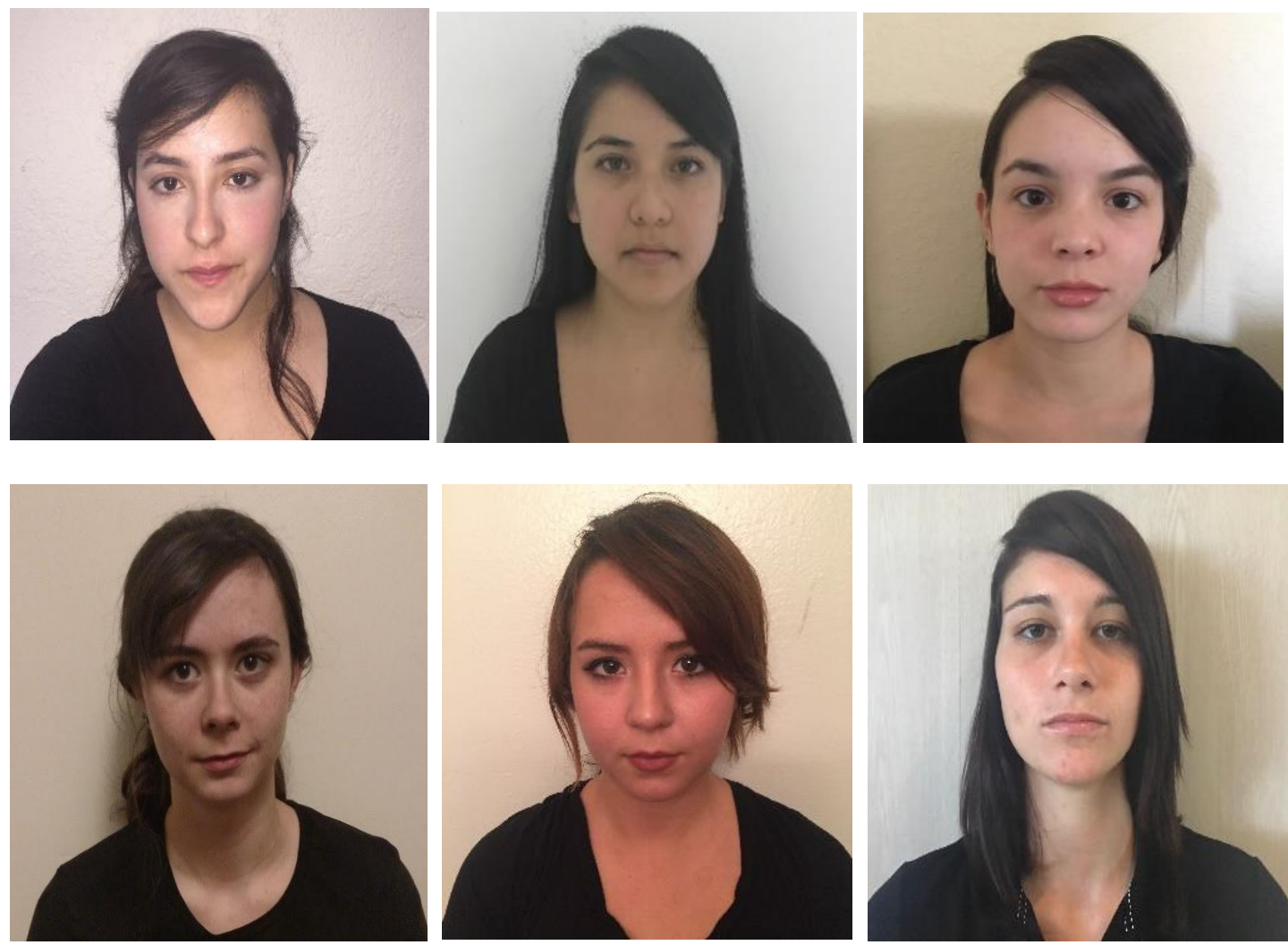
Appendix M

\section{Target-present Lineups}
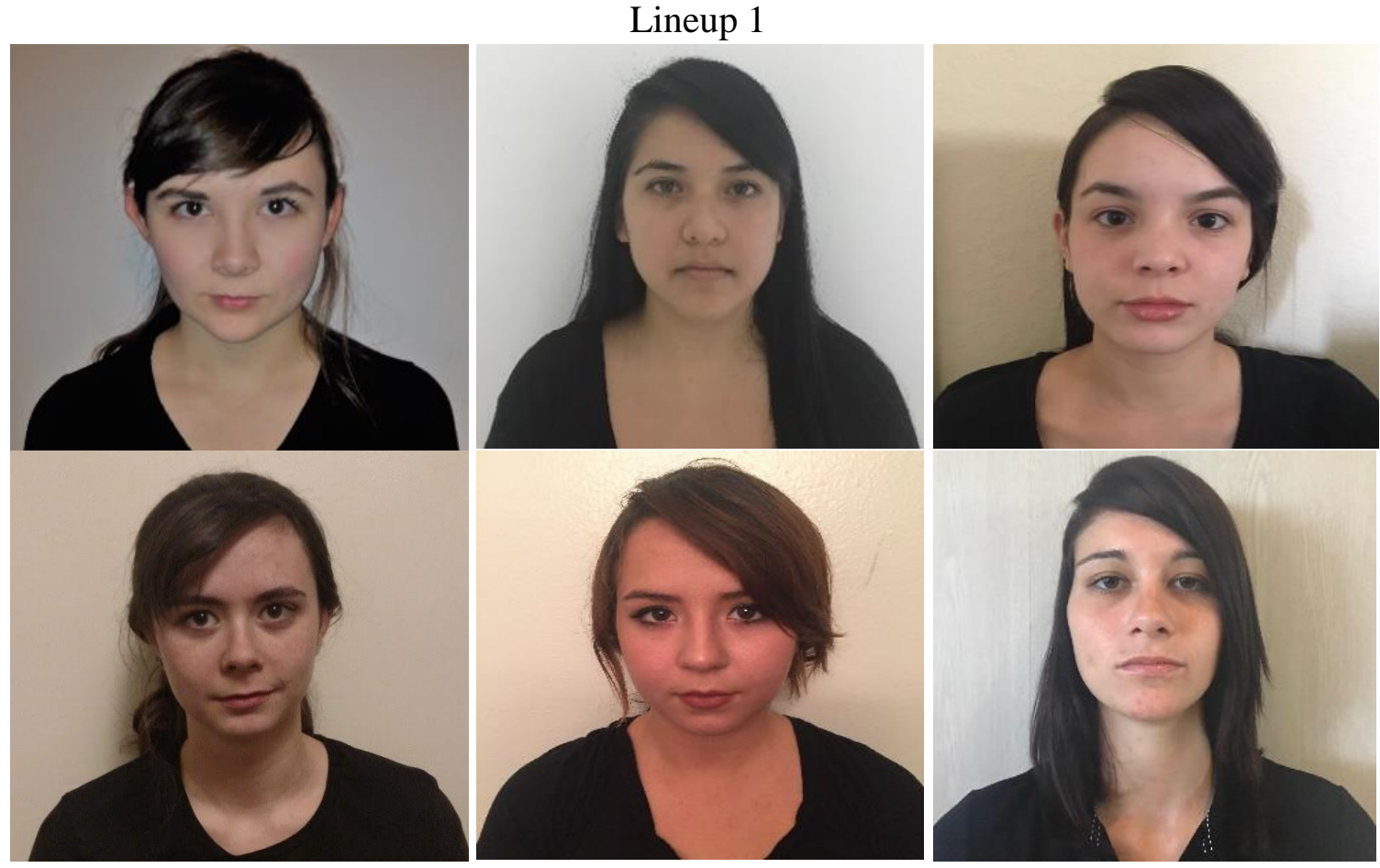

Lineup 2
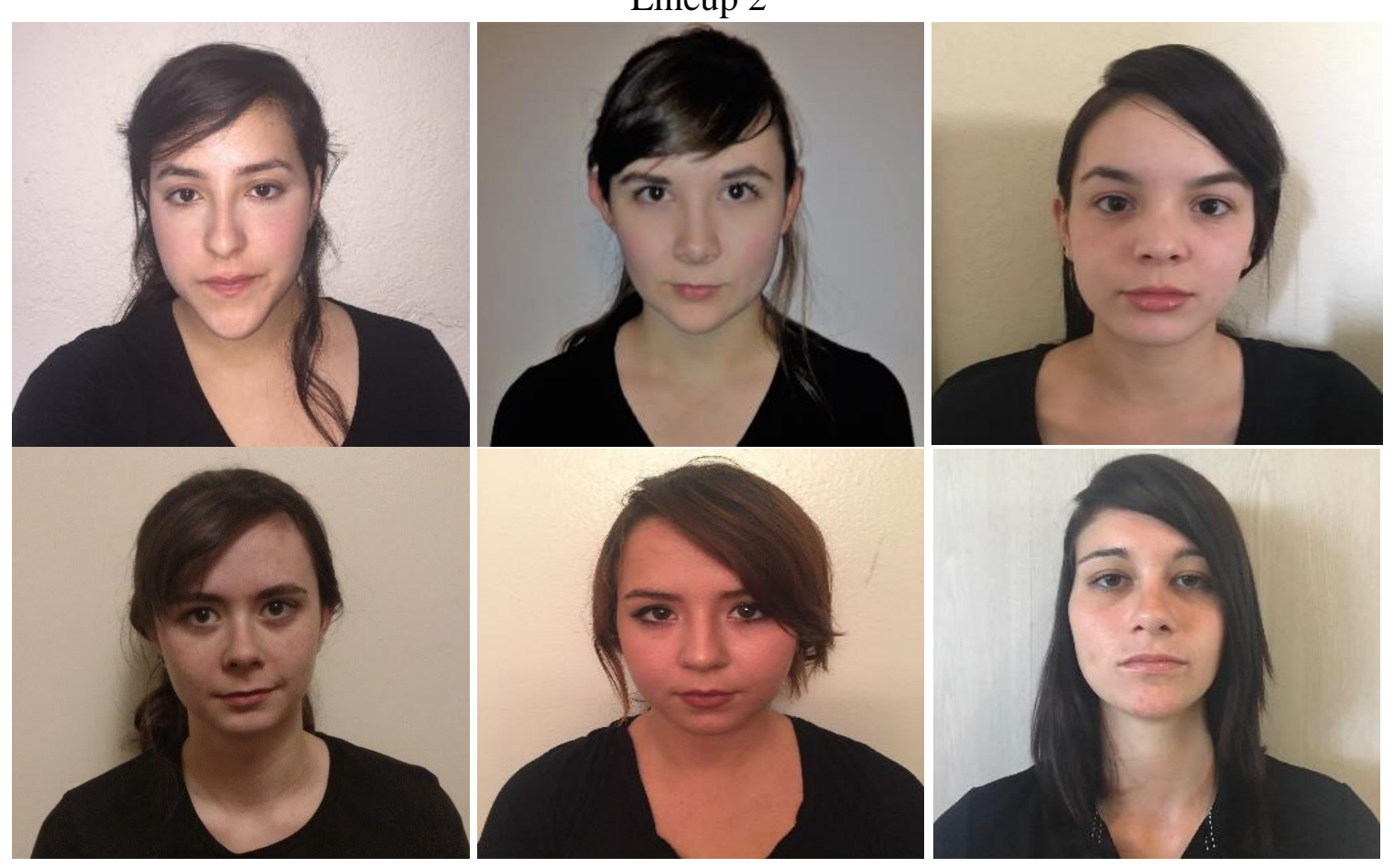
Lineup 3

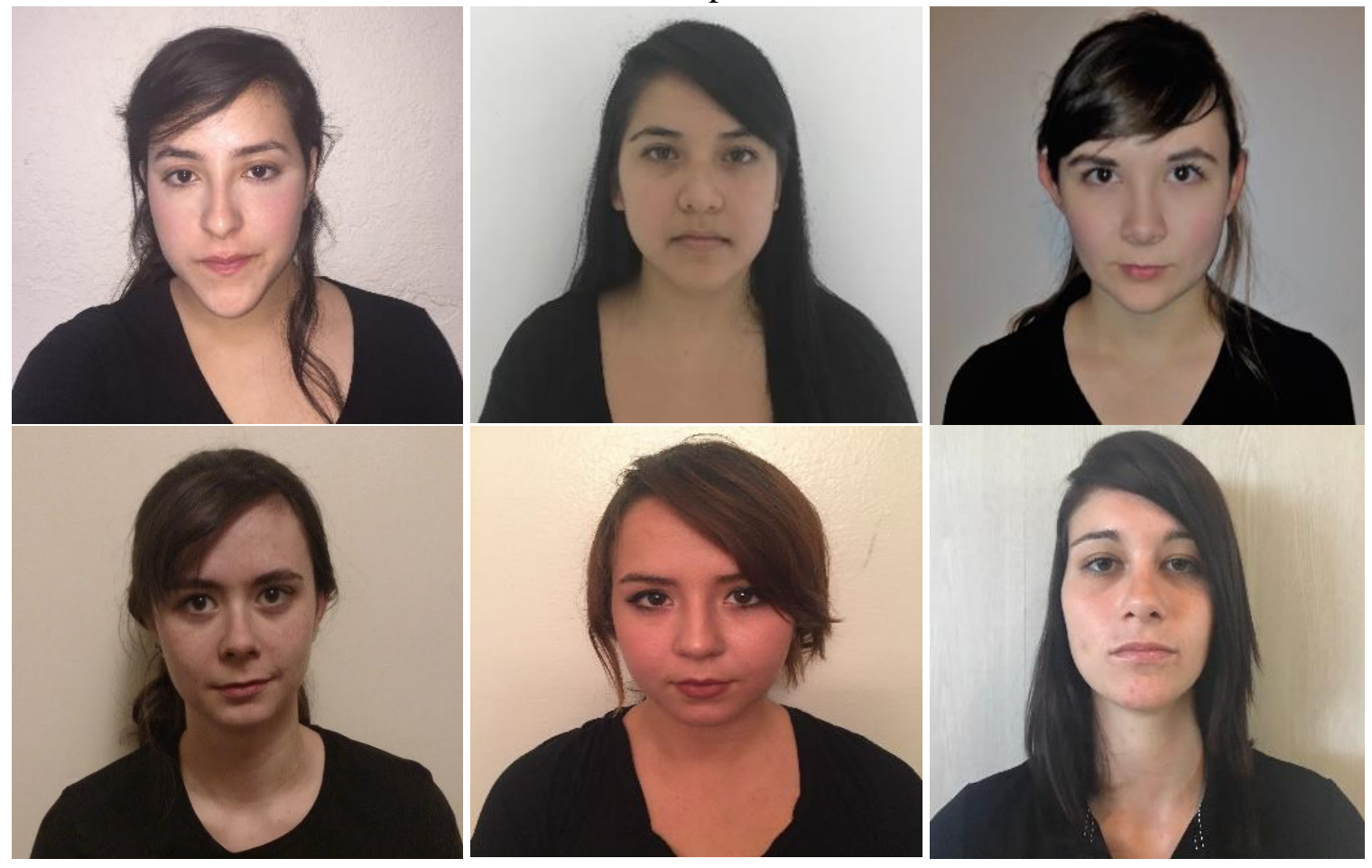

Lineup 4

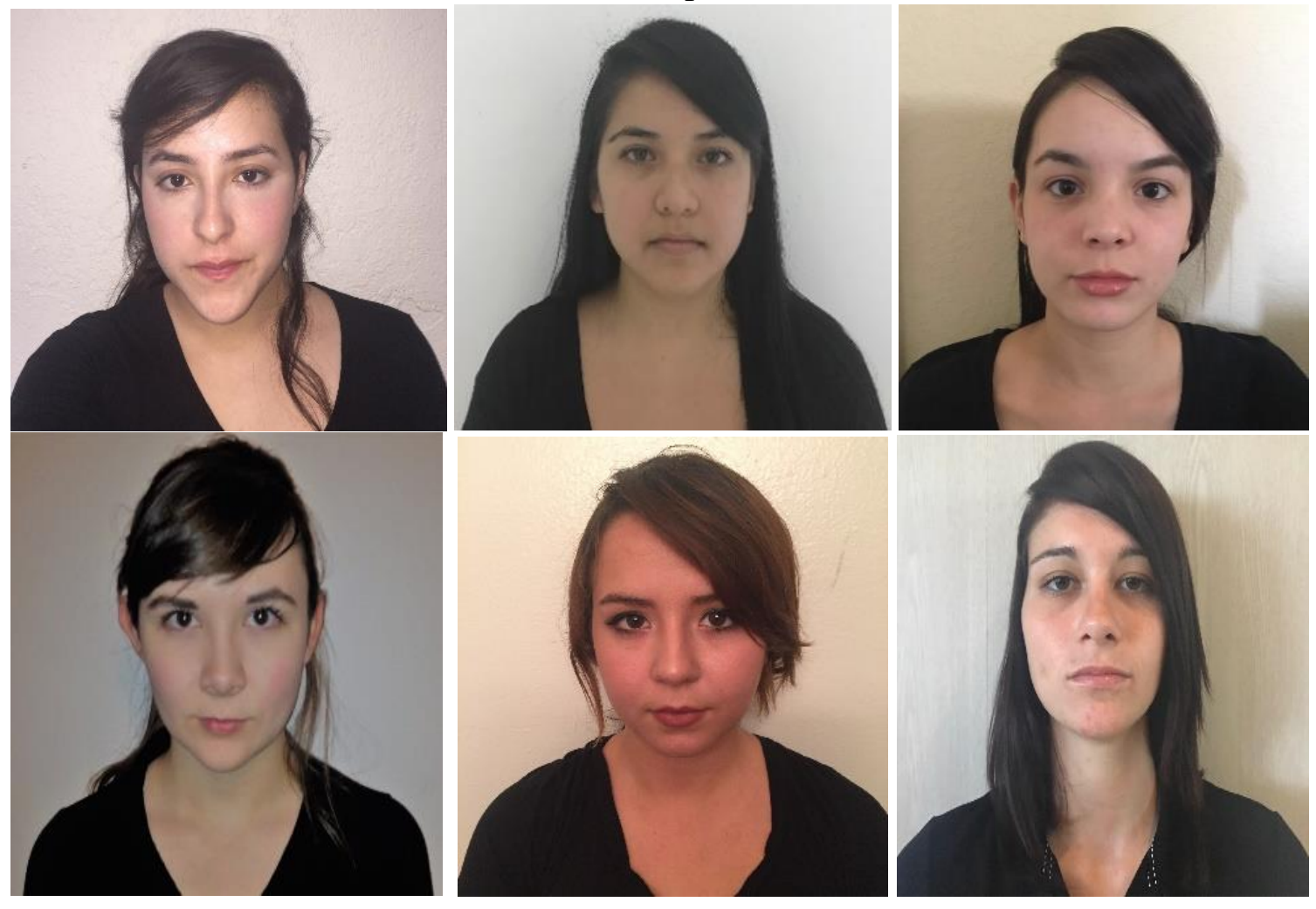


Lineup 5

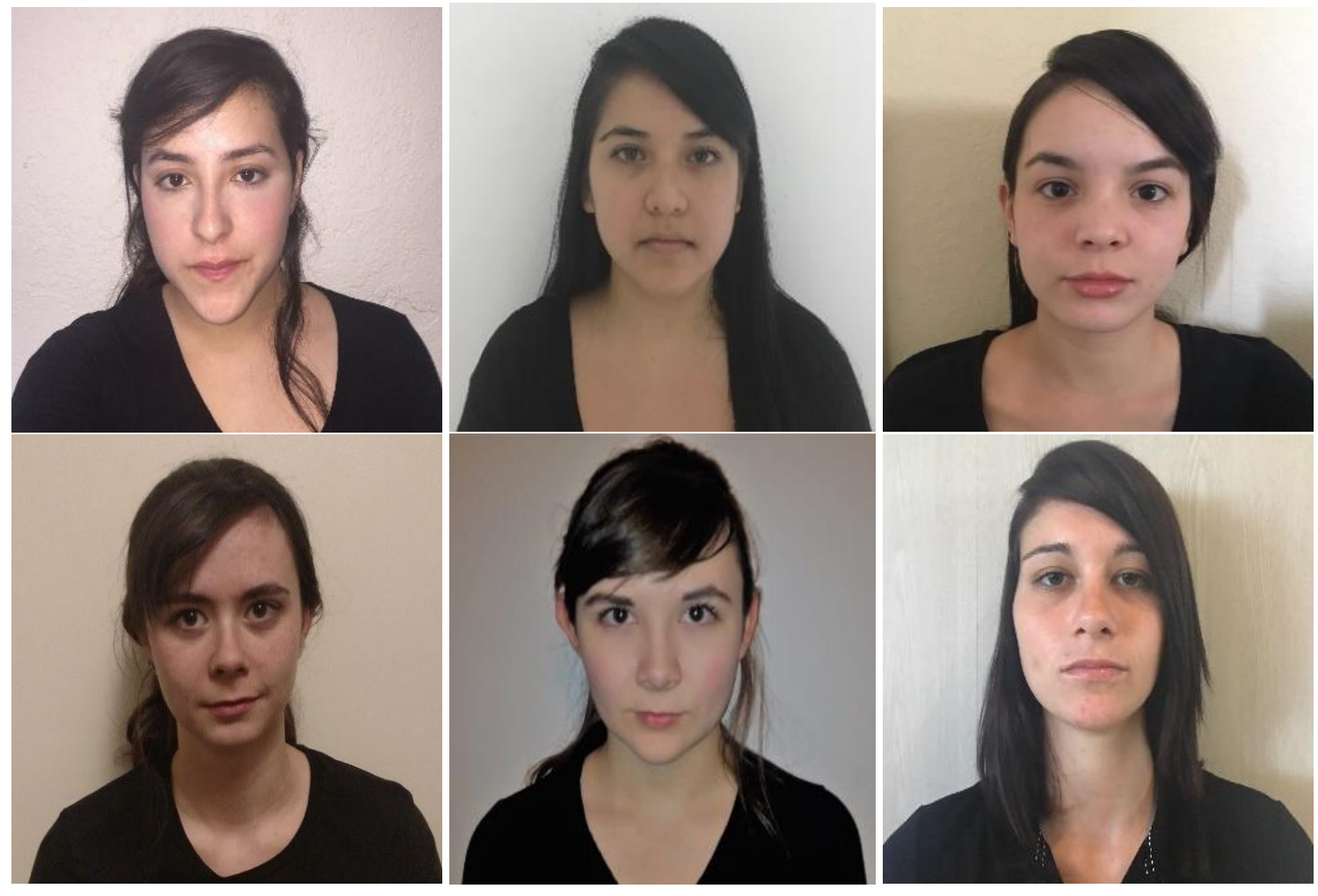

Lineup 6

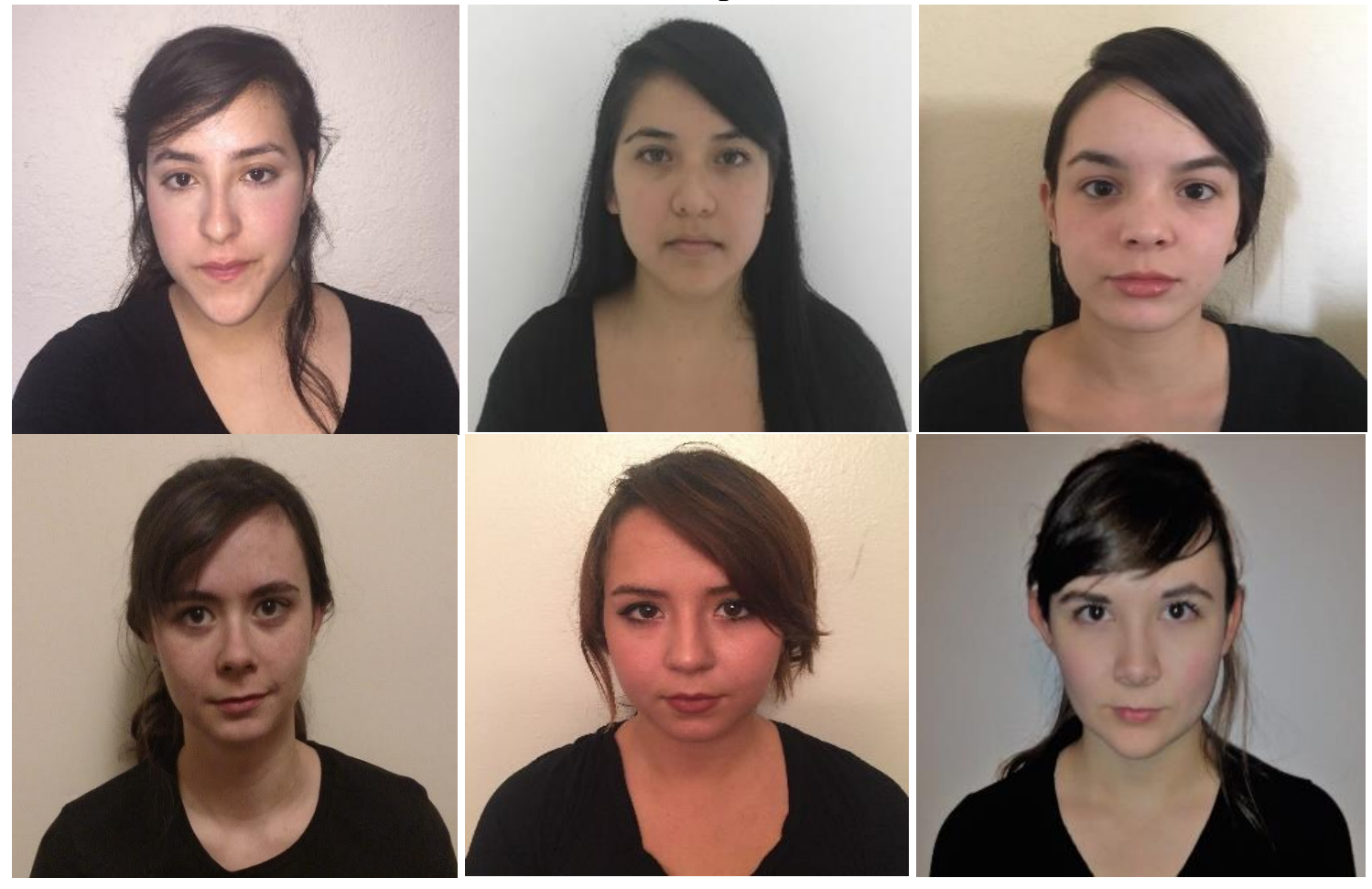


Appendix N

\section{Eyewitness Identification Sheet}

In addition to those questions from the University the bar also gave us photos of people who have been here before and caused disturbances. We need you to look through the female photos and see if any match the girl who interrupted your game.

[Pause for 1-2 seconds]

Interviewer: Keep in mind that the individual may or may not be here.

[Pause for 1-2 seconds]

Interviewer:

$\mathrm{F} 1=$ Is this the girl who walked into the room while you were playing Cornhole?

F2= Are any of these the girl who walked into the room while you were playing Cornhole?

[Show participant the photo]

Yes, the participant selected one of the photos as the intruder.

The participant selected number.... (circle one)

$\begin{array}{llllllll}1 & 2 & 3 & 4 & 5 & 6 & 7\end{array}$

No, the participant said the photo/s did not depict the intruder.

Unsure, the participant could not determine if the person pictured was the intruder.

Interviewer: [if participant answered yes or no] Alright, and on a scale from 0 (not at all certain) to 100 (extremely certain), how certain are you in your decision? (If number is listed, circle and write it in below. If number is not listed, mark where it lies on the scale and write it in below.)

$\begin{array}{lllllllllllllllllllll}0 & 5 & 10 & 15 & 20 & 25 & 30 & 35 & 40 & 45 & 50 & 55 & 60 & 65 & 70 & 75 & 80 & 85 & 90 & 95 & 100\end{array}$ percent 


\section{Appendix $\mathrm{O}$}

\section{Drinking History Questionnaire}

\section{Frequency}

1) On average, how often do you drink per week?

2) On a typical drinking occasion do you drink beer?

If yes, about how many beers? bottles/cans

3) On a typical drinking occasion do you drink wine?

If yes, about how many glasses? glasses bottles

4) On a typical drinking occasion do you drink liquor?

If yes, about how many shots? shots mixed drinks

[List mixed drinks in the margins (e.g., 2 long islands). We will calculate them later]

*Mixed Drinks $=1$ shot $*$

$*$ Double $=2$ shots $*$

Note: Participants alcohol consumption will be standardized using the ABC Bartending School handbook which lists how many beverages in one form (e.g., beers) are needed to be equivalent to beverage in another form (e.g., shots or wine glasses). This system was previously used in quantifying participants' alcohol consumption (Altman et al., 2018).

\section{Present Alcohol Consumption}

1) How long have you been drinking tonight? hours minutes total time in minutes

2) Did you drink beer tonight?

If yes, how many beers? bottles/cans 
3) Did you drink wine tonight?

$$
\text { If yes, how many glasses? __ }
$$

4) Did you drink liquor tonight?

$$
\text { If yes, how many liquor? } \_ \text {shots }
$$

5) Are you currently under the influence of any recreational or prescribed drugs?

$$
\text { - Yes - No }
$$

If yes, can you name them:

If possible, can you quantify the dose/amount:

How long ago did you last take them:

\section{Demographics}

1) Gender: male female don't wish to report

2) Age: years

3) Race/Ethnicity: Caucasian/ White African American/ Black Asian Hispanic/Latino (White) Hispanic/Latino (Black) Native American/Alaskan Native Other:

4) First language: English Spanish Other:

Second Language: English Spanish Other: 
VITA

\section{CHRISTOPHER ALTMAN}

2012

B.A., Psychology

University of Pittsburgh-Greensburg,

Greensburg, PA

2014

M.S., Psychology (Cognitive \& Social Process)

Ball State University,

Muncie, IN

\section{PUBLICATIONS AND PRESENTATIONS}

Altman, C., Schreiber Compo, N., Hagsand, A. V., \& Evans, J. R. (in press). State of Intoxication: A Review of the Effects of Alcohol on Witnesses Memory. In Dickinson, J., Schreiber Compo, N., Carol, R. N., McCauley, M., \& Schwartz, B. (Ed). Evidence-based investigative interviewing (Chapter 5). New York, NY: Routledge

Altman, C., Schreiber Compo, N., McQuiston, D. E., Hagsand, A. V., \& Cervera, J. (2018). Witnesses memory for events and faces under elevated levels of intoxication Memory, Advanced Online Publication. doi: 10.1080/09658211.2018.1445758

Altman, C., Schreiber-Compo, N., Slapinski, K., Leszczynski, H., Reynolds, S., Kuzminski, C., Briggs, A., \& Cervera, J. (March, 2018). Show me one or six? A field study examining how lineup format affects real-world intoxicated witnesses' identification performance. Paper presented at the annual meeting of the American Psychology- Law Society, Memphis, TN.

Schreiber Compo, N., Vallano, J., Rivard, J., Hagsand, A., Pena, M., \& Altman, C. (2018). Methods of studying eyewitness memory. In H. Otani \& B. Schwartz (Eds.). Research methods in human memory (Chapter 8). New York; NY; Routledge

Altman, C. M., Schreiber Compo, N., Hagsand, A., McQuiston, D., \& Cervera, J. (March, 2017). Over the limit: Highly intoxicated witnesses' ability to recall an event. Paper presented at the annual meeting of the American Psychology- Law Society, Seattle, WA.

Altman, C. M., Schreiber Compo, N., McQuiston, D., Hagsand, A., Gonzalez, R., Cervera, J., \& Saint-Flour, O. (March, 2016). How much is too much? The effects of realworld intoxication levels on eyewitness identifications. Paper presented at the annual meeting of the American Psychology- Law Society, Atlanta, GA. 
Gonzalez, R., Altman, C. M., \& Schreiber Compo, N. (March, 2016). How much is too much? The effects of real-world intoxication levels on witness precision and certainty. Paper presented at the annual meeting of the American Psychology- Law Society, Atlanta, GA.

Schreiber Compo, N., Carol, R.N., Hoogesteyn, K., Altman, C., Hagsand, A., Evans, J.R., Holness, H., Furton, K., \& Rose, S. (March, 2016). Alcohol and witness memory. Plenary presentation at the International Forensic Research Institute Symposium, Florida International University, Miami, FL.

Altman, C. M. (January, 2016). The effects of distance on eyewitness identifications. Poster presented at the Society for Personality and Social Psychology annual meeting, San Diego, CA.

Altman, C. M. (March, 2015). Can you see me now? Examining the maximum distance of eyewitness identifications. Poster presented at the annual meeting of the American Psychology-Law Society, San Diego, CA.

Charman, S., Altman, C. M., Schreiber Compo, N., \& Hirn, D. (March, 2015). A prelineup investigative interview can mitigate the post-identification feedback effect. Paper presented at the annual meeting of the American Psychology-Law Society, San Diego, CA.

Altman, C. M., Bauer, H. M., Klauser, B. M., Alves, K. M., \& Pickel, K. L. (May, 2014). Judging veracity makes eyewitnesses remember a suspect less accurately but with more certainty. Poster presented at the annual Association for Psychological Science convention, San Fransisco, CA.

Vallano, J. P., Lawson, K. L., \& Altman, C. M. (March, 2014). An examination of the existence and content of psychological injury schemas in civil cases: A comparison with physical injury schemas. Paper presented at the annual meeting of the American Psychology-Law Society, New Orleans, LA.

Ring, N. S., Burgan, D. E., Altman, C. M., Smith, C. K., Devia, M., Sachs, N. A., \& Butler, D. L. (May, 2013). A method using response time as an indicator of type of myth. Poster presented at the annual Association for Psychological Science convention, Washington, D.C.

Atman, C. M., Burgan, D. E., Devia, M., Sachs, N., Smith, C., Butler, D. L., \& Ring, N. (April, 2013). What do you believe?: Developing accurate measures of myths and misconceptions. Poster presented at the Butler Undergraduate Research Conference, Indianapolis, IN. 